\title{
Physiological Resolution of Periodic Breath Holding During Heavy Intensity Fartlek Exercise
}

David J. Lim, The University of Western Ontario

Supervisor: Dr. Glen Belfry, The University of Western Ontario

A thesis submitted in partial fulfillment of the requirements for the Master of Science degree in Kinesiology

(c) David J. Lim 2017

Follow this and additional works at: https://ir.lib.uwo.ca/etd

Part of the Exercise Physiology Commons

\section{Recommended Citation}

Lim, David J., "Physiological Resolution of Periodic Breath Holding During Heavy Intensity Fartlek Exercise" (2017). Electronic Thesis and Dissertation Repository. 4600.

https://ir.lib.uwo.ca/etd/4600

This Dissertation/Thesis is brought to you for free and open access by Scholarship@Western. It has been accepted for inclusion in Electronic Thesis and Dissertation Repository by an authorized administrator of Scholarship@Western. For more information, please contact wlswadmin@uwo.ca. 


\begin{abstract}
The purpose was to compare the physiological responses to periodic $5 \mathrm{~s}$ breath holds $(\mathrm{CBH})$, increased power output (FLK), and both (FBH) every $30 \mathrm{~s}$ followed by $25 \mathrm{~s}$ of continuous heavy intensity cycling exercise with free-breathing $(\mathrm{CON})$. Minute ventilation $\left(\dot{\mathrm{V}}_{\mathrm{E}}\right)$ was greater $(p<$ 0.05) in $\mathrm{CBH}\left(97.58 \pm 16 \mathrm{~L} \cdot \mathrm{min}^{-1}\right)$ and $\mathrm{FBH}\left(100.9 \pm 19 \mathrm{~L} \cdot \mathrm{min}^{-1}\right)$, pulmonary oxygen uptake $\left(\dot{\mathrm{VO}}_{2 \mathrm{p}}\right)$ was similar in $\mathrm{CBH}\left(2.73 \pm 0.14 \mathrm{~L} \cdot \mathrm{min}^{-1}\right)$ and $\mathrm{FBH}\left(2.73 \pm 0.14 \mathrm{~L} \cdot \mathrm{min}^{-1}\right)$ and greater in FLK $\left(2.85 \pm 0.12 \mathrm{~L} \cdot \mathrm{min}^{-1}\right)$, compared to $\mathrm{CON}\left(2.71 \pm 0.12 \mathrm{~L} \cdot \mathrm{min}^{-1}\right) . \mathrm{FBH}$ also resulted in slower $\dot{\mathrm{V}} \mathrm{O}_{2 \mathrm{p}}$ kinetics $(62.2 \pm 19 \mathrm{~s})$ and greater blood lactate concentrations $(11.5 \pm 2.7 \mathrm{mM})$, compared to $\mathrm{CON}(48.8 \pm 12 \mathrm{~s} ; 9.0 \pm 2.3 \mathrm{mM})$. Together, we demonstrated that breath hold-induced hypoxemia and hypercapnia were resolved when not combined with additional work.
\end{abstract}

Keywords: breath-by-breath pulmonary $\mathrm{O}_{2}$ uptake, gas exchange, breath hold, hypoxia, muscle deoxygenation, intermittent exercise, heavy intensity 


\section{Co-Authorship Statement}

This study was designed by G. R. Belfry and D. J. Lim with input from the advisory committee

(J. M. Kowalchuk and G. D. Marsh). Majority of the data was collected and analyzed by D. J.

Lim with the assistance of J. Kim. D. J. Lim wrote the original manuscript for the study. 


\section{Acknowledgments}

First and foremost, I would like to extend my gratitude towards my supervisor, Glen R. Belfry for the opportunity to experience and expound my research in integrative exercise physiology at the Master's level. Words cannot contain my gratitude for your encouragement and patience in my development as a researcher and scientific writer. As a role-model and mentor beyond research, the impact you have made in my life will never be forgotten.

I would also like to thank Dr. Greg D. Marsh, for the invaluable insights on the manuscript, and acknowledge my colleagues, Michael Hodgson, Lorenzo Love, André Pelletier, James Vanhie, and Jae Joon Kim for their camaraderie in the lab, the motivation to give my best, and the perspective to enjoy the ride.

Lastly, I would like to express my gratitude to my parents and Grace for their inspiration and unconditional support as I navigate through my convoluted academic journey, and to Esther -

you are the love of my life, my best friend, and the light that shines through the murky grime.

I dedicate my thesis to my grandmother, who encouraged my academic endeavors far greater than I could imagine. 


\section{Table of Contents}

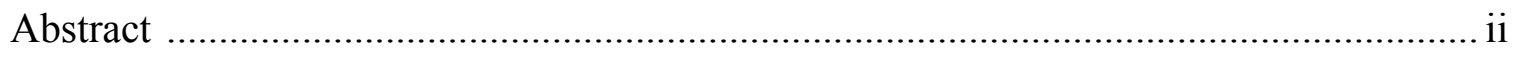

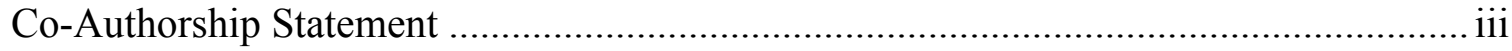

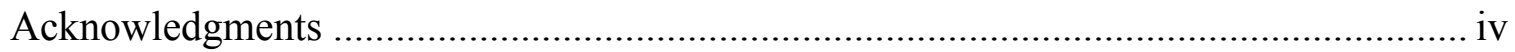

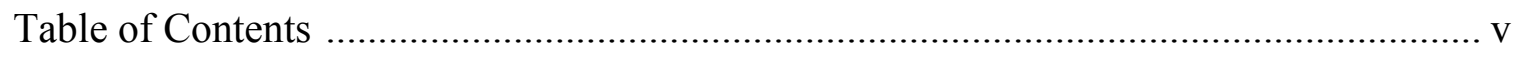

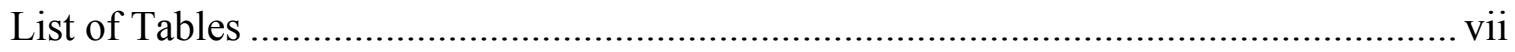

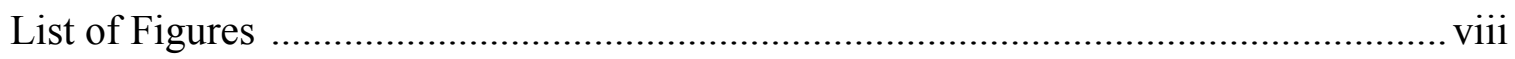

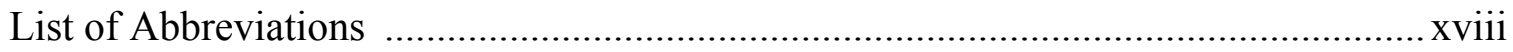

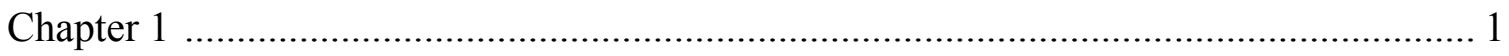

1 REVIEW OF LITERATURE ….................................................................. 1

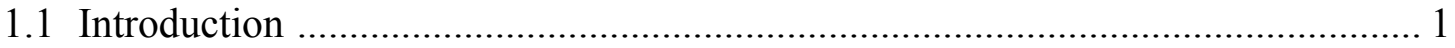

1.2 Energy Systems and Lactate Threshold ................................................... 2

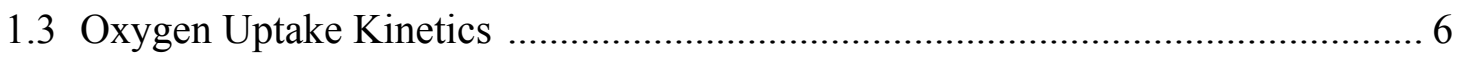

1.4 Intermittent Exercise ........................................................................... 7

1.5 Hypoxia and Breath Holding During Exercise ........................................... 9

1.6 Breath-by-Breath Analysis by Mass Spectroscopy ...................................... 11

1.7 Near - Infrared Spectroscopy and Muscle Deoxygenation .............................. 12

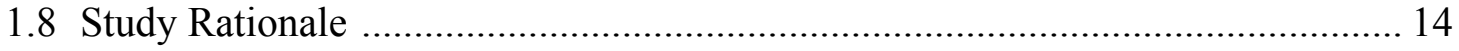

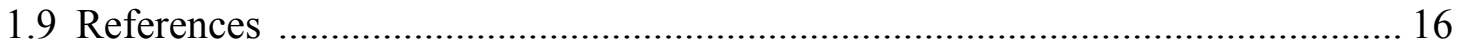

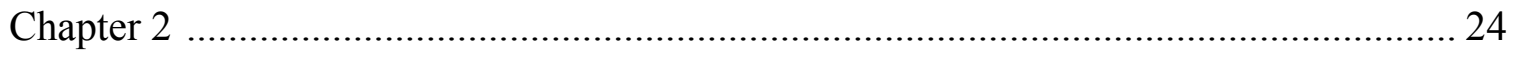

2 PHYSIOLOGICAL RESOLUTION OF PERIODIC BREATH HOLDING DURING HEAVY INTENSITY FARTLEK EXERCISE ............................................... 24

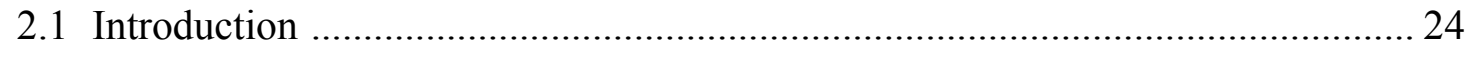

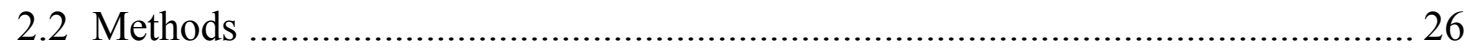

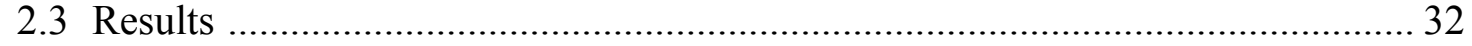

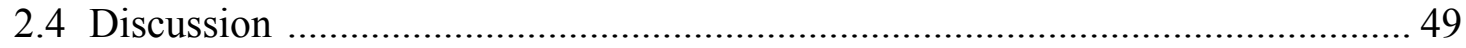




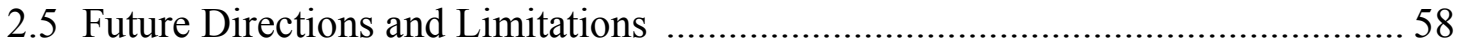

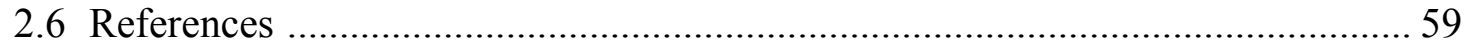

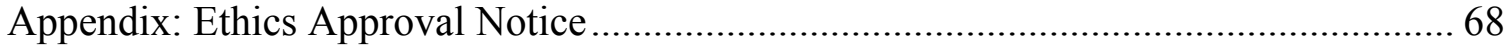

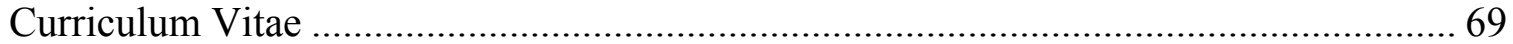




\section{List of Tables}

Table 1. Participant characteristics and performance variables from the ramp incremental test including age, height, body mass, $\dot{\mathrm{V}} \mathrm{O}_{2 \text { peak }}$, estimated LT, peak PO, and PO at $\Delta 50 \ldots \ldots \ldots \ldots \ldots \ldots . . . . . .36$

Table 2. Summary of physiological parameters collected during $\mathrm{CON}, \mathrm{CBH}, \mathrm{FLK}$, and FBH

Table 3. Summary of fluctuations in $\dot{\mathrm{V}} \mathrm{O}_{2 \mathrm{p}}, \dot{\mathrm{V}} \mathrm{CO}_{2 \mathrm{p}}, \dot{\mathrm{V}}_{\mathrm{E}}, \mathrm{P}_{\mathrm{ET}} \mathrm{O}_{2}, \mathrm{P}_{\mathrm{ET}} \mathrm{CO}_{2}, \Delta[\mathrm{HHb}]$, and $\Delta[\mathrm{HHb}] / \dot{\mathrm{V}}_{2 \mathrm{p}}$ over the $25 \mathrm{~s}$ and $5 \mathrm{~s}$ intervals within the $30 \mathrm{~s}$ cycles of $\mathrm{CON}, \mathrm{CBH}, \mathrm{FLK}$, and

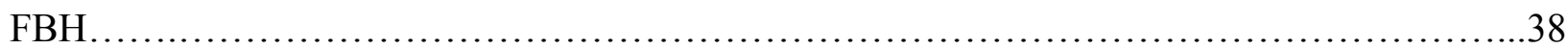




\section{List of Figures}

Figure 1. Mean pulmonary oxygen uptake $\left(\dot{\mathrm{VO}}_{2 \mathrm{p}}\right)$ profile during $\mathrm{CON}$ (continuous exercise at $\Delta 50$ : 50 percent of the difference between the $\mathrm{LT}$ and $\dot{\mathrm{V}} \mathrm{O}_{2 \text { peak }}$ ), $\mathrm{CBH}$ (continuous exercise at $\Delta 50$ with repeated $25 \mathrm{~s}$ free breathing and $5 \mathrm{~s}$ breath holds), FLK (repeated $25 \mathrm{~s} \Delta 50$ and $5 \mathrm{~s}$ free breathing sprints - peak work rate attained during ramp incremental test), and FBH (repeated $25 \mathrm{~s}$ free breathing $\Delta 50$ and $5 \mathrm{~s}$ sprints with breath holds). The mean $\dot{\mathrm{V}} \mathrm{O}_{2 \mathrm{p}}$ from $120 \mathrm{~s}$ to the end of exercise was greater in FLK than all other conditions $(p<0.05) \ldots$

Figure 2a. Mean end-tidal partial pressure of oxygen $\left(\mathrm{P}_{\mathrm{ET}} \mathrm{O}_{2}\right)$ during $\mathrm{CON}$ (continuous exercise at $\Delta 50$ : 50 percent of the difference between the $\mathrm{LT}$ and $\dot{\mathrm{V}} \mathrm{O}_{2 \text { peak }}$ ), $\mathrm{CBH}$ (continuous exercise at $\Delta 50$ with repeated $25 \mathrm{~s}$ free breathing and $5 \mathrm{~s}$ breath holds), FLK (repeated $25 \mathrm{~s} \Delta 50$ and $5 \mathrm{~s}$ free breathing sprints - peak work rate attained during ramp incremental test), and FBH (repeated $25 \mathrm{~s}$ free breathing $\Delta 50$ and $5 \mathrm{~s}$ sprints with breath holds). The $\mathrm{P}_{\mathrm{ET}} \mathrm{O}_{2}$ from $120 \mathrm{~s}$ to the end of exercise was greater in FLK than $\mathrm{CON}$, greater in FBH than $\mathrm{CON}$, and lower in FBH than FLK $(p<$ $0.05)$

Figure 2b. Fluctuations in mean end-tidal partial pressure of oxygen $\left(\mathrm{P}_{\mathrm{ET}} \mathrm{O}_{2}\right)$ during $\mathrm{CON}$ and $\mathrm{CBH}$. This reflects the acute resolution of transient hypoxia associated with each breath hold episode. The $\mathrm{P}_{\mathrm{ET}} \mathrm{O}_{2}$ during the last $5 \mathrm{~s}$ of were lower than the peak values during the $25 \mathrm{~s}$ periods over the 30 s cycles $(p<0.05)$

Figure 3a. Mean end-tidal partial pressure of carbon dioxide $\left(\mathrm{P}_{\mathrm{ET}} \mathrm{CO}_{2}\right)$ during $\mathrm{CON}$ (continuous exercise at $\Delta 50$ : 50 percent of the difference between the LT and $\dot{\mathrm{VO}}_{2 \text { peak }}$ ), $\mathrm{CBH}$ (continuous exercise at $\Delta 50$ with repeated $25 \mathrm{~s}$ free breathing and $5 \mathrm{~s}$ breath holds), FLK (repeated $25 \mathrm{~s} \Delta 50$ and $5 \mathrm{~s}$ free breathing sprints - peak work rate attained during ramp incremental test), and $\mathrm{FBH}$ (repeated $25 \mathrm{~s}$ free breathing $\Delta 50$ and $5 \mathrm{~s}$ sprints with breath holds). The $\mathrm{P}_{\mathrm{ET}} \mathrm{CO}_{2}$ from $120 \mathrm{~s}$ to the end of exercise was lower in FLK than CON, and greater in FBH than FLK $(p<0.05) \ldots \ldots \ldots . .42$ 
Figure 3b. Fluctuations in mean end-tidal partial pressure of carbon dioxide $\left(\mathrm{P}_{\mathrm{ET}} \mathrm{CO}_{2}\right)$ during $\mathrm{CON}$ and $\mathrm{CBH}$. This reflects the acute resolution of transient hypercapnia associated with each breath hold episode. The $\mathrm{P}_{\mathrm{ET}} \mathrm{CO}_{2}$ during the last $5 \mathrm{~s}$ were greater than the nadir values during the $25 \mathrm{~s}$ periods over the $30 \mathrm{~s}$ cycles $(p<0.05)$.

Figure 4. Mean minute ventilation $\left(\dot{\mathrm{V}}_{\mathrm{E}}\right)$ during $\operatorname{CON}$ (continuous exercise at $\Delta 50$ : 50 percent of the difference between the $\mathrm{LT}$ and $\dot{\mathrm{V}} \mathrm{O}_{2 \text { peak }}$ ), $\mathrm{CBH}$ (continuous exercise at $\Delta 50$ with repeated $25 \mathrm{~s}$ free breathing and $5 \mathrm{~s}$ breath holds), FLK (repeated $25 \mathrm{~s} \Delta 50$ and $5 \mathrm{~s}$ free breathing sprints - peak work rate attained during ramp incremental test), and FBH (repeated $25 \mathrm{~s}$ free breathing $\Delta 50$ and 5 s sprints with breath holds). The $\dot{\mathrm{V}}_{\mathrm{E}}$ from $120 \mathrm{~s}$ to the end of exercise was greater in FLK and

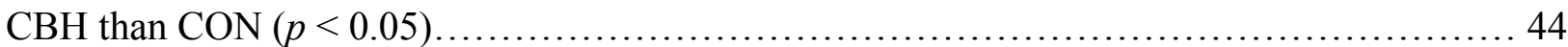

Figure 5a. Mean total hemoglobin concentration changes $\left(\Delta\left[\mathrm{Hb}_{\text {tot }}\right]\right)$ from baseline values during $\mathrm{CON}$ (continuous exercise at $\triangle 50: 50$ percent of the difference between the $\mathrm{LT}$ and $\mathrm{V}_{2 \text { peak }}$ ), $\mathrm{CBH}$ (continuous exercise at $\Delta 50$ with repeated $25 \mathrm{~s}$ free breathing and $5 \mathrm{~s}$ breath holds), FLK (repeated $25 \mathrm{~s} \Delta 50$ and $5 \mathrm{~s}$ free breathing sprints - peak work rate attained during ramp incremental test), and $\mathrm{FBH}$ (repeated $25 \mathrm{~s}$ free breathing $\Delta 50$ and $5 \mathrm{~s}$ sprints with breath holds). The mean $\Delta\left[\mathrm{Hb}_{\text {tot }}\right]$ from $120 \mathrm{~s}$ to the end of exercise during $\mathrm{CBH}$ and FLK were lower than CON and FBH $(p<$ $0.05)$

Figure 5b. Mean deoxygenated hemoglobin concentration changes $(\Delta[\mathrm{HHb}])$ from baseline values during $\mathrm{CON}, \mathrm{CBH}, \mathrm{FLK}$, and $\mathrm{FBH}$. The mean $\Delta[\mathrm{HHb}]$ from $120 \mathrm{~s}$ to the end of exercise were

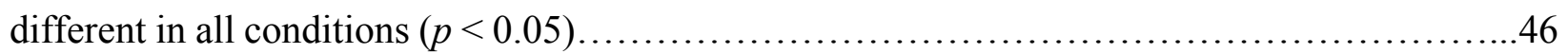

Figure 5c. Mean tissue hemoglobin saturation $\left(\mathrm{S}_{\mathrm{at}} \mathrm{O}_{2}\right)$ during $\mathrm{CON}, \mathrm{CBH}, \mathrm{FLK}$, and FBH. The mean $\mathrm{S}_{\mathrm{at}} \mathrm{O}_{2}$ from $120 \mathrm{~s}$ to the end of exercise during $\mathrm{CBH}$ and $\mathrm{FBH}$ were greater than CON $(p<$ $0.05)$ 
Figure 6. Mean adjustment of normalized $[\mathrm{HHb}]-$ to- $-\mathrm{VO}_{2 \mathrm{p}}$ ratio $\left(\Delta[\mathrm{HHb}] / \mathrm{VO}_{2 \mathrm{p}}\right)$ during $\mathrm{CON}$ (continuous exercise at $\Delta 50$ : 50 percent of the difference between the LT and $\dot{\mathrm{V}} \mathrm{O}_{2 \text { peak }}$ ), CBH (continuous exercise at $\triangle 50$ with repeated $25 \mathrm{~s}$ free-breathing and $5 \mathrm{~s}$ breath holds), FLK (repeated $25 \mathrm{~s} \Delta 50$ and $5 \mathrm{~s}$ free-breathing sprints - peak power output attained during ramp incremental test), and FBH (repeated $25 \mathrm{~s}$ free-breathing $\Delta 50$ and $5 \mathrm{~s}$ sprints with breath holds). $\Delta[\mathrm{HHb}] / \dot{\mathrm{VO}}_{2 \mathrm{p}}$ during the last $5 \mathrm{~s}$ were greater than the nadir values during the $25 \mathrm{~s}$ periods over the $30 \mathrm{~s}$ cycles $(p<$

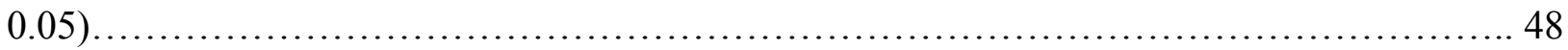




\section{List of Abbreviations}

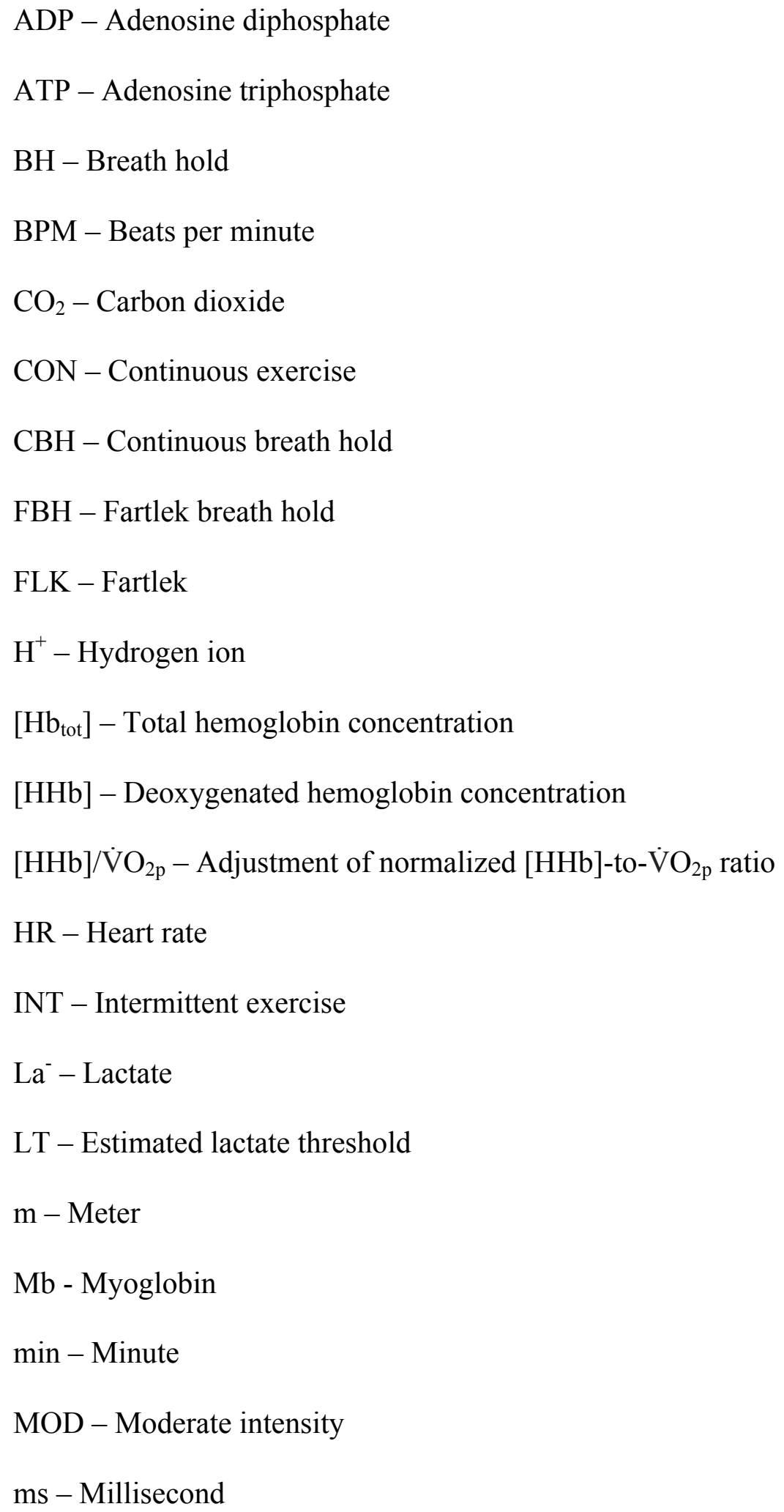


$\mathrm{N}_{2}-$ Nitrogen

NIRS - Near-infrared spectroscopy

$\mathrm{O}_{2}$ - Oxygen

$\left[\mathrm{O}_{2} \mathrm{Hb}\right]$ - Oxygenated hemoglobin concentration

$\mathrm{PCr}-$ Phosphocreatine

$\mathrm{PCO}_{2}-$ Partial pressure of carbon dioxide

$\mathrm{P}_{\mathrm{ET}} \mathrm{CO}_{2}-$ End-tidal partial pressure of carbon dioxide

$\mathrm{P}_{\mathrm{ET}} \mathrm{O}_{2}$ - End-tidal partial pressure of oxygen

$\mathrm{pKa}-$ Acid dissociation constant

$\mathrm{PO}$ - Power output

$\mathrm{PO}_{2}$ - Partial pressure of oxygen

$\mathrm{QO}_{2}-$ Blood flow

RAMP - Incremental ramp test

RPM - Revolutions per minute

$\mathrm{s}-$ Second

SD - Standard deviation

SE - Standard error

$\mathrm{S}_{\mathrm{at}} \mathrm{O}_{2}-$ Tissue hemoglobin saturation

$\tau-$ Time constant

$\dot{\mathrm{V}} \mathrm{CO}_{2 p}$ - Pulmonary carbon dioxide production

$\dot{\mathrm{V}}_{\mathrm{E}}-$ Minute ventilation

$\dot{\mathrm{V}} \mathrm{O}_{2 \mathrm{~m}}-$ Muscle oxygen uptake

$\dot{\mathrm{V}}_{2 \mathrm{p}}$ - Pulmonary oxygen uptake 
$\dot{\mathrm{V}} \mathrm{O}_{2 \text { peak }}$ - Peak pulmonary oxygen uptake

W - Watts

WR - Work rate

$\mu_{\mathrm{A}}-$ Absorption coefficient

$\mu_{\mathrm{S}}-$ Scattering coefficient 


\section{Chapter 1}

\section{REVIEW OF LITERATURE}

\subsection{Introduction}

Intermittent exercise patterns are inherent to a variety of sports such as cycling (59), rowing (72), and swimming (16). During training and competition, these intermittent exercise patterns may be comprised of brief periods of higher power output. In the sport of swimming, these periods of higher power output may be performed during the underwater kicking phase after a turn in a $50 \mathrm{~m}$ pool, to maintain or increase speed $(45,80)$. As such, a breath hold is required. Olympic swimming rules (18) dictate that the swimmer may stay under water after a turn for a distance no greater than $15 \mathrm{~m}$.

A swimmer may elect to perform underwater kicking for the total $15 \mathrm{~m}$ distance at various intensities. They will cover that $15 \mathrm{~m}$ distance in approximately $5 \mathrm{~s}$. Upon reaching the surface of the water, the swimmers continue to kick for approximately $25 \mathrm{~s}(73)$ as a complementary propulsive component to the upper limbs for the remainder of the $50 \mathrm{~m}$ distance.

Thus, during swimming training and/or competitions requiring multiple lengths of a $50 \mathrm{~m}$

pool, numerous cardiovascular, respiratory and metabolic challenges associated with the regular and intermittent changes in power output, and breath hold-induced reductions in $\mathrm{O}_{2}$ delivery to the tissues (hypoxia) must be resolved. The present study examined the physiological responses associated with the regular insertions of $5 \mathrm{~s}$ breath holds and/or periods of higher power output 
(sprints) after a $25 \mathrm{~s}$ period performed at a work rate that is above the lactate threshold during leg only exercise, on a cycle ergometer.

This chapter reviews the background literature of breath holding and intermittent exercise including energy systems, pulmonary gas exchange, oxygen uptake kinetics, lactate threshold and buffering, and muscle deoxygenation to underpin the rationale for this study. Thereafter, an overview of the equipment used for the cardiorespiratory and metabolic data collection, and their relevance to this research study is presented.

\subsection{Energy Systems and Lactate Threshold}

Energy Systems

The current study utilized six minute ( $\mathrm{min}$ ) bouts of high intensity constant load exercise. Therefore, the energy systems responsible for providing adenosine triphosphate (ATP) for this intensity and duration will be addressed first. At the onset of exercise, there is an instantaneous increase in ATP requirement at the exercising muscles that matches the prescribed work rate. However, the energy contribution from aerobic metabolism is delayed for a brief period until cardic output increases and due to the "sluggishness" of the metabolic pathways (91). The phosphorylation necessary during the first $\sim 60 \mathrm{~s}$ after the onset of exercise is primarily provided by the adenosine triphosphate-phosphocreatine (ATP-PCr) and the glycolytic systems. Its magnitude and duration determines the ' $\mathrm{O}_{2}$ deficit' (47). Figure 1 below illustrates the interplay between both the PCr-derived, glycolytic and oxidative phosphorylation contributions to 5 min of constant-load exercise (20). Thus, a similar energy system interplay is expected during the 6 min constant-load exercise in the present study. 


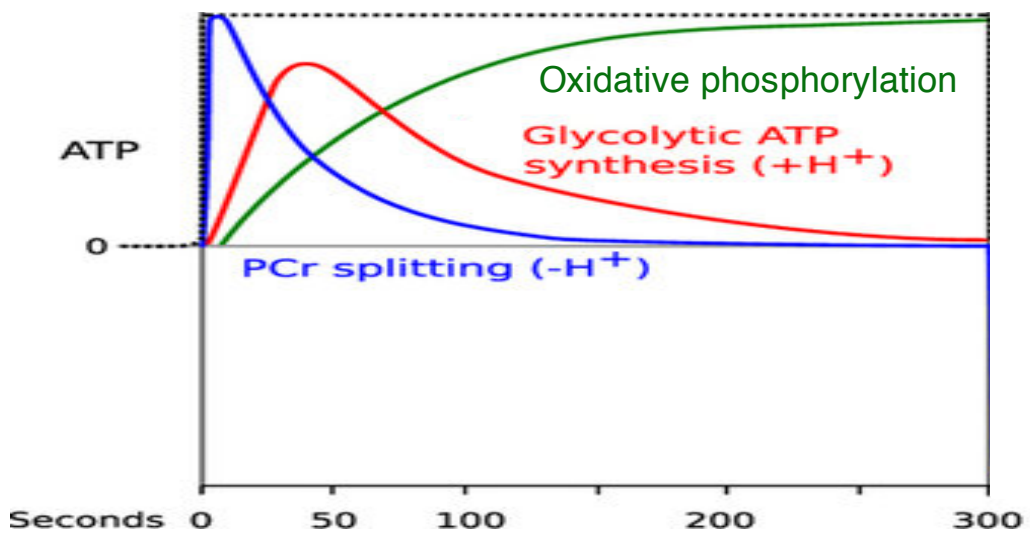

Figure 1. Energy system contribution during a five-minute constantload exercise bout. The first (blue) line represents the ATP-PCr system, the second (red) line represents anaerobic glycolysis, and the third (green) line represents oxidative phosphorylation (modified from Fielder et al., 2016).

The final stage of the oxidative phosphorylation pathway is the electron transport chain. It is here where the movement of $\mathrm{H}^{+}$generates a proton gradient within the inner mitochondrial membrane that facilitates adenosine diphosphate (ADP) phosphorylation in the presence of ATP synthase. The final reaction of the electron transport chain involves the coupling of a pair of $\mathrm{H}^{+}$ to $1 / 2$ an $\mathrm{O}_{2}$. Oxygen utilization or uptake at the mouth is dictated by this final step (47). Thus, increasing the ATP demand and related $\mathrm{O}_{2}$ utilization results in decreased partial pressure of $\mathrm{O}_{2}$ $\left(\mathrm{PO}_{2}\right)$ at the muscle. This stimulates offloading of the $\mathrm{O}_{2}$ from the myoglobin $(\mathrm{Mb})$ in the muscle and subsequently $\mathrm{O}_{2}$ from the hemoglobin $(\mathrm{Hb})$ in the microvasculature. This in turn results in an increase in deoxygenated $\mathrm{Hb}$ and a decrease in the $\mathrm{PO}_{2}$ (26). This drop in $\mathrm{PO}_{2}$ also results in increased vasodilation that enhances blood flow, and thus $\mathrm{O}_{2}$ delivery (55). As this blood reaches the lungs, an elevated alveolar-capillary $\mathrm{PO}_{2}$ gradient results (83). Under steady-state $\dot{\mathrm{V}}_{2 \mathrm{p}}$ 
conditions, deoxygenated hemoglobin concentrations ([HHb]) have been utilized to provide insight to changes in $\mathrm{O}_{2}$ delivery (55).

\section{Lactate Threshold}

High intensity exercise during training and competition is associated with increased lactate production. Within the context of the high intensity exercise performed in the present study, a greater rate of pyruvate production than its oxidation in Kreb's cycle results in pyruvate accumulation. Initially, the build-up of pyruvate is minimized as lactate dehydrogenase reduces pyruvate into lactic acid (47). Lactic acid, due to its high $\mathrm{pK}_{\mathrm{a}}$, immediately dissociates into lactate $\left(\mathrm{La}^{-}\right)$, a strong anion, and equimolar (1.5) amounts of hydrogen ions $\left(\left[\mathrm{H}^{+}\right]\right)$. High concentrations of $\mathrm{La}^{-}$and $\mathrm{H}^{+}$in the cytosol are co-transported across the sarcolemma via monocarboxylate transporters to the blood (27). Assuming bicarbonate ions are available, $\mathrm{H}^{+}$is buffered by the carbonic anhydrase reaction, producing $\mathrm{CO}_{2}(23)$. This leads to increased partial pressures of $\mathrm{CO}_{2}$ in the blood (hypercapnia). As peripheral chemoreceptors are most sensitive to changes in $\mathrm{PCO}_{2}$, this increase in non-metabolic $\mathrm{CO}_{2}$ will stimulate the peripheral chemoreceptors (88) to induce hyperventilation for the removal of $\mathrm{CO}_{2}$ from the blood. If $\mathrm{H}^{+}$ production continues to increase beyond the maximal capacity of bicarbonate-ventilatory buffering, termed as the lactate threshold, $\mathrm{H}^{+}$will accumulate and result in decreased $\mathrm{pH}$.

As exercise intensity increases within work rates below the lactate threshold, the increase in oxidative phosphorylation is matched by an identical increase in respiratory $\mathrm{CO}_{2}$ production $\left(\mathrm{V}^{2} \mathrm{O}_{2 \mathrm{p}}\right)$ originating from the pyruvate to acetyl-CoA reaction and the Kreb's cycle. Under steady state conditions, $\dot{\mathrm{V}}_{2 p}$ stabilizes after approximately 3 min and $\dot{\mathrm{V}} \mathrm{CO}_{2 p}$ after 4 min (11). 
Under prolonged submaximal exercise intensities, oxidative phosphorylation is responsible primarily for meeting the ATP requirement. However, as mentioned, ATP supply from aerobic metabolism does not increase instantaneously to meet the energy demand at exercise onset (91). During this upregulation period of oxidative phosphorylation ATP is produced primarily via the breakdown of intramuscular $\mathrm{PCr}$ stores and substrate level phosphorylation (Wilmore et al., 2008). Moreover, at intensities below the lactate threshold (moderate intensity exercise), this transient mismatch between the rate of ATP hydrolysis required to fuel mitochondrial metabolism and the actual rate of ATP supply, also known as the ' $\mathrm{O}_{2}$ deficit', is overcome and a steady state $\mathrm{V}_{2 p}$ is achieved (11).

In the present study, exercise will be performed at supra-lactate threshold intensities for 6 min. Thus, increased $\left[\mathrm{La}^{-}\right]$is expected upon completion of each exercise bout. During exercise at intensities above the lactate threshold, the buffering and subsequent accumulation of $\mathrm{H}^{+}$via the carbonic anhydrase reaction (Equation 1) results in increased in non-respiratory $\dot{\mathrm{VCO}}_{2 \mathrm{p}}$ resulting in the accumulation, and subsequent buffering of $\mathrm{H}^{+}$.

Equation 1. Interconversion of carbon dioxide and water to bicarbonate and protons.

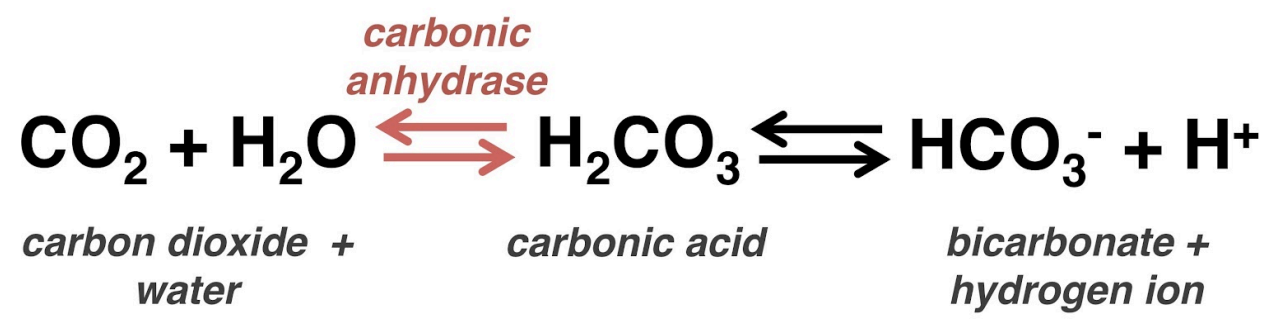

This is linked with substrate level phosphorylation and ATP hydrolysis, which is associated with increases in chemoreceptor output from increased $\dot{\mathrm{VCO}}_{2 \mathrm{p}}$, that results in an 
increase in ventilation (61). Moreover, work rates above the lactate threshold are also associated with the evolution of the $\dot{\mathrm{V}} \mathrm{O}_{2 \mathrm{p}}$ "slow component" that delays the onset of steady state $\dot{\mathrm{V}} \mathrm{O}_{2 \mathrm{p}}(91)$. The $\dot{\mathrm{V}} \mathrm{O}_{2 \mathrm{p}}$ slow component will be described in depth later in this review.

\subsection{Oxygen Uptake Kinetics}

At exercise intensities below the lactate threshold (moderate intensity), the rate of adjustment of $\dot{\mathrm{VO}}_{2 \mathrm{p}}$ exhibits a mono-exponential response to match ATP demand during exercise. Three distinct $\dot{\mathrm{V}} \mathrm{O}_{2 p}$ kinetic phases are observed (Whipp et al., 1982). Phase I is the 'cardio-dynamic' phase, comprised of a temporal delay $(\sim 20 \mathrm{~s})$ between the deoxygenated blood arriving at the lungs, prior to the increase in cardiac output. Phase II or the "fundamental" phase is the larger mono-exponential that projects towards steady-state, reflective of both the increased rate of ATP utilization and $\mathrm{O}_{2}$ delivery (89). At work rates below the lactate threshold Phase III is the point at which $\mathrm{VO}_{2 p}$ reaches a steady-state at which the ATP requirement is met entirely by oxidative phosphorylation.

At exercise intensities above the lactate threshold (heavy intensity domain), similar to the work rates employed in the present study, Phase III exhibits as a second exponential called the "slow component" and the onset of steady state $\dot{\mathrm{V}} \mathrm{O}_{2 \mathrm{p}}$ is delayed, and if the work rate is high enough, may not be attained (91). This phenomena during supra-lactate threshold constant-load exercise has been used to describe the increase in $\dot{\mathrm{VO}}_{2}$ /work rate relationship, or gain (35).

The kinetic response of the phase II $\dot{\mathrm{VO}}_{2 \mathrm{p}}$ is described by the time constant tau $(\tau)$. This reflects the time it takes $\dot{\mathrm{V}} \mathrm{O}_{2 \mathrm{p}}$ to reach $63 \%$ of the difference from baseline $\dot{\mathrm{VO}} 2 \mathrm{p}$ to steady-state $\dot{\mathrm{V}} \mathrm{O}_{2 \mathrm{p}}$. In healthy young adults, the $\tau \dot{\mathrm{V}} \mathrm{O}_{2 \mathrm{p}}$ for exercise below the lactate threshold (moderate 
intensity) has shown to range from $20-35 \mathrm{~s}(3,14)$, and even longer for exercise above the lactate threshold (heavy intensity) (17).

Earlier research has also observed a slowing of $\dot{\mathrm{VO}}_{2 \mathrm{p}}$ kinetics from moderate to severe intensity (upper range of heavy intensity) work rates (9). It has been suggested that this slowing is linked to increased type II muscle fibre recruitment associated with the greater force requirement $(62,87)$ and the consequent increase in lactate production and $\mathrm{H}^{+}(43), \dot{\mathrm{V}} \mathrm{O}_{2 \mathrm{p}}(31)$, and PCr breakdown (3). This observed slowing of $\dot{\mathrm{VO}}_{2 \mathrm{p}}$ kinetics was attributed to the intrinsic slowness of skeletal muscle oxidative metabolism associated with the increased ATP demand and type II fibre recruitment during high intensity exercise (87).

\section{$1.4 \quad$ Intermittent Exercise}

In the present study, intermittent exercise patterns of differing intensities of six min in duration were utilized. From the beginning of research on intermittent exercise (Astrand et al.,1960; Christensen et al., 1960), different durations of the short work: recovery durations have been investigated: $5 \mathrm{~min}: 2 \mathrm{~min}$ (Fox et al., 1975); $30 \mathrm{~s}: 30 \mathrm{~s}$ (Astrand et al., 1960) and $10 \mathrm{~s}: 5 \mathrm{~s}$ (Christensen et al., 1960). The $10 \mathrm{~s}: 5 \mathrm{~s}$ work was only performed with a sample size of two. As such, data from Christensen et al. (1960) were speculative.

More recent work by Belfry et al. (7) has observed the effects of intermittent 5 s recovery periods of two sub-lactate threshold intensities (moderate and light) followed by $10 \mathrm{~s}$ of supralactate threshold intensity over an 8 min exercise bout (INT). In comparison to the continuous exercise performed at the same power output as the $10 \mathrm{~s}$ work periods of the INT, the INT with 5 s of recovery performed at moderate intensity was associated with a lower mean $\dot{\mathrm{V}} \mathrm{O}_{2 \mathrm{p}}$ and the 5 $\mathrm{s}$ of recovery performed at light intensity exercise elicited a further reduction in $\dot{\mathrm{V}} \mathrm{O}_{2 \mathrm{p}}$. These 
observations are also consistent with previous literature linking the changes in phosphocreatine concentrations ([PCr]) with changes in $\dot{\mathrm{V}} \mathrm{O}_{2 \mathrm{p}}$, which has been suggested to be a proxy for oxidative phosphorylation (67). Oscillations in $\dot{\mathrm{V}} \mathrm{O}_{2 \mathrm{p}}$ were also observed over the work: recovery cycles. These fluctuations were matched temporally with NIRS-derived $\Delta[\mathrm{HHb}](7)$ that also suggested fluctuations in oxidative phosphorylation.

Since the insertion of $5 \mathrm{~s}$ recovery periods has been shown to increase mean [PCr] (8) and decrease mean $\dot{\mathrm{VO}}_{2 \mathrm{p}}(7)$, repeated insertions of $5 \mathrm{~s}$ at higher power output in the present study would be expected to result in the opposite $\dot{\mathrm{VO}}_{2 \mathrm{p}}$ response. These $10 \mathrm{~s}$ work: $5 \mathrm{~s}$ recovery cycles were also associated with increases in PCr-derived phosphorylation substrate level phosphorylation over the first $4 \mathrm{~s}$ of the work period (8). It would be expected that the proposed intermittent $5 \mathrm{~s}$ sprints would require a similar increase in ATP-PCr derived and substrate level phosphorylation.

Furthermore, these intermittent exercise protocols were associated with lower $\Delta[\mathrm{HHb}]$ compared to continuous exercise (7). This was attributed to reduced intramuscular pressures (64) and impedance to flow in the exercising muscles during the rest periods $(2,21,44)$. Therefore, if the $5 \mathrm{~s}$ periods in the present study are performed at higher power output, it is suggested that the opposite response (greater $\Delta[\mathrm{HHb}]$ and impaired blood flow distribution or $\mathrm{O}_{2}$ delivery) will be observed.

As previously mentioned, the adjustment of normalized $[\mathrm{HHb}]$-to- $\dot{\mathrm{V}} \mathrm{O}_{2}$ ratio $\left(\Delta[\mathrm{HHb}] / \dot{\mathrm{VO}}_{2}\right)$ has been utilized to provide insight to the balance between $\mathrm{O}_{2}$ utilization to $\mathrm{O}_{2}$ delivery (i.e. measure of muscle blood flow distribution) (55). Within the intermittent exercise paradigm, our previous work with $10 \mathrm{~s}$ work: $5 \mathrm{~s}$ recovery (7), $10 \mathrm{~s}$ work: $3 \mathrm{~s}$ (49) recovery were 
associated with decreases in $\Delta[\mathrm{HHb}] / \mathrm{VO}_{2}$ ratio. Thus, it is suggested that intermittent patterns of exercise, in comparison to continuous exercise, improves muscle blood flow distribution.

Conversely, increasing the mean work rate, as is achieved by inserting $5 \mathrm{~s}$ sprint periods in the present study would increase the contribution of type II fibre recruitment as well as intramuscular pressures/impedance to muscle blood flow. Thus, as has been suggested previously, the insertions of $5 \mathrm{~s}$ higher power output intervals will further increase $[\mathrm{HHb}]$ and improve muscle blood flow distribution consequent to the local vasodilatory effects of $\mathrm{La}^{-}$(40, $51,77)$.

More recently, the effects of $3 \mathrm{~s}$ recovery periods during heavy intensity exercise (49) have shown that more frequent short recovery periods were associated with faster $\dot{\mathrm{V}} \mathrm{O}_{2 \mathrm{p}}$ kinetics. It was postulated that the insertions of recovery periods facilitated an improved microvasculature perfusion, and hence $\mathrm{O}_{2}$ delivery, resulting in faster $\dot{\mathrm{VO}}_{2 \mathrm{p}}$ kinetics (49). Conversely, if these brief periods were replaced with higher intensity exercise as opposed to recovery, it is expected that the opposite results would occur.

\subsection{Hypoxia and Breath Holding During Exercise}

Breathing hypoxic gas mixtures $\left(\sim 15 \% \mathrm{O}_{2}\right)$ during moderate $(56,76)$ and heavy $(4,17)$ intensity exercise has shown to slow $\dot{\mathrm{VO}}_{2 \mathrm{p}}$ kinetics $(17,22,30,76)$. This slowing of $\dot{\mathrm{VO}}_{2 \mathrm{p}}$ kinetics during exercise in hypoxia has been linked to increased recruitment of less-oxidative type II muscle fibres $(24,57)$, which also contributes to the development of an increased gain and consequently an increased duration to reach the end of phase II. Hypoxia during exercise also has been associated with greater $\mathrm{O}_{2}$ deficit, implying a greater reliance on substrate level 
and PCr-derived phosphorylation (43), resulting in increased intracellular PCr depletion and blood $\mathrm{La}^{-}$concentrations $(29,56)$ that has been associated with slower $\dot{\mathrm{V}} \mathrm{O}_{2 \mathrm{p}}$ kinetics.

The previous research on breath holding during exercise has shown effects comparable to hypoxia $(1,85)$. During a breath hold, the diffusion of $\mathrm{O}_{2}$ from the lung to the blood continues. As such, $\mathrm{PO}_{2}$ in the lung and pulmonary capillaries decreases, giving rise to arterial hypoxemia (65) which reduces the total $\mathrm{O}_{2}$ delivery to exercising muscles $(86,88)$. With reduced $\mathrm{O}_{2}$ availability at the muscle, contribution from substrate level phosphorylation is expected to increase, in order to replace the ATP originally derived from oxidative phosphorylation (53).

Similarly, breath holds of varying durations, from 45 s every 5 min, to 15 s every min, have resulted in reduced $\dot{\mathrm{VO}}_{2 \mathrm{p}}$, and increased $[\mathrm{HHb}]$, arterialized-capillary lactate concentrations ([La] $)$, and proton $\left(\left[\mathrm{H}^{+}\right]\right)$accumulation $(1,28,38,93,94)$. Moreover, breath holds have also been associated with increased muscle deoxygenation, as increased $\mathrm{O}_{2}$ offloading from the $\mathrm{Hb}$ attempts to compensate for the reduced $\mathrm{O}_{2}$ delivery (93). Consequently, [La'] would increase, reflecting an increased contribution from substrate level phosphorylation (66).

Consequent to the cessation of ventilation during the periods of the breath holds, increased $\mathrm{CO}_{2}$ levels in the blood (hypercapnia) have also been observed $(28,41,48,85)$. As $\mathrm{CO}_{2}$ is a major stimulus to the peripheral chemoreceptors $(84,88)$, hypercapnia would be responsible for a hyperventilatory response. However, these hyperventilatory responses associated with longer duration breath holds, of approximately $40 \mathrm{~s}$, were insufficient to attenuate the decreases in $\dot{\mathrm{V}}_{2 \mathrm{p}}(41,85)$. In the current study, it is possible that the $25 \mathrm{~s}$ freebreathing periods of each 30 s cycle would be sufficient duration to resolve the hypoxic effects of the $5 \mathrm{~s}$ breath hold. 
Previous work on breath holds also observed a breath hold-induced bradycardia (1, 38, 42). Mechanistically, it has been suggested that breath holds after an inspiration increases intrathoracic pressure and decreases abdominal pressures $(28,60,75)$. This creates a pressure gradient between the infra- and supra-diaphragmatic portions of the inferior vena cava that "pulls" the blood towards the right side of the heart $(28,60,75)$. This facilitates venous return and diastole to the right side of the heart. It appears that the breath hold-induced increases in stroke volume and mean arterial pressure, and the consequent baroreflex-mediated bradycardia associated with the 'human diving response' observed previously with deep diving, is an attempt to reduce cardiac $\mathrm{O}_{2}$ utilization $(25,70)$.

Previous work on breath holds during exercise suggests that the compensatory responses associated with breath holds and/or hypoxia are insufficient to resolve successfully the hypoxic and hypercapnic effects demanded of longer duration breath holds. Within the context of shorter duration $5 \mathrm{~s}$ breath holds every $30 \mathrm{~s}$ in the present study, a physiological resolution of the breath hold effects may be expected. However, if the $5 \mathrm{~s}$ breath holds are combined with the sprints, the $25 \mathrm{~s}$ of hyperventilation may be insufficient to support the increased ATP demand via oxidative phosphorylation.

\subsection{Breath-by-Breath Analysis by Mass Spectroscopy}

In the present study, $\dot{\mathrm{V}} \mathrm{O}_{2 \mathrm{p}}$ will reflect the contribution of oxidative phosphorylation to heavy intensity exercise. $\dot{\mathrm{V}} \mathrm{O}_{2 p}$ will be measured at the mouth for breath-by-breath analysis. These breath-by-breath $\dot{\mathrm{V}}_{2 \mathrm{p}}$, carbon dioxide production $\left(\dot{\mathrm{V}}_{\mathrm{CO}} \mathrm{p}\right)$, and minute ventilation $\left(\dot{\mathrm{V}}_{\mathrm{E}}\right)$ determinations are calculated using the inspired and expired flow rates from a low dead-space bidirectional turbine. Inspired and expired gases were sampled continuously at the mouth and 
analyzed for concentrations of $\mathrm{O}_{2}, \mathrm{CO}_{2}$, and $\mathrm{N}_{2}$ by mass spectrometry, which were also calibrated with fixed gas mixtures. Changes in gas concentrations were aligned with gas volumes by measuring the time delay for a square-wave bolus of gas passing through the turbine, resulting in changes in fractional gas concentrations as measured by the mass spectrometer. The data were collected every $20 \mathrm{~ms}$ and transferred to a computer, which aligned concentrations with the volumes to build a profile of each breath.

Breath-by-breath alveolar gas exchange was calculated using algorithms (79), which were developed to estimate breath-by-breath alveolar gas exchange by accounting for changes in both functional residual capacity and alveolar gas concentrations during ventilation. Total lung gas exchange was computed with correction for accuracy.

\subsection{Near - Infrared Spectroscopy and Muscle Deoxygenation}

The previously observed $\mathrm{HHb}$ responses have been detected utilizing near-infrared spectroscopy $(7,13,14,49)$. At the onset of high intensity exercise in the present study, $\mathrm{O}_{2}$ delivery to the muscles were provided by increased $\mathrm{O}_{2}$ offloading by hemoglobin, consequent to greater $\mathrm{PO}_{2}$ gradient, until the time which $\mathrm{O}_{2}$ delivery by blood flow increases (40). Thus, oxygenated hemoglobin, deoxygenated hemoglobin, and total hemoglobin saturation provides useful information to the extent of muscle deoxygenation (15). The near-infrared spectroscopy (NIRS) was utilized to observe these changes in the exercising muscle at the site of interrogation. NIRS enables a continuous and non-invasive monitoring of the relative concentration changes in oxygenated hemoglobin $\left(\left[\mathrm{O}_{2} \mathrm{Hb}\right]\right)$, deoxygenated hemoglobin $([\mathrm{HHb}])$, total hemoglobin concentrations $\left(\left[\mathrm{Hb}_{\mathrm{tot}}\right]\right)$, and tissue hemoglobin saturation $\left(\mathrm{S}_{\mathrm{at}} \mathrm{O}_{2}\right)$ in the muscle microvasculature during dynamic exercise (14). 
The theoretical foundation for the NIRS technology are explained in detail by Ferrari et al. (19). In brief, there are varying lengths and frequencies of waves in the electromagnetic spectrum, and infrared is the domain in between the visible and microwave domains. Thus, the infrared spectroscopy exposes organic molecules like hemoglobin $(\mathrm{Hb})$ and myoglobin $(\mathrm{Mb})$ to the infrared radiation, which range from $790-850 \mathrm{~nm}$. Upon infrared radiation, $\mathrm{Hb}$ and $\mathrm{Mb}$ "resonate" at these wavelength frequencies and is absorbed. When infrared spectroscopy is utilized for organic tissues, it allows for the measurement of muscle $\left[\mathrm{O}_{2} \mathrm{Hb}\right],[\mathrm{HHb}]$, and $\left[\mathrm{Hb}_{\text {tot }}\right]$ (36).

The measurement is determined by the amount of absorption of the near-infrared (NIR) light projected by the diode refracted back to the optode from the organic tissue and the NIR spectrum can particularly penetrate the organic tissue and enable absorption by $\mathrm{Hb}$ and $\mathrm{Mb}$, with varying amounts of absorption depending on the extent of $\mathrm{O}_{2}$ binding of these molecules. The $\mathrm{HHb}$ and $\mathrm{O}_{2} \mathrm{Hb}$ absorbs different wavelengths of NIR depending on the presence of $\mathrm{O}_{2}$-binding (690-760 $\mathrm{nm}$ and 800-850 $\mathrm{nm}$, respectively). Therefore, the difference in wavelength emitted by the NIRS optode from the diode provides measures of $\left[\mathrm{O}_{2} \mathrm{Hb}\right],[\mathrm{HHb}]$, and $\left[\mathrm{Hb}_{\mathrm{tot}}\right]$ in the microvasculature (50).

As $\mathrm{O}_{2}$ is transported from the pulmonary capillaries towards the exercising muscles via the hemoglobin molecules, the decrease in partial pressure of oxygen $\left(\mathrm{PO}_{2}\right)$ and the partial pressure gradient facilitates $\mathrm{O}_{2}$ diffusion (i.e. $\mathrm{O}_{2}$-offloading) into the muscles. Thus, the NIRSderived $[\mathrm{HHb}]$ signal provides insight to the balance between oxygen delivery $\left(\mathrm{QO}_{2}\right)$ and uptake $\left(\dot{\mathrm{VO}}_{2}\right)$ at the site of muscle interrogation $(14,46)$. Furthermore, the sum of $\left[\mathrm{O}_{2} \mathrm{Hb}\right]$ and $[\mathrm{HHb}]$ is utilized to calculate a measure of $\left[\mathrm{Hb}_{\text {tot }}\right]$. Since the total hemoglobin volume is expressed in 
concentrations, $\left[\mathrm{Hb}_{\text {tot }}\right]$ provides insight to microvascular blood flow changes at the site of interrogation.

Moreover, the adjustment of normalized $[\mathrm{HHb}]-$ to- $\dot{\mathrm{V}} \mathrm{O}_{2}$ ratio $\left([\mathrm{HHb}] / \mathrm{V}_{2}\right)$ provides insight to the matching of $\mathrm{O}_{2}$ delivery to $\mathrm{O}_{2}$ utilization, and blood flow distribution at the site of interrogation (55). Thus, a collection of NIRS parameters will provide valuable insight to the physiological effects of $5 \mathrm{~s}$ periods of peak aerobic power and breath holds.

Possible limitations of the NIRS is that NIRS-derived [HHb] signal may be influenced by small arteries and venules, reflecting both the vasculature and the muscle, as the absorption spectra of the myoglobin is similar to that of the hemoglobin. However, the ratio of hemoglobin to myoglobin in human skeletal muscle has been suggested to be approximately 10:1 and it has been accepted that the NIRS-derived [HHb] signal can be used as a proxy for the dynamic adjustment of $\mathrm{O}_{2}$ extraction from the hemoglobin molecules (71). In summary, the NIRS enables for a convenient and non-invasive observation of the microvascular oxygenation and blood flow changes at the site of interrogation.

\subsection{Study Rationale}

The current breath hold literature is limited to longer breath hold durations of $15-45 \mathrm{~s}$ every $\min (1,38,93,94)$. With breathing patterns similar to elite swimming training and competitions in $50 \mathrm{~m}$ pools, if the breath holds are shortened to $5 \mathrm{~s}$ every $30 \mathrm{~s}$ (i.e. $10 \mathrm{~s}$ every $\min$ ), the cardiovascular, respiratory, and metabolic responses associated with the breath holds may be sufficient to resolve the associated transient hypoxia.

Thus, the main purpose of this study was to compare and contrast $\dot{\mathrm{V}} \mathrm{O}_{2 \mathrm{p}}, \tau \dot{\mathrm{V}} \mathrm{O}_{2 \mathrm{p}}, \dot{\mathrm{V}}_{\mathrm{E}}$, $[\mathrm{HHb}], \mathrm{HR}$, and arterialized-capillary lactate concentrations ([La- $]$ ) during a 6 min constant-load 
heavy intensity cycle ergometer exercise bout (CON) to three different intermittent protocols consisting of repeated $30 \mathrm{~s}$ cycles. The elucidation of the acute effects of the brief breath hold intervals and/or sprints in the present study will provide insight to the associated cardiovascular and respiratory responses. 


\section{$1.9 \quad$ References}

1. Andersson JP, Linér MH, Fredsted A, Schagatay EK. Cardiovascular and respiratory responses to apneas with and without face immersion in exercising humans. $J$ Appl Physiol 96: 1005-1010, 2004.

2. Barcroft BYH, Dornhorst AC. The blood flow through the human calf during rhythmic exercise. J Physiol 109: 402-411, 1949.

3. Barstow J, Cooper DANM, Thomas J, Buchthal S. Muscle energetics and pulmonary during moderate exercise oxygen uptake kinetics. J Appl Physiol 77: 1742-1749, 1994.

4. Barstow TJ, Mole PA. Linear and nonlinear characteristics of oxygen uptake kinetics during heavy exercise. J Appl Physiol 71: 2099-2106, 1991.

5. Belfry GR, Paterson DH, Murias JM, Thomas SG. The Effects of Short Recovery duration on VO2 and muscle deoxygenation during intermittent exercise. Eur J Appl Physiol 112: 1907-1915, 2012.

6. Belfry GR, Raymer GH, Marsh GD, Paterson DH, Thompson RT, Thomas SG. Muscle metabolic status and acid-base balance during 10-s work : 5-s recovery intermittent and continuous exercise. J Appl Physiol 113: 410-417, 2012.

7. Da Boit M, Bailey SJ, Callow S, Dimenna FJ, Jones AM. Effects of interval and continuous training on $\mathrm{O} 2$ uptake kinetics during severe-intensity exercise initiated from an elevated metabolic baseline. J Appl Physiol 116: 1068-77, 2014.

8. Burnley M, Jones AM. Oxygen uptake kinetics as a determinant of sports performance. Eur J Sport Sci 7: 63-79, 2007.

9. Chin LMK, Heigenhauser GJF, Paterson DH, Kowalchuk JM. Effect of hyperventilation and prior heavy exercise on $\mathrm{O} 2$ uptake and muscle deoxygenation 
kinetics during transitions to moderate exercise. Eur J Appl Physiol 108: 913-925, 2010.

10. Delorey DS, Kowalchuk JM, Paterson DH. Relationship between pulmonary O2 uptake kinetics and muscle deoxygenation during moderate-intensity exercise. J Appl Physiol 7: 113-120, 2003.

11. DeLorey DS, Shaw CN, Shoemaker JK, Kowalchuk JM, Paterson DH. The effect of hypoxia on pulmonary $\mathrm{O} 2$ uptake, leg blood flow and muscle deoxygenation during single-leg knee-extension exercise. ExpPhysiol 89: 293-302, 2004.

12. Dicker SG, Lofthus GK, Thornton NW, Brooks G. Respiratory and heart rate responses to tethered controlled frequency breathing swimming. Med Sci Sports Exerc 12: 20-23, 1980.

13. Engelen M, Porszasz J, Riley M, Wasserman K, Maehara K, Barstow TJ. Effects of hypoxic hypoxia on $\mathrm{O} 2$ uptake and heart rate kinetics during heavy exercise. $J$ Appl Physiol 81: 2500-2508, 1996.

14. Fédération Internationale De Natation. Fina General Rules. FINA Congr : 1-11, 2014.

15. Ferrari M, Mottola L, Quaresima V. Principles, techniques, and limitations of near infrared spectroscopy. Can J Appl Physiol 29: 463-87, 2004.

16. Fiedler GB, Schmid AI, Goluch S, Schewzow K, Laistler E, Niess F, Unger E, Wolzt M, Mirzahosseini A, Kemp GJ, Moser E, Meyerspeer M. Skeletal muscle ATP synthesis and cellular $\mathrm{H}+$ handling measured by localized 31P-MRS during exercise and recovery. Sci Rep 6: 32037, 2016.

17. Folkow B, Gaskell P, Waaler BA. Blood Flow through Limb Muscles during Heavy Rhythmic Exercise. Acta Physiol Scand 80: 61-72, 1970.

18. Fukuoka Y, Poole DC, Barstow TJ, Kondo N, Nishiwaki M, Okushima D, Koga S. 
Reduction of VO2 slow component by priming exercise: novel mechanistic insights from time-resolved near-infrared spectroscopy. Physiol Rep 3: e12432, 2015.

19. Geers C, Gros G. Carbon dioxide transport and carbonic anhydrase in blood and muscle. Physiol Rev 80: 681-715, 2000.

20. Gollnick PD, Sjödin B, Karlsson J, Jansson E, Saltin B. Human soleus muscle: A comparison of fiber composition and enzyme activities with other leg muscles. Pflügers Arch Eur J Physiol 348: 247-255, 1974.

21. Gooden BA. Mechanism of the Human Diving Response. 29: 6-16, 1994.

22. Grassi B, Quaresima V, Marconi C, Ferrari M, Cerretelli P. Blood lactate accumulation and muscle deoxygenation during incremental exercise. J Appl Physiol 87: $348-355,1999$.

23. Hill A V., Long CNH, Lupton H. Muscular Exercise, Lactic Acid, and the Supply and Utilisation of Oxygen. Ergebnisse der Physiol 24: 43-51, 1925.

24. Hoffmann U, Smerecnik M, Leyk D, Essfeld O. Cardiovascular responses to apnea during dynamic exercise. Int $J$ Sports Med 26: 426-431, 2005.

25. Hogan MC, Cox RH, Welch HG. Lactate accumulation during incremental exercise with varied inspired oxygen fractions. J Appl Physiol 55: 1134-1140, 1983.

26. Hughson RL, Kowalchuk JM. Kinetics of oxygen uptake for submaximal exercise in hyperoxia, normoxia, and hypoxia. Can J Appl Physiol 20: 198-210, 1995.

27. Jones AM, Campbell FIT, Pringle JSM. Influence of muscle fibre type and pedal rate on the V rate slope during ramp exercise. Eur J Appl Physiol 91: 238-245, 2004.

28. Keir DA, Robertson TC, Benson AP, Rossiter HB, Kowalchuk JM. The influence of metabolic and circulatory heterogeneity on the expression of pulmonary VO2 kinetics in 
humans. Exp Physiol 101: 176-192, 2016.

29. Koga S, Poole DC, Fukuoka Y, Ferreira LF, Kondo N, Ohmae E, Barstow TJ.

Methodological validation of the dynamic heterogeneity of muscle deoxygenation within the quadriceps during cycle exercise. Am J Physiol Regul Integr Comp Physiol 301: R534-R541, 2011.

30. Kume D, Akahoshi S, Song J, Yamagata T, Wakimoto T, Nagao M, Matsueda S, Nagao N. Intermittent breath holding during moderate bicycle exercise provokes consistent changes in muscle oxygenation and greater blood lactate response. $J$ Sports Med Phys Fitness 53: 327-335, 2013.

31. Laughlin MH, Armstrong RB. Muscle blood flow during locomotory exercise. Exerc Sport Sci Rev 13: 95-136, 2003.

32. Lindholm P, Linnarsson D. Pulmonary gas exchange during apnoea in exercising men. Eur J Appl Physiol 86: 487-491, 2002.

33. Lindholm P, Sundblad P, Linnarsson D. Oxygen-conserving effects of apnea in exercising men. J Appl Physiol 87: 2122-2127, 1999.

34. Linnarsson D, Karlsson J, Fagraeus L, Saltin B. Muscle metabolites with exercise and oxygen deficit and hyperoxia. J Appl Physiol 36: 399-402, 1974.

35. Lutjemeier BJBJ, Miura AA, Scheuermann BWBW, Koga SS, Townsend DKDK, Barstow TJTJ. Muscle contraction-blood flow interactions during upright knee extension exercise in humans. J Appl Physiol 98: 1575-1583, 2005.

36. Lyttle AD, Blanksby BA, Elliott BC, Lloyd DG. Net forces during tethered simulation of underwater streamlined gliding and kicking techniques of the freestyle turn. $J$ Sports Sci 18: 801-807, 2000. 
37. Mancini DM, Bolinger L, Li H, Kendrick K, Chance B, Wilson JR. Validation of nearinfrared spectroscopy in humans. $J$ Appl Physiol 77: 2740-7, 1994. http://jap.physiology.org/content/jap/77/6/2740.full.pdf.

38. Manning JM. Physiology of Sport and Exercise. J Athl Train 34: 298-299, 1999.

39. Matheson GO, McKenzie DC. Breath holding during intense exercise: arterial blood gases, pH, and lactate. J Appl Physiol 64: 1947-52, 1988.

40. McCrudden M, Keir DA, Belfry G. The effects of short work versus longer work periods within intermittent exercise on VO2p kinetics, muscle deoxygenation and energy system contribution. J Appl Physiol 122: 1435-1444, 2017.

41. McCully KK, Hamaoka T. Near-infrared spectroscopy: what can it tell us about oxygen saturation in skeletal muscle? Exerc Sport Sci Rev 28: 123-127, 2000.

42. Murias JM, Dey A, Campos OA, Estaki M, Hall KE, Melling CWJ, Noble EG. HighIntensity Endurance Training Results in Faster Vessel-Specific Rate of Vasorelaxation in Type 1 Diabetic Rats. PLoS One 8: e59678, 2013.

43. Murias JM, Kowalchuk JM, Paterson DH. Speeding of VO2 kinetics with endurance training in old and young men is associated with improved matching of local O2 delivery to muscle O2 utilization. $J$ Appl Physiol 108: 913-922, 2010.

44. Murias JM, Spencer MD, Paterson DH. The Critical Role of O2 Provision in the Dynamic Adjustment of Oxidative Phosphorylation. Exerc Sport Sci Rev 42: 4-11, 2014.

45. Murphy PC, Cuervo LA, Hughson RL. A study of cardiorespiratory dynamics with step and ramp exercise tests in normoxia and hypoxia. Cardiovasc Res 23: 825-832, 1989.

46. Nuutinen EM, Nishiki K, Erecinska M, Wilson DF. Role of mitochondrial oxidative phosphorylation in regulation of coronary blood flow. Am J Physiol - Hear Circ Physiol 
243: H159-H169, 1982.

47. Paterson DJ, Wood GA, Morton AR, Henstridge JD. The entrainment of ventilation frequency to exercise rhythm. Eur J Appl Physiol Occup Physiol 55: 530-537, 1986.

48. Paulev P -E. Cardiac Rhythm during Breath-Holding and Water Immersion in Man. Acta Physiol Scand 73: 139-150, 1968.

49. Peronnet F, Aguilaniu B. Lactic acid buffering, nonmetabolic CO2 and exercise hyperventilation: A critical reappraisal. Respir Physiol Neurobiol 150: 4-18, 2006.

50. Poole DC, Barstow TJ, Gaesser, Willis, Whipp BJ. VO2 slow component: physiological and functional significance. Med Sci Sports Exerc 26: 1354-1358, 1994.

51. Rådegran G, Saltin B. Muscle blood flow at onset of dynamic exercise in humans. Am J Physiol - Hear Circ Physiol 274: H314-H322, 1998. http://ajpheart.physiology.org/content/274/1/H314.abstract.

52. Richardson RS, Duteil S, Wary C, Wray DW, Hoff J, Carlier PG. Human skeletal muscle intracellular oxygenation: the impact of ambient oxygen availability. $J$ Physiol 571: 415-424, 2006.

53. Rossiter HB, Ward SA, Doyle VL, Howe FA, Griffiths JR, Whipp BJ. Inferences from pulmonary $\mathrm{O} 2$ uptake with respect to intramuscular [phosphocreatine] kinetics during moderate exercise in humans. J Physiol 518: 921-932, 1999.

54. Rossiter HB, Ward SA, Kowalchuk JM, Howe F a, Griffiths JR, Whipp BJ. Dynamic asymmetry of phosphocreatine concentration and $\mathrm{O}(2)$ uptake between the on- and offtransients of moderate- and high-intensity exercise in humans. J Physiol 541: 991-1002, 2002.

55. Schagatay E, Andersson JPA, Nielsen B. Hematological response and diving response 
during apnea and apnea with face immersion. Eur J Appl Physiol 101: 125-132, 2007.

56. Seiyama A, Hazeki O, Tamura M. Noninvasive quantitative analysis of blood oxygenation in rat skeletal muscle. J Biochem 103: 419-24, 1988.

http://www.ncbi.nlm.nih.gov/pubmed/3391996.

57. Siegmund GP, Edwards MR, Moore KS, Tiessen DA, Sanderson DJ, McKenzie DC. Ventilation and locomotion coupling in varsity male rowers. J Appl Physiol 87: 233-242, 1999. http://jap.physiology.org/content/87/1/233.short.

58. Skorski S, Faude O, Caviezel S, Meyer T. Reproducibility of Competition Pacing Profiles in Elite Swimmers. Int J Sports Physiol Perform 9: 217-225, 2013.

59. Song SH, Lee WK, Chung YA, Hong SK. Mechanism of apneic bradycardia in man. $J$ Appl Physiol 27: 323-327, 1969.

60. Springer C, Barstow T, Wasserman K, Cooper D. Oxygen uptake and heart rate responses during hypoxic exercise in children and adults. Med. Sci. Sports Exerc. 23: 7179, 1991. http://europepmc.org/abstract/MED/1997815.

61. Stocker F, Oldershausen C Von, Paternoster FK, Schulz T, Oberhoffer R. Endexercise $\mathrm{DHHb} / \mathrm{DVO} 2$ and post-exercise local oxygen availability in relation to exercise intensity. Clin. Physiol (2015). doi: 10.1111/cpf.12314.

62. Swanson GD, Sherrill DL. On the breath-to-breath estimation of gas exchange. J Appl Physiol 56: 259-261, 1984.

63. Veiga S, Cala A, Mallo J, Navarro E, Arellano R, Terres-Nicoli JM, Redondo JM, Veiga S, Roig A. Underwater and surface strategies of $200 \mathrm{~m}$ world level swimmers. $J$ Sports Sci 34: 1-6, 2015.

64. Wasserman K, Van Kessel AL, Burton GG. Interaction of physiological mechanisms 
during exercise. J Appl Physiol 22: 71-85, 1967.

65. Wasserman K, Whipp BJ, Castagna J. Cardiodynamic hyperpnea: hyperpnea secondary to cardiac output increase. J Appl Physiol 36: 457-464, 1974.

66. Wein J, Andersson JP, Erdéus J. Cardiac and ventilatory responses to apneic exercise. Eur J Appl Physiol 100: 637-644, 2007.

67. Whipp BJ. The hyperpnea of dynamic muscular exercise. Exerc Sport Sci Rev 5: 295$311,1977$.

68. Whipp BJ. The Slow Component of O2 uptake kinetics during heavy exercise. Med Sci Sports Exerc 26: 1319-1326, 1994.

69. Whipp BJ, Davis JA. Peripheral chemoreceptors and exercise hyperpnea. Med Sci Sports Exerc 11: 204-212, 1979.

70. Whipp BJ, Ward SA, Lamarra N, Davis JA, Wasserman K. Parameters of ventilatory and gas exchange dynamics during exercise. J Appl Physiol 52: 1506-13, 1982. http://www.ncbi.nlm.nih.gov/pubmed/6809716.

71. Whipp BJ, Wasserman K. Oxygen uptake kinetics work for various intensities of constant-load. J Appl Physiol : 351-356, 1972.

72. Woorons X, Bourdillon N, Vandewalle H, Lamberto C, Mollard P, Richalet JP, Pichon A. Exercise with hypoventilation induces lower muscle oxygenation and higher blood lactate concentration: Role of hypoxia and hypercapnia. Eur J Appl Physiol 110: 367-377, 2010.

73. Woorons X, Mollard P, Pichon A, Duvallet A, Richalet JP, Lamberto C. Prolonged expiration down to residual volume leads to severe arterial hypoxemia in athletes during submaximal exercise. Respir Physiol Neurobiol 158: 75-82, 2007. 


\section{Chapter 2}

\section{PHYSIOLOGICAL RESOLUTION OF PERIODIC BREATH HOLDING}

\section{DURING HEAVY INTENSITY FARTLEK EXERCISE}

\subsection{Introduction}

Many sports require brief intermittent periods of maximal power output such as cycling (59), rowing (72) and swimming (16), in both training and competition. There are also periods where an athlete must produce maximal power while breathing irregularly or not breathing at all. For example, during backstroke swimming, breath holds are required as the swimmers push off the wall and kick underwater after a turn. In a $50 \mathrm{~m}$ pool, elite backstroke swimmers may perform these underwater kicking phases at various intensities that may be sustained for approximately $5 \mathrm{~s}(80)$. After surfacing, swimmers are able to breathe freely while completing the remaining distance in approximately $25 \mathrm{~s}$ (73). Little is known about the physiological consequences to this type of intermittent breath holding during high intensity exercise. The elucidation and interpretation of the acute singular and combined physiological effects of intermittent $5 \mathrm{~s}$ breath holds, while performing various intensities of work, followed by $25 \mathrm{~s}$ of free-breathing may provide insights to exercise performance.

Previous research has shown that both breath holding of longer durations (15 to $45 \mathrm{~s}$ every min to $5 \mathrm{~min}$, respectively), and breathing low partial pressure of $\mathrm{O}_{2}$ gases during exercise have been associated with decreases and increases in alveolar and arterial partial pressures of $\mathrm{O}_{2}$

$\left(\mathrm{PO}_{2} ;\right.$ hypoxemia $)$ and $\mathrm{CO}_{2}\left(\mathrm{PCO}_{2} ;\right.$ hypercapnia $)$, respectively $(38,82)$. These conditions resulted 
in decreased pulmonary oxygen uptake $\left(\dot{\mathrm{V}}_{2 \mathrm{p}}\right)(1)$, slowed $\dot{\mathrm{V}} \mathrm{O}_{2 \mathrm{p}}$ kinetics $(17,30,76)$, and increased muscle deoxygenation $([\mathrm{HHb}])(38,92)$, as well as arterialized-capillary lactate concentrations ([La']), compared to continuous exercise $(28,41,48,84,85,88)$.

During steady state exercise, the reduced alveolar and arterial $\mathrm{PO}_{2}$, and increased $\mathrm{PCO}_{2}$ are reflected in the decreased end-tidal $\mathrm{PO}_{2}\left(\mathrm{P}_{\mathrm{ET}} \mathrm{O}_{2}\right)$ and increased $\mathrm{PCO}_{2}\left(\mathrm{P}_{\mathrm{ET}} \mathrm{O}_{2}\right)$ in the expired air. It is possible that decreased $\mathrm{PO}_{2}$, increased $\mathrm{PCO}_{2}$ and [La'] provoked by the $5 \mathrm{~s}$ breath hold would induce a compensatory increase in ventilation during the $25 \mathrm{~s}$ free-breathing intervals (86), which would be sufficient to resolve the breath hold-induced hypoxemic condition.

Breath holding after an inspiration has also resulted in increased intrathoracic pressures, inducing temporary increases in venous return and stroke volumes that results in reflex bradycardia, and thus, reduced $\mathrm{O}_{2}$ delivery $(1,28,38,42,60,75)$. If the aforementioned $5 \mathrm{~s}$ breath holds are repeated every $30 \mathrm{~s}$, it is possible that a similar cardiovascular response would be observed. Previously, near-infrared spectroscopy-derived muscle deoxygenation ( $\Delta[\mathrm{HHb}])$ and tissue hemoglobin saturation $\left(\mathrm{S}_{\mathrm{at}} \mathrm{O}_{2}\right)$ have been shown to reflect changes in $\mathrm{PO}_{2}$ associated with the coupling of $\mathrm{O}_{2}$ utilization to oxidative phosphorylation, and/or a change in microvascular blood flow under constant $\dot{\mathrm{VO}}_{2 \mathrm{p}}$ conditions (6). If the breath holds result in hypoxemia and hypercapnia, it is expected that muscle deoxygenation would increase in an attempt to maintain $\mathrm{O}_{2}$ utilization at the muscle.

In previous intermittent exercise studies, it has been found that reducing the mean power output by inserting $5 \mathrm{~s}$ active recovery periods at regular intervals within heavy intensity exercise (supra-lactate threshold) decreased mean $\dot{\mathrm{V}}_{2 p}$ and muscle deoxygenation (7). Furthermore, with similar decreases in power output, others have also observed faster $\dot{\mathrm{V}}_{2 p}$ kinetics and decreased $\left[\mathrm{La}^{-}\right](9,58)$. Thus, it is proposed in the present study that with the 
inclusion of $5 \mathrm{~s}$ periods of higher power output, known as fartlek exercise, a differential slowing of $\dot{\mathrm{VO}}_{2 \mathrm{p}}$ kinetics, and increased mean $\dot{\mathrm{VO}}_{2 \mathrm{p}}$, and [La'] would result. Moreover, combining these 5 s periods of higher power output with the breath holds may also result in an attenuation of the expected increase in $\dot{\mathrm{V}}_{2 \mathrm{p}}$ associated with the increased mean power output, through the replacement of oxidative phosphorylation with increased substrate level phosphorylation, that would be reflected in increased [La'] (66).

Thus, the purpose of this study was to compare and contrast $\mathrm{P}_{\mathrm{ET}} \mathrm{O}_{2}$ and $\mathrm{P}_{\mathrm{ET}} \mathrm{CO}_{2}$, ventilation, $\dot{\mathrm{V}}_{2 \mathrm{p}}, \dot{\mathrm{V}}_{2 \mathrm{p}}$ kinetics, muscle deoxygenation, and [La'] during continuous heavy intensity cycling exercise with free-breathing (CON), with three differing exercise conditions: 1) Continuous heavy intensity exercise with repeated $5 \mathrm{~s}$ breath holds every $30 \mathrm{~s}(\mathrm{CBH}), 2)$ Repeated $30 \mathrm{~s}$ cycles comprised of $25 \mathrm{~s}$ of heavy intensity exercise and $5 \mathrm{~s}$ of higher power output (fartlek) with free-breathing (FLK) and, 3) combining the $5 \mathrm{~s}$ breath holds with $5 \mathrm{~s}$ of higher power output during heavy intensity exercise (fartlek breath hold (FBH)).

It was hypothesized that, in comparison to $\mathrm{CON}$ : 1) $\mathrm{CBH}$ would result in similar $\dot{\mathrm{VO}}_{2 \mathrm{p}}$ kinetics and mean $\dot{\mathrm{VO}}_{2 \mathrm{p}}$ as a function of increased ventilation stemming from the breath holds; 2) FLK would result in similar $\dot{\mathrm{V}}_{2 \mathrm{p}}$ kinetics, and increased mean $\dot{\mathrm{V}}_{2 \mathrm{p}}$, ventilation, and [ $\left.\mathrm{La}{ }^{-}\right]$, however, 3) when the two perturbations are combined, the attempted physiological resolution to the increased $\dot{\mathrm{V}}_{2 \mathrm{p}}$ demand and the breath hold-induced hypoxemia would be overwhelmed, resulting in similar mean $\dot{\mathrm{VO}}_{2 \mathrm{p}}$, but slower $\dot{\mathrm{V}}_{2 \mathrm{p}}$ kinetics, and increased ventilation and [ $\left.\mathrm{La}^{-}\right]$.

\subsection{Methods}

Participants. Ten adult males ( $24 \pm 3$ years old) volunteered and gave written consent to participate in this study. All procedures were approved by the Western University Research 
Ethics Board for Health Sciences Research Involving Human Participants. All participants were healthy, recreationally active (moderate intensity activities 1-3 times per week), and nonsmokers. No participants were taking any medications that would affect the cardiorespiratory or hemodynamic responses to exercise.

Testing protocol. Participants were asked to maintain their usual levels of physical activity throughout their participation in the present study and to refrain from drinking caffeine 6 hours prior to their tests. All tests were performed on an electronically braked cycle ergometer on five separate days, with a minimum of 48 hours of recovery after each test. During each test, the participants were required to wear a nose-clip to prevent the participant from breathing through their nose, and a rubber mouthpiece, similar to that of breathing through a snorkel or diving mask.

Testing Day 1: Incremental ramp test to fatigue on a cycling ergometer with a work rate increment of 25 Watts (W) per minute was performed with verbal encouragement to facilitate peak efforts. These baseline tests took approximately $15 \mathrm{~min}$ to complete and were used to determine the $\dot{\mathrm{V}}_{2 \text { peak }}$ and the estimated lactate threshold (LT) to prescribe the work rate for the heavy intensity (HVY) and peak aerobic power outputs in subsequent tests. The LT was defined as the $\dot{\mathrm{V}}_{2 p}$ at which $\dot{\mathrm{V} C O}$ p began to increase out of proportion to $\dot{\mathrm{VO}}_{2 \mathrm{p}}$ with a systematic rise in minute ventilation-to- $\dot{\mathrm{V}} \mathrm{O}_{2 \mathrm{p}}$ ratio and end-tidal $\mathrm{PO}_{2}$ whereas minute ventilation-to- $\dot{\mathrm{V}} \mathrm{CO}_{2 \mathrm{p}}$ ratio and end-tidal $\mathrm{PCO}_{2}$ were stable. The LT was determined through visual inspection by two researchers familiar with this procedure. Data analysis of the LT began after accounting for the delay between $\dot{\mathrm{V}}_{2 \mathrm{p}}$ and work rate (the cardiodynamic phase) during the incremental ramp test to fatigue. 
Testing Day 2: Participants performed a 'square-wave' cycling exercise test that began with a 3 min warm-up with light intensity cycling $(20 \mathrm{~W})$ followed by a step transition to HVY for 6 min with free-breathing $(\mathrm{CON})$. The work rate during the HVY corresponded to the work rate at which the participant's $\dot{\mathrm{V}} \mathrm{O}_{2 \mathrm{p}}$ was at $50 \%$ difference between the $\mathrm{LT}$ and $\dot{\mathrm{VO}} 2$ peak $(\Delta 50)$ during their incremental ramp test.

Testing Day 3: Participants performed a 'square-wave' cycling exercise test that began with a 3 min light intensity cycle $(20 \mathrm{~W})$ followed by a step transition to HVY for 6 min while performing a breath hold protocol $(\mathrm{CBH})$. The breath hold $(\mathrm{BH})$ protocol required repeated $30 \mathrm{~s}$ cycles of a 25 s of non-regulated breathing followed by a $5 \mathrm{~s}$ of $\mathrm{BH}$. This sequence was performed repeatedly over the total four min light intensity and six 6 min HVY exercise bout. To ensure proper execution, participants were given a 5 s verbal count-down leading into each $\mathrm{BH}$. Participants were also instructed to regulate their breathing during this $5 \mathrm{~s}$ lead in period to ensure an inspiration initiated the $\mathrm{BH}$.

Testing Day 4: Participants performed a 'square-wave' cycling exercise test that began with a 3 min light intensity cycle $(20 \mathrm{~W})$ followed by repeated $30 \mathrm{~s}$ cycles comprised of $25 \mathrm{~s}$ at $\Delta 50$, and $5 \mathrm{~s}$ at the peak work rate attained during ramp incremental test (sprints). Free-breathing was performed throughout.

Testing Day 5: Participants performed a 'square-wave' cycling exercise test that began with a 3 min light intensity cycle $(20 \mathrm{~W})$ followed by repeated $30 \mathrm{~s}$ cycles comprised of $25 \mathrm{~s}$ at $\Delta 50$ with free-breathing and $5 \mathrm{~s}$ sprints combined with $\mathrm{BH}(\mathrm{FBH})$ for $6 \mathrm{~min}$. The order of performing the four conditions $(\mathrm{CON}, \mathrm{CBH}, \mathrm{FLK}$, and $\mathrm{FBH})$ were systematically randomized via the iPhone application. 
Measurements. Inspired and expired gases were measured breath-by-breath by utilizing a mass spectrometer (Innovision, AMIS 2000, Lindvedvej, Denmark). Gas collection for inspired and expired flow rates were also measured with a low-dead-space $(90 \mathrm{ml})$ bidirectional turbine (Alpha Technologies, VMM 110) and pneumotach (Hans Rudolph, Model 4813) which were calibrated before each test by using a syringe of known volume. Inspired and expired gases were sampled continuously at the mouth and analyzed for concentrations of $\mathrm{O}_{2}, \mathrm{CO}_{2}$, and $\mathrm{N}_{2}$ by mass spectrometry after calibration with precision-analyzed gas mixtures. Changes in gas concentrations were aligned with gas volumes by measuring the time delay for a square-wave bolus of gas passing the turbine to the resulting changes in fractional gas concentrations as measured by the mass spectrometer. Data were collected every $20 \mathrm{~ms}$ and transferred to a computer, which aligned concentrations with volume information to build a profile of each breath. The measurement for each breath began with the inspiration and concluded with the expiration, thus enabling to capture the breath during each breath hold.

During the exercise, the vastus lateralis of the quadriceps muscle was monitored continuously by Near-Infrared Spectroscopy (NIRS; Oxiplex TS, model 95205, ISS, Champaign, IL). The NIRS system was arranged as a single channel consisting of eight laser diodes operating at two wavelengths (690 and $828 \mathrm{~nm}, 4$ at each wavelength) that were pulsed in a rapid succession (frequency modulation of laser intensity was $110 \mathrm{MHz}$ ) and a photomultiplier tube. The lightweight plastic NIRS probe (connected to laser diodes and a photomultiplier tube by optical fibres) consisted of two parallel rows of light-emitter fibres and one detector fibre bundle; the source-detector separations for this probe were $2.0,2.5,3.0$, and $3.5 \mathrm{~cm}$ for both wavelengths. The probe was placed on the muscle belly midway between the lateral epicondyle and greater trochanter of the femur; it was secured in place with an elastic strap tightened to 
prevent movement. The outline of the probe was marked with a permanent marker for future tests. This placement allowed for accurate and continuous measurement of absolute concentration changes $(\mu \mathrm{M})$ in muscle oxyhemoglobin $\left(\left[\mathrm{O}_{2} \mathrm{Hb}\right]\right)$, deoxyhemoglobin $([\mathrm{HHb}])$, total hemoglobin concentration $\left(\left[\mathrm{Hb}_{\mathrm{tot}}\right]\right)$, and tissue hemoglobin saturation $\left(\mathrm{S}_{\mathrm{at}} \mathrm{O}_{2}\right)$. The location of measurement was covered with an optically dense, black vinyl sheet, to minimize the intrusion of extraneous light. The thigh was wrapped with elastic bandages to further minimize intrusion of extraneous light and movement of the probe. NIRS measurements started $60 \mathrm{~s}$ before each test and were collected continuously throughout the entire duration of each test.

The NIRS instrument was calibrated at the beginning of each testing session following a warm-up period of 10 minutes. The calibration was done with the probe placed on a calibration block (phantom), with absorption $\left(\mu_{\mathrm{A}}\right)$ and reduced scattering coefficients $\left(\mu_{\mathrm{S}}\right)$ previously measured; thus, correction factors were determined and were automatically implemented by the manufacturer's software for the calculation of the $\mu_{\mathrm{A}}$ and $\mu_{\mathrm{S}}$ for each wavelength during the data collection. Calculation of $[\mathrm{HHb}]$ reflected continuous measurements of $\mu_{\mathrm{S}}$ throughout each testing session (i.e. constant scattering value not assumed). Data were stored online at an output frequency of $25 \mathrm{~Hz}$ but were reduced to $1 \mathrm{~s}$ bins for all subsequent analyses and zeroed to the baseline of each test.

Heart rate (HR) was measured continuously by a heart rate monitor (Polar Electro T34) using PowerLab (ML132/ML880, ADInstruments, Colorado Springs, CO) and was calculated (using a $5 \mathrm{~s}$ rolling average) based on the RR interval. Data were recorded using LabChart version 6.1 (ADInstruments) on a separate computer.

Arterialized-capillary blood lactate concentrations ([La“]) were measured 3 min before and $3 \mathrm{~min}$ after each test. Prior to the use of the lancet, a topical thermogenic (Finalgon, 
Boehringer Ingelheim) was applied onto the left index finger then sterilized with a rubbing alcohol swab for each test. Blood was revealed using an ACCU-CHEK Safe-T-Pro Plus sterile, single use lancing device and was immediately analyzed by SensLab GmbH Lactate SCOUT arterialized-capillary lactate analyzer $\left(\mathrm{mmol} \mathrm{L}^{-1}\right)$. Latex gloves were worn by the attending researcher.

Data analysis. Breath-by-breath gas exchange data were filtered by removal of aberrant data points that lay $3 \mathrm{SD}$ above and below the local mean (39). Data for each protocol were then interpolated linearly to $1 \mathrm{~s}$ intervals and time-aligned, such that time 0 represented the increase from the $20 \mathrm{~W}$ cycling period to the HVY. This second-by-second data were then averaged into $5 \mathrm{~s}$ bins for statistical analysis and graphing. $[\mathrm{HHb}]$ and $\left[\mathrm{Hb}_{\text {tot }}\right]$ data were zeroed with the baseline $[\mathrm{HHb}]$ and $\left[\mathrm{Hb}_{\mathrm{tot}}\right]$ values determined by the average of $60 \mathrm{~s}$ before the step-transition to yield the changes in concentrations respective to their baseline values ( $\Delta[\mathrm{HHb}]$ and $\Delta\left[\mathrm{Hb}_{\mathrm{tot}}\right]$ ), and raw $\mathrm{S}_{\mathrm{at}} \mathrm{O}_{2}$ data was reported. The adjustment of normalized-[HHb]-to- $\dot{\mathrm{V}}_{2 \mathrm{p}}$ ratio $\left(\Delta[\mathrm{HHb}] / \dot{\mathrm{V}}_{2 \mathrm{p}}\right)$ was obtained by zeroing and normalizing both the $[\mathrm{HHb}]$ and $\dot{\mathrm{V}} \mathrm{O}_{2 \mathrm{p}}$ data as percent changes, as previously described (54). The baseline values were considered " 0 ," and peak values determined from the final $30 \mathrm{~s}$ of the exercise were considered " $100 \%$." to the steady state response. Analysis of the mean data of the different physiological measures were limited from 120 s to end exercise to eliminate the initial $\dot{\mathrm{V}}_{2 p}$ kinetic response.

The on-transient of each $\dot{\mathrm{V}}_{2 \mathrm{p}}$ profile was modeled with the following mono-exponential function:

Equation 1.

$$
y(t)=y_{B S L}+A_{p} \cdot\left(1-e^{-(t-T D) / \tau}\right)
$$


In this equation, $\mathrm{y}(\mathrm{t})$ is the value of the dependent variable at any time during the transition, $\mathrm{y}_{\mathrm{BSL}}$ is the pre-transition baseline value, $\mathrm{A}_{\mathrm{p}}$ is the steady-state increase in $\mathrm{y}$ above the baseline value, $\tau$ is the time constant of the response or the time for $y$ to increase to $63 \%$ of the new steady-state, and TD is the time delay. The details of the fitting procedure are described elsewhere (34). Briefly, the Levenberg-Marquardt algorithm was applied to find the minimum sum of squared residuals between the mono- exponential function and the experimental data using specialized software (Origin 8.5; OriginLab, Northampton, MA). The phase I-phase II transition was determined by examining the change in $\tau$ and $\mathrm{CI}_{95}$ of the fitting window from the end of exercise, and demarcated as the point at which there was a significant increase in $\tau$ and/or $\mathrm{CI}_{95}$ closer to the onset of exercise. The end of the phase II fitting window was determined by examining the change in $\tau, \mathrm{CI}_{95}, \chi^{2}$, and plotted residuals in response to progressive increases at the end of the fitting window. The point at which there was a systematic increase in $\tau, \mathrm{CI}_{95}$, and $\chi^{2}$ was considered as the end of phase II.

Statistics. Analysis of the results $(n=10)$ between each exercise condition $(\mathrm{CON}, \mathrm{CBH}$, FLK, FBH) on changes in $\dot{\mathrm{VO}}_{2},[\mathrm{HHb}], \dot{\mathrm{V} C O} 2 \mathrm{p}, \dot{\mathrm{V}}_{\mathrm{E}}, \mathrm{P}_{\mathrm{ET}} \mathrm{O}_{2}, \mathrm{HR}$, and [La`] were calculated by one-way repeated-measures (RM) ANOVA. Significant differences were further tested by Tukey post hoc analysis. Data are reported as mean \pm SD unless otherwise presented. Statistical significance was declared when $p<0.05$.

\section{$2.3 \quad$ Results}

Participant characteristics. Summary of the anthropometric characteristics and performance variables assessed during the ramp incremental tests are shown in Table 1. 
$\dot{V} O_{2 p}$ and $\dot{V} O_{2 p}$ kinetics. Mean $\dot{\mathrm{V}} \mathrm{O}_{2 \mathrm{p}}$ from $120 \mathrm{~s}$ to the end of exercise was greater in FLK than all the other conditions (Table 2; Figure $1 ; p<0.05)$. $\dot{\mathrm{V}} \mathrm{O}_{2 \mathrm{p}}$ at the end of exercise $\left(\dot{\mathrm{V}}_{2 \mathrm{end}}\right)$ during FLK was greater than $\mathrm{CON}$ (Table $2 ; p<0.05$ ). $\dot{\mathrm{V}}_{2 \mathrm{p}}$ fluctuations were observed during $\mathrm{CBH}$ and FBH during each $30 \mathrm{~s}$ cycles; last $5 \mathrm{~s}$ periods were lower than the greatest $25 \mathrm{~s}$ period during FBH (Table $2 ; p<0.05$ ). There were no fluctuations in CON and FLK over the same period (Table 3; $p>0.05$ ). $\tau \dot{\mathrm{V}} \mathrm{O}_{2 \mathrm{p}}$ was greater in FBH than CON and FLK (Table $2 ; p<0.05$ ) but similar in CBH and FLK to CON (Table 2; $p>0.05$ ).

End-tidal partial pressure of oxygen $\left(\mathrm{P}_{E T} \mathrm{O}_{2}\right)$ and carbon dioxide $\left(\mathrm{P}_{E T} \mathrm{CO}_{2}\right)$. The mean $\mathrm{P}_{\mathrm{ET}} \mathrm{O}_{2}$ from $120 \mathrm{~s}$ to the end of exercise was greater in FLK and FBH than CON (Table 2; Figure $2 \mathrm{a} ; p<0.05$ ), and similar in $\mathrm{CBH}$ to $\mathrm{CON}$ (Table $2 ; p>0.05$ ). Mean $\mathrm{P}_{\mathrm{ET}} \mathrm{O}_{2}$ fluctuations were observed during the last $5 \mathrm{~s}$ of $\mathrm{CBH}$ and $\mathrm{FBH}$ compared to the highest $5 \mathrm{~s}$ period in their respective $25 \mathrm{~s}$ periods of each $30 \mathrm{~s}$ cycle (Table 3; Figure $2 \mathrm{~b} ; p<0.05$ ) but not during FLK (Table 3; $p>0.05$ ). The mean $\mathrm{P}_{\mathrm{ET}} \mathrm{CO}_{2}$ from $120 \mathrm{~s}$ to the end of exercise was lower in FLK than CON, greater in FBH than FLK (Table 2; Figure 3a $p<0.05$ ) but similar in CBH to CON (Table 3; Figure 2b; $p>0.05)$. Mean $\mathrm{P}_{\mathrm{ET}} \mathrm{CO}_{2}$ fluctuations were observed during the last $5 \mathrm{~s}$ period of $\mathrm{CBH}$ and FBH compared to the lowest $5 \mathrm{~s}$ period in their respective $25 \mathrm{~s}$ periods of each $30 \mathrm{~s}$ cycle (Table 3; Figure 3b; $p<0.05$ ) but not during FLK (Table 3; $p>0.05$ ).

Carbon dioxide production $\left(\dot{V} C O_{2 p}\right)$ and minute ventilation $\left(\dot{V}_{E}\right)$. The mean $\dot{\mathrm{V}} \mathrm{CO}_{2 \mathrm{p}}$ from $120 \mathrm{~s}$ to the end of exercise was greater in FLK than CON and lower in FBH than FLK (Table 2; $p<0.05$ ) but similar in $\mathrm{CBH}$ to $\mathrm{CON}$ (Table $2 ; p>0.05$ ). Mean $\dot{\mathrm{V}}_{2 \mathrm{p}}$ fluctuations were observed during the last $5 \mathrm{~s}$ period of $\mathrm{CBH}$ and $\mathrm{FBH}$ compared to the lowest $5 \mathrm{~s}$ period in their 
respective $25 \mathrm{~s}$ periods of each $30 \mathrm{~s}$ cycle (Table $3 ; p<0.05$ ) but not during FLK (Table $3 ; p>$ 0.05). The mean $\dot{\mathrm{V}}_{\mathrm{E}}$ from $120 \mathrm{~s}$ to the end of exercise was greater in CBH, FLK, and FBH than CON, greater in FBH than CBH (Table 2; Figure 4; $p<0.05$ ), and similar in FBH and FLK (Table 2; Figure 4; $p>0.05$ ). Mean $\dot{\mathrm{V}}_{\mathrm{E}}$ fluctuations were observed during the last $5 \mathrm{~s}$ period of $\mathrm{CBH}$ and FBH compared to the lowest $5 \mathrm{~s}$ period in their respective $25 \mathrm{~s}$ periods of each $30 \mathrm{~s}$ cycle (Table 3; $p<0.05$ ).

Total hemoglobin concentration $\left(\Delta\left[H b_{t o t}\right]\right)$, muscle deoxygenation $(\Delta[H H b])$, tissue hemoglobin saturation $\left(\mathrm{S}_{a t} \mathrm{O}_{2}\right)$. A summary of NIRS measures are presented in Table 2. The mean $\Delta\left[\mathrm{Hb}_{\text {tot }}\right]$ changes from baseline values from $120 \mathrm{~s}$ to the end of exercise during $\mathrm{CBH}$ and FLK was lower than CON, and FLK was lower than FBH (Table 2; Figure 5a; $p<0.05$ ). The mean $\Delta[\mathrm{HHb}]$ changes from baseline values from $120 \mathrm{~s}$ to the end of exercise were different between all conditions; $\mathrm{CBH}$ lower than CON, FBH lower than CBH, FLK lower than FBH (Table 2; Figure 5b; $p<0.05$ ). The $\mathrm{S}_{\mathrm{at}} \mathrm{O}_{2}$ from $120 \mathrm{~s}$ to the end of exercise during CBH, FLK, and FBH were greater than CON (Table 2; Figure 5c; $p<0.05$ ). Mean $\Delta[\mathrm{HHb}]$ fluctuations were not observed during the last $5 \mathrm{~s}$ of $\mathrm{CBH}$ and $\mathrm{FBH}$ of each $30 \mathrm{~s}$ cycle (Table $3 ; p<0.05$ ).

Adjustment of normalized $\Delta[H H b]$-to- $V_{2 p}$ ratio $\left(\Delta[H H b] / \dot{V} O_{2 p}\right)$. Mean $\Delta[\mathrm{HHb}] / \mathrm{VO}_{2 p}$ from $0-360 \mathrm{~s}$ was similar between all conditions (Table 2; Figure 6; $p>0.05$ ). Mean $\Delta[\mathrm{HHb}] / \mathrm{VO}_{2 p}$ of the last $5 \mathrm{~s}$ of each $30 \mathrm{~s}$ cycle were greater than the lowest $5 \mathrm{~s}$ point during the $25 \mathrm{~s}$ in $\mathrm{CBH}$ and FBH (Table 3; Figure 3; $p<0.05$ ). Mean $\Delta[\mathrm{HHb}] / \mathrm{VO}_{2 \mathrm{p}}$ fluctuations were observed during the last $5 \mathrm{~s}$ of each $30 \mathrm{~s}$ cycle during $\mathrm{CBH}$ and FBH (Table $3 ; p<0.05$ ). 
Heart rate and $\mathrm{O}_{2}$-Pulse. The mean heart rate was different between all conditions from $120 \mathrm{~s}$ to the end of exercise; CBH lower than CON, FBH lower than FLK, FLK greater than CON (Table 2; $p<0.05$ ). The mean $\mathrm{O}_{2}$-Pulse from $120 \mathrm{~s}$ to the end of exercise was greater in $\mathrm{CBH}$ than $\mathrm{CON}$ and lower in FBH than CON, but similar in FLK to CON (Table 2; $p>0.05$ ).

Arterialized-capillary lactate concentration ([La-]). The mean pre-exercise [ $\left.\mathrm{La}^{-}\right]$across all conditions were similar (Table $2 ; p>0.05$ ) and the mean post-exercise $\left[\mathrm{La}^{-}\right]$in FBH was greater than all other conditions (Table $2 ; p<0.05$ ). 
Table 1. Participant characteristics and performance variables from the ramp incremental test including age, height, body mass, $\dot{\mathrm{VO}}_{2 \text { peak, }}$ estimated LT, peak PO, and PO at $\Delta 50$.

\begin{tabular}{|c|c|c|c|c|c|c|c|}
\hline & $\begin{array}{c}\text { Age } \\
\text { (years) }\end{array}$ & $\begin{array}{l}\text { Height } \\
(\mathrm{cm})\end{array}$ & $\begin{array}{c}\text { Body } \\
\text { mass }(\mathrm{kg})\end{array}$ & $\begin{array}{c}\dot{\mathrm{V}} \mathrm{O}_{2 \text { peak }} \\
\left(\mathrm{L} \cdot \mathrm{min}^{-1}\right)\end{array}$ & $\begin{array}{l}\text { Estimated LT } \\
\left(\mathrm{L} \cdot \mathrm{min}^{-1}\right)\end{array}$ & $\begin{array}{c}\text { PO at } \Delta 50 \\
\text { (W) }\end{array}$ & $\begin{array}{c}\text { Peak PO } \\
\text { (W) }\end{array}$ \\
\hline Mean & 24 & 179 & 80 & 3.17 & 1.77 & 218 & 314 \\
\hline SD & 3 & 6 & 9 & 0.52 & 0.22 & 30 & 49 \\
\hline
\end{tabular}

$\dot{V} O_{2 p e a k}:$ Peak pulmonary oxygen uptake $\left(\dot{\mathrm{V}} \mathrm{O}_{2}\right)$, estimated $L T$ : estimated lactate threshold, $P O$ at 450 : power output at 50 percent of the difference between the LT and $\mathrm{VO}_{2 \text { peak, }}$ Peak $P O$ : peak power output attained during ramp incremental test (sprints) 
Table 2. Summary of physiological parameters collected during CON, CBH, FLK, and FBH.

\begin{tabular}{|c|c|c|c|c|c|c|c|c|c|}
\hline & $\mathrm{CON}$ & $\mathrm{CBH}$ & FLK & FBH & & $\mathrm{CON}$ & $\mathrm{CBH}$ & FLK & FBH \\
\hline $\begin{array}{l}\text { Mean PO } \\
\text { (Watts) } \\
\text { SD }\end{array}$ & $\begin{array}{l}218 \\
30\end{array}$ & $\begin{array}{l}218 \\
30\end{array}$ & $\begin{array}{l}234 * \\
33\end{array}$ & $\begin{array}{l}234^{*} \\
323\end{array}$ & $\begin{array}{l}\text { HR (bpm) } \\
\text { SD }\end{array}$ & $\begin{array}{l}169 \\
7 \\
\end{array}$ & $\begin{array}{l}166^{* \dagger} \\
7\end{array}$ & $\begin{array}{l}175^{*} \\
7 \\
\end{array}$ & $\begin{array}{l}173^{*} \S \dagger \\
6\end{array}$ \\
\hline $\begin{array}{l}\dot{\mathrm{VO}_{2 p}} \\
\left(\mathrm{~L} \cdot \mathrm{min}^{-1}\right) \\
\mathrm{SD}\end{array}$ & $\begin{array}{l}2.71 \\
0.12\end{array}$ & $\begin{array}{l}2.73 \\
0.14\end{array}$ & $\begin{array}{l}2.85^{*} \\
0.12\end{array}$ & $\begin{array}{l}2.73 \dagger \\
0.14\end{array}$ & $\begin{array}{l}\mathrm{O}_{2} \text {-Pulse } \\
\left(\mathrm{mlO}_{2} \cdot \mathrm{min}^{-1}\right. \\
\left.\cdot \mathrm{HR} \text { beat }^{-1}\right) \\
\mathrm{SD}\end{array}$ & $\begin{array}{l}16.3 \\
0.3\end{array}$ & $\begin{array}{l}16.7^{*} \\
0.7\end{array}$ & $\begin{array}{l}16.3 \\
0.4\end{array}$ & $\begin{array}{l}15.7 * \S \dagger \\
0.8\end{array}$ \\
\hline $\begin{array}{l}\dot{\mathrm{V}} \mathrm{O}_{2 \mathrm{p}} \mathrm{BSL} \\
\left(\mathrm{L} \cdot \mathrm{min}^{-1}\right) \\
\mathrm{SD}\end{array}$ & $\begin{array}{l}0.92 \\
0.04\end{array}$ & $\begin{array}{l}0.90 \\
0.03\end{array}$ & $\begin{array}{l}0.93 \\
0.04\end{array}$ & $\begin{array}{l}0.90 \\
0.05\end{array}$ & $\begin{array}{l}\Delta\left[\mathrm{Hb}_{\text {tot }}\right](\mathrm{uM}) \\
\mathrm{SD}\end{array}$ & $\begin{array}{l}4.94 \\
0.4\end{array}$ & $\begin{array}{l}3.85^{*} \\
0.7\end{array}$ & $\begin{array}{l}2.44 * \S \\
0.7\end{array}$ & $\begin{array}{l}5.42 * \S \dagger \\
0.8\end{array}$ \\
\hline 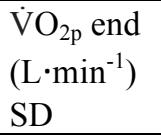 & $\begin{array}{l}2.88 \\
0.02\end{array}$ & $\begin{array}{l}2.83 \\
0.10\end{array}$ & $\begin{array}{l}2.97 * \\
0.04\end{array}$ & $\begin{array}{l}2.86 \\
0.10\end{array}$ & $\begin{array}{l}\Delta[\mathrm{HHb}](\mathrm{uM}) \\
\mathrm{SD}\end{array}$ & $\begin{array}{l}16.3 \\
0.7\end{array}$ & $\begin{array}{l}14.4^{*} \\
0.6\end{array}$ & $\begin{array}{l}12.0 * \S \\
0.4\end{array}$ & $\begin{array}{l}13.9 * \S \dagger \\
0.5\end{array}$ \\
\hline $\begin{array}{l}\tau \dot{\mathrm{V}} \mathrm{O}_{2 p}(\mathrm{~s}) \\
\mathrm{SD}\end{array}$ & $\begin{array}{l}48.8 \\
12 \\
\end{array}$ & $\begin{array}{l}53.2 \\
11 \\
\end{array}$ & $\begin{array}{l}44.1 \S \ddagger \\
8\end{array}$ & $\begin{array}{l}62.2^{*} \\
19\end{array}$ & $\begin{array}{l}\mathrm{S}_{\mathrm{at}} \mathrm{O}_{2}(\%) \\
\mathrm{SD}\end{array}$ & $\begin{array}{l}51.7 \\
0.7\end{array}$ & $\begin{array}{l}55.5^{* \dagger} \dagger \\
0.5\end{array}$ & $\begin{array}{l}54.4^{*} \\
0.2\end{array}$ & $\begin{array}{l}55.5 * \dagger \\
0.5\end{array}$ \\
\hline $\begin{array}{l}\dot{\mathrm{V} C O} \mathrm{CO}_{2 \mathrm{p}} \\
\left(\mathrm{L} \cdot \mathrm{min}^{-1}\right) \\
\mathrm{SD}\end{array}$ & $\begin{array}{l}3.12 \\
0.13 \\
\end{array}$ & $\begin{array}{l}3.16 \\
0.38 \\
\end{array}$ & $\begin{array}{l}3.43^{*}+ \\
0.16\end{array}$ & $\begin{array}{l}3.28 * \S \\
0.35 \\
\end{array}$ & $\begin{array}{l}\Delta[\mathrm{HHb}] / \dot{\mathrm{VO}}_{2 \mathrm{p}} \\
\mathrm{SD}\end{array}$ & $\begin{array}{l}0.99 \\
0.13\end{array}$ & $\begin{array}{l}0.99 \\
0.15\end{array}$ & $\begin{array}{l}1.00 \\
0.12\end{array}$ & $\begin{array}{l}1.00 \\
0.15 \\
\end{array}$ \\
\hline $\begin{array}{l}\dot{\mathrm{V}}_{\mathrm{E}} \\
\left(\mathrm{L} \cdot \mathrm{min}^{-1}\right) \\
\mathrm{SD}\end{array}$ & $\begin{array}{l}89.74 \\
7 \\
\end{array}$ & $\begin{array}{l}97.58 * \\
16\end{array}$ & $\begin{array}{l}105.0 * \S \\
10\end{array}$ & $\begin{array}{l}100.9^{*} \\
19\end{array}$ & $\begin{array}{l}\text { pre [La`] } \\
(\mathrm{mM}) \\
\mathrm{SD}\end{array}$ & $\begin{array}{l}2.0 \\
0.5\end{array}$ & $\begin{array}{l}1.8 \\
0.3\end{array}$ & $\begin{array}{l}1.7 \\
0.4\end{array}$ & $\begin{array}{l}1.7 \\
0.4\end{array}$ \\
\hline $\begin{array}{l}\mathrm{P}_{\mathrm{ET}_{2} \mathrm{O}_{2}} \\
(\mathrm{mmHg}) \\
\mathrm{SD}\end{array}$ & $\begin{array}{l}103.9 \\
2\end{array}$ & $\begin{array}{l}105.4 \\
5\end{array}$ & $\begin{array}{l}108.4 * \\
2\end{array}$ & $\begin{array}{l}106.4 * \S \\
5\end{array}$ & $\begin{array}{l}\text { post }\left[\mathrm{La}^{-}\right] \\
(\mathrm{mM}) \\
\text { SD }\end{array}$ & $\begin{array}{l}9.0 \dagger \\
2.3\end{array}$ & $\begin{array}{l}10.0 \dagger \\
2.4\end{array}$ & $\begin{array}{l}9.9 \dagger \\
2.0\end{array}$ & $\begin{array}{l}11.5 \\
2.7\end{array}$ \\
\hline $\begin{array}{l}\mathrm{P}_{\mathrm{ET}} \mathrm{CO}_{2} \\
(\mathrm{mmHg}) \\
\mathrm{SD}\end{array}$ & $\begin{array}{l}42.3 \\
2 \\
\end{array}$ & $\begin{array}{l}42.7 \\
4 \\
\end{array}$ & $\begin{array}{l}40.2 * \\
3 \\
\end{array}$ & $\begin{array}{l}42.2 \S \dagger \\
4\end{array}$ & & & & & \\
\hline
\end{tabular}

Data analyzed by one way repeated measures ANOVA. Values are given as means $+\mathrm{SD}$. Mean data are from $120 \mathrm{~s}-360 \mathrm{~s}$. $C O N$ : continuous exercise at $\triangle 50$ with free-breathing; $C B H$ : continuous exercise at $\Delta 50$ with repeated $30 \mathrm{~s}$ cycles comprised of $25 \mathrm{~s}$ free-breathing periods and $5 \mathrm{~s}$ breath holds; FLK: continuous exercise with repeated $30 \mathrm{~s}$ cycles comprised of $25 \mathrm{~s} \Delta 50$ and $5 \mathrm{~s}$ sprints with free-breathing; $F B H: 6$ min of continuous exercise with repeated $30 \mathrm{~s}$ cycles comprised of $25 \mathrm{~s} \triangle 50$ with free-breathing and $5 \mathrm{~s}$ sprints combined with a breath hold; Mean $P O$ : mean power output; $\dot{V} O_{2 p}$ : mean pulmonary oxygen uptake; $B S L$ : baseline during $4 \mathrm{~min}$ of $20 \mathrm{~W}$ cycling; end: last $30 \mathrm{~s}$ of exercise; $\tau$ : time constant representing $63 \%$ of time to reach steady state; $\dot{V} C O_{2 p}$ : mean carbon dioxide production; $\dot{V}_{E}$ : mean minute ventilation; $P_{E T} O_{2}$ : mean end-tidal partial pressures of oxygen; $P_{E T} C_{2}$ : mean end-tidal partial pressures of carbon dioxide; $H R$ : mean heart rate; $\mathrm{O}_{2}$-Pulse: mean oxygen utilization per heart beat; $\Delta\left[H b_{t o t}\right]$ : mean change in total hemoglobin concentration from baseline values; $\triangle[H H b]$ : mean change in deoxygenated hemoglobin concentration from baseline values; $\mathrm{S}_{a t} \mathrm{O}_{2}$ : mean tissue hemoglobin saturation; $\triangle[\mathrm{HHb}] / \dot{V} \mathrm{O}_{2 p}$ : adjustment of normalized $[\mathrm{HHb}]$-to-normalized $\dot{\mathrm{V}} \mathrm{O}_{2 \mathrm{p}}$ ratio from 0 $360 \mathrm{~s} ;\left[\mathrm{La}^{-}\right]$: arterialized-capillary lactate concentration; * different from $\mathrm{CON}$, § different from $\mathrm{CBH}, \uparrow$ different from FLK, $\$$ different from FBH 
Table 3. Summary of fluctuations in $\dot{\mathrm{V}} \mathrm{O}_{2 \mathrm{p}}, \dot{\mathrm{V}} \mathrm{CO}_{2 \mathrm{p}}, \dot{\mathrm{V}}_{\mathrm{E}}, \mathrm{P}_{\mathrm{ET}} \mathrm{O}_{2}, \mathrm{P}_{\mathrm{ET}} \mathrm{CO}_{2}, \Delta[\mathrm{HHb}]$, and $\Delta[\mathrm{HHb}] / \dot{\mathrm{VO}}_{2 \mathrm{p}}$ over the $25 \mathrm{~s}$ and $5 \mathrm{~s}$ intervals within the $30 \mathrm{~s}$ cycles of $\mathrm{CON}, \mathrm{CBH}, \mathrm{FLK}$, and FBH.

\begin{tabular}{|c|c|c|c|c|c|c|c|c|}
\hline \multirow{3}{*}{$\dot{\mathrm{V}} \mathrm{O}_{2 \mathrm{p}}\left(\mathrm{L} \cdot \mathrm{min}^{-1}\right)$} & \multicolumn{2}{|c|}{$\mathrm{CON}$} & \multicolumn{2}{|c|}{$\mathrm{CBH}$} & \multicolumn{2}{|c|}{ FLK } & \multicolumn{2}{|c|}{$\mathrm{FBH}$} \\
\hline & \multicolumn{2}{|c|}{$25 \mathrm{~s}$} & \multicolumn{2}{|l|}{$25 \mathrm{~s}$} & \multicolumn{2}{|c|}{$25 \mathrm{~s}$} & \multicolumn{2}{|c|}{$25 \mathrm{~s} \quad 5 \mathrm{~s}$} \\
\hline & 2.58 & 2.36 & $2.67 *$ & $2.25 *$ & $2.72 *$ & $2.48^{*}$ & $2.70 *$ & $2.20 *+$ \\
\hline $\mathrm{SD}$ & 0.4 & 0.5 & 0.4 & 0.5 & 0.4 & 0.5 & 0.5 & 0.5 \\
\hline$\dot{\mathrm{V}} \mathrm{CO}_{2 \mathrm{p}}\left(\mathrm{L} \cdot \mathrm{min}^{-1}\right)$ & 2.87 & 2.60 & $3.13 *$ & $2.03 *+$ & $3.20 *$ & $2.83 *$ & $3.29 *$ & $2.07 *+t$ \\
\hline $\mathrm{SD}$ & 0.6 & 0.7 & 0.8 & 0.5 & 0.7 & 0.8 & 0.9 & 0.7 \\
\hline$\dot{\mathrm{V}}_{\mathrm{E}}\left(\mathrm{L} \cdot \mathrm{min}^{-1}\right)$ & 83.2 & 72.8 & $96.9 *$ & $59.1 *+$ & $97.7 *$ & $83.9 *$ & $100 *$ & $57.2 *+t$ \\
\hline $\mathrm{SD}$ & 20 & 20 & 25 & 19 & 23 & 26 & 27 & 16 \\
\hline $\mathrm{P}_{\mathrm{ET}} \mathrm{O}_{2}(\mathrm{mmHg})$ & 103 & 97 & $107^{*}$ & $88 *+$ & $107^{*}$ & $100 *$ & $108^{*}$ & $89 *+t$ \\
\hline $\mathrm{SD}$ & 4 & 6 & 4 & 12 & 4 & 9 & 5 & 13 \\
\hline $\mathrm{P}_{\mathrm{ET}} \mathrm{CO}_{2}(\mathrm{mmHg})$ & 41 & 43 & $39 *$ & $49 *+$ & $39 *$ & $42 \beta$ & $38 *$ & $49 *+t$ \\
\hline SD & 2 & 2 & 2 & & 3 & 3 & 3 & \\
\hline$\Delta[\mathrm{HHb}](\mathrm{uM})$ & 14.3 & 16.1 & $14.1 *$ & $12.5 *$ & $10.5^{*}$ & $11.9^{*}$ & $12.1 * \dagger$ & $13.63 * \S \dagger$ \\
\hline SD & 4 & 1 & 4 & 1 & 3 & 1 & 4 & 1 \\
\hline$\Delta[\mathrm{HHb}] / \dot{\mathrm{VO}}_{2 p}$ & 0.9 & 1.0 & 0.9 & $1.1 *+$ & 0.9 & 1.0 & $0.8 \dagger$ & $1.1 *+$ \\
\hline SD & 0.2 & 0.1 & 0.2 & 0.1 & 0.2 & 0.1 & 0.2 & 0.2 \\
\hline
\end{tabular}

Data analyzed by two way repeated measures ANOVA. Values are given as means \pm SD. $25 s$ : represents the peak $\left(\dot{\mathrm{V} O} \mathrm{~V}_{2 \mathrm{p}}, \dot{\mathrm{V} C O} \mathrm{C}_{2 \mathrm{p}}, \dot{\mathrm{V}}_{\mathrm{E}}, \mathrm{P}_{\mathrm{ET}} \mathrm{O}_{2}\right)$ or nadir $\left(\mathrm{P}_{\mathrm{ET}} \mathrm{CO}_{2}, \Delta[\mathrm{HHb}] / \dot{\mathrm{VO}}_{2 \mathrm{p}}\right) 5 \mathrm{~s}$ values during the first $25 \mathrm{~s}$ period of each $30 \mathrm{~s}$ cycle; $5 \mathrm{~s}$ : represents the last $5 \mathrm{~s}$ of each $30 \mathrm{~s}$ cycle; $C O N$ : continuous; $C B H$ : continuous breath hold; FLK: FLK; FBH: FLK breath hold; $\dot{V} O_{2 p}$ : mean pulmonary oxygen uptake from $0-360 \mathrm{~s} ; \dot{V} C O_{2 p}$ : mean carbon dioxide production from $0-360 \mathrm{~s} ; \dot{V}_{E}$ : mean minute ventilation from $0-360 \mathrm{~s} ; P_{E T} O_{2}$ : mean end-tidal partial pressures of oxygen; $\mathrm{P}_{\mathrm{ET}} \mathrm{CO}_{2}$ : mean end-tidal partial pressures of carbon dioxide; $\triangle[\mathrm{HHb}]$ : change in deoxygenated hemoglobin concentration; $\Delta[H H b] / \dot{V} O_{2 p}$ : mean ratio of adjustment of normalized $[\mathrm{HHb}]$-to-normalized $\dot{\mathrm{V}} \mathrm{O}_{2 \mathrm{p}}$; + different from $25 \mathrm{~s}$ within the same condition, * different from $\mathrm{CON}, \S$ different from $\mathrm{CBH}, \dagger$ different from $\mathrm{FLK}$ 


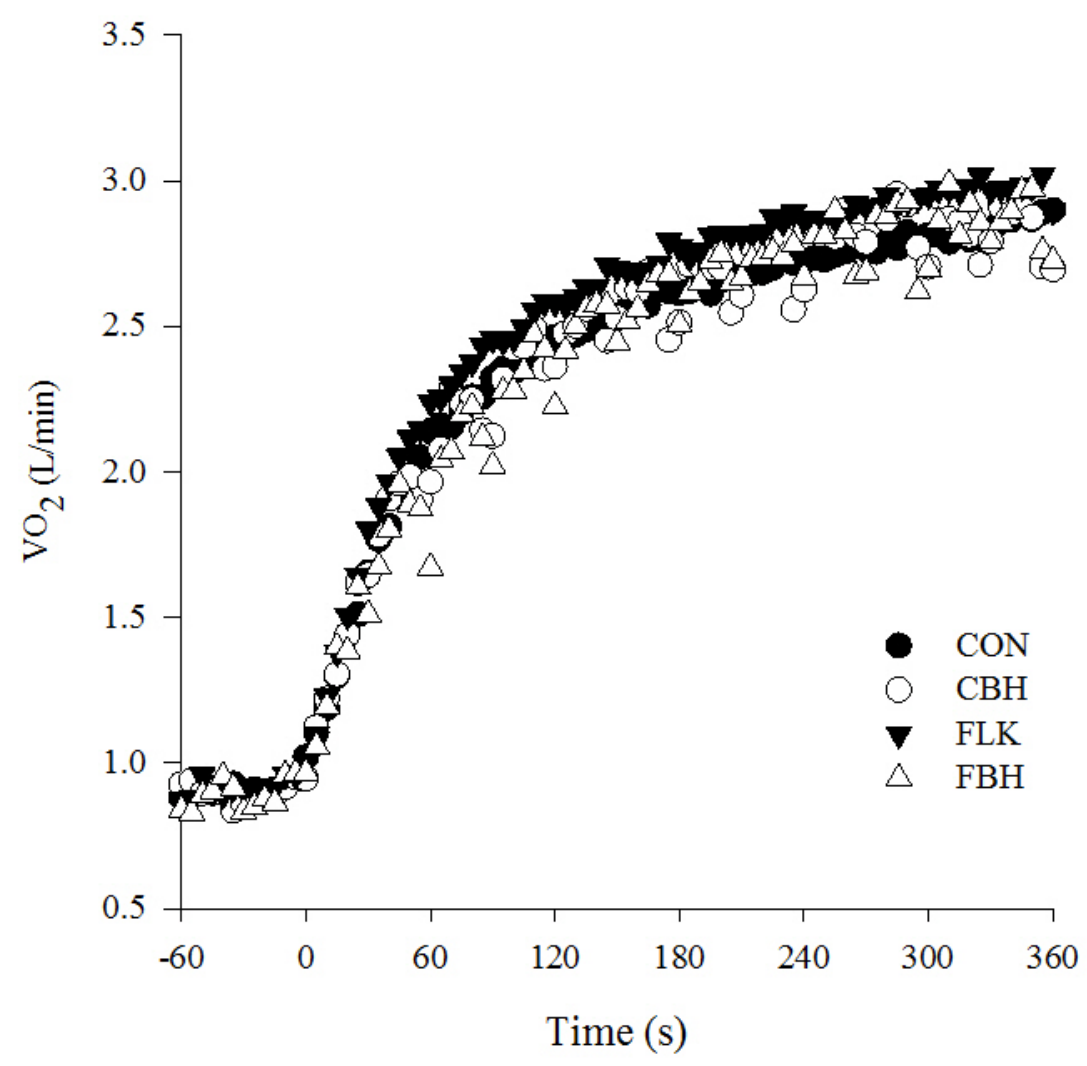

Figure 1. Mean pulmonary oxygen uptake $\left(\dot{\mathrm{V}}_{2 \mathrm{p}}\right)$ profile during CON (continuous exercise at $\triangle 50: 50$ percent of the difference between the $\mathrm{LT}$ and $\dot{\mathrm{V}}_{2 \text { peak }}$ ), CBH (continuous exercise at $\Delta 50$ with repeated $25 \mathrm{~s}$ free breathing and $5 \mathrm{~s}$ breath holds), FLK (repeated 25 s $\Delta 50$ and $5 \mathrm{~s}$ free breathing sprints - peak work rate attained during ramp incremental test), and FBH (repeated $25 \mathrm{~s}$ free breathing $\Delta 50$ and $5 \mathrm{~s}$ sprints with breath holds). The mean $\mathrm{V}_{2 p}$ from 120 s to the end of exercise was greater in FLK than all other conditions $(p<0.05)$. 


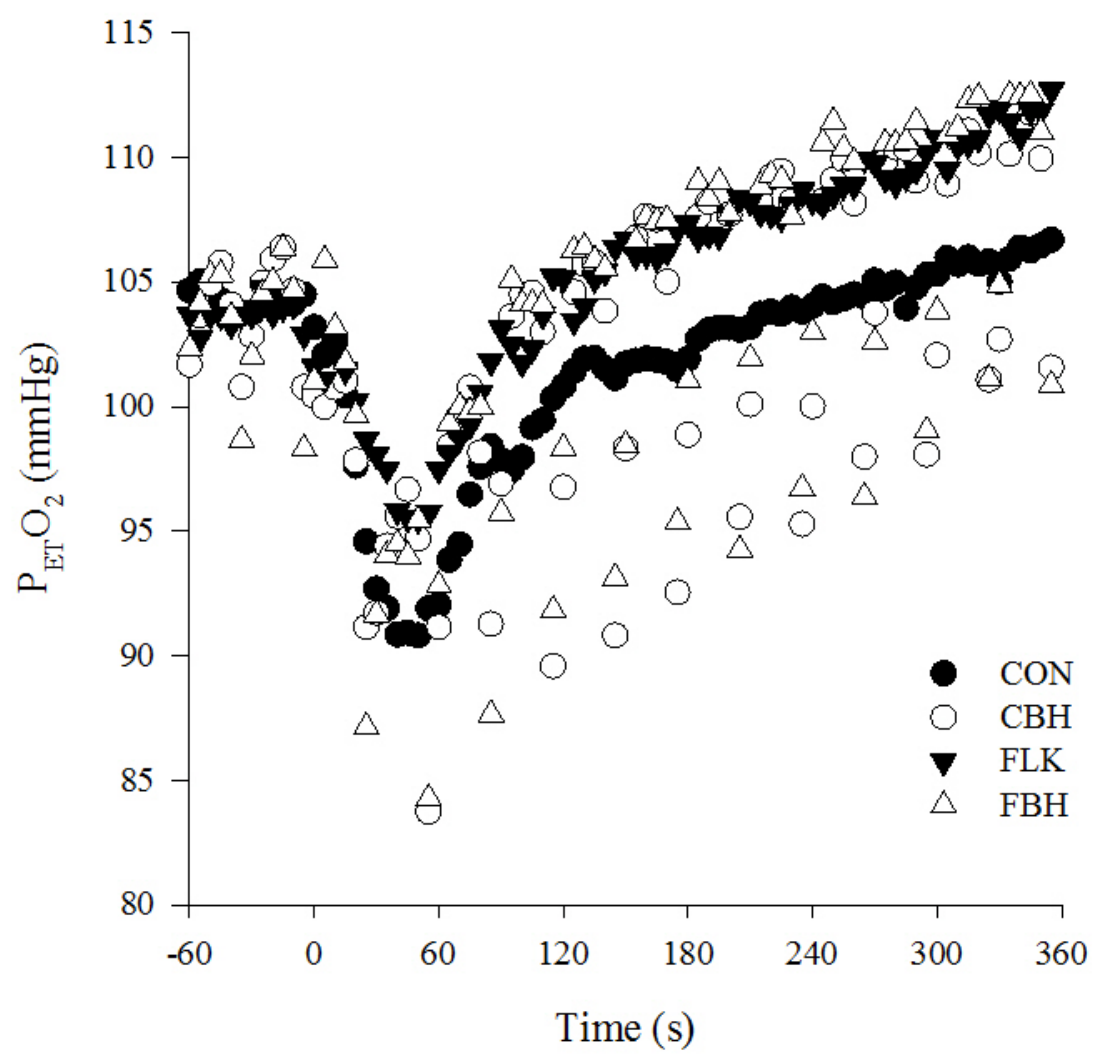

Figure 2a. Mean end-tidal partial pressure of oxygen $\left(\mathrm{P}_{\mathrm{ET}} \mathrm{O}_{2}\right)$ during $\mathrm{CON}$ (continuous exercise at $\Delta 50$ : 50 percent of the difference between the $\mathrm{LT}$ and $\dot{\mathrm{V}}_{2 \text { peak }}$ ), CBH (continuous exercise at $\Delta 50$ with repeated $25 \mathrm{~s}$ free breathing and $5 \mathrm{~s}$ breath holds), FLK (repeated 25 s $\Delta 50$ and $5 \mathrm{~s}$ free breathing sprints - peak work rate attained during ramp incremental test), and FBH (repeated $25 \mathrm{~s}$ free breathing $\Delta 50$ and $5 \mathrm{~s}$ sprints with breath holds).The $\mathrm{P}_{\mathrm{ET}} \mathrm{O}_{2}$ from $120 \mathrm{~s}$ to the end of exercise was greater in FLK than CON, greater in FBH than CON, and lower in FBH than FLK $(p<0.05)$. 


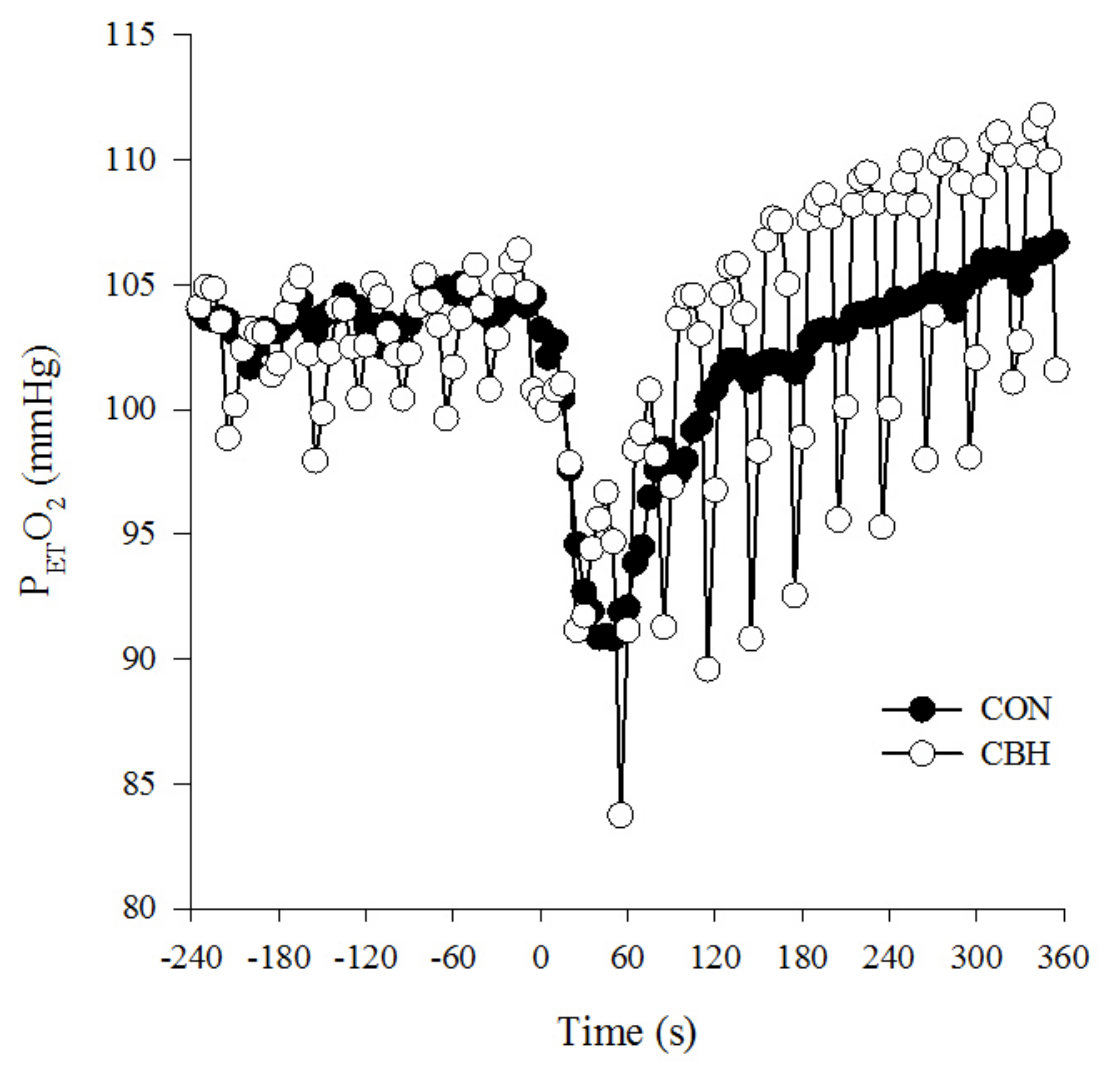

Figure 2b. Fluctuations in mean end-tidal partial pressure of oxygen $\left(\mathrm{P}_{\mathrm{ET}} \mathrm{O}_{2}\right)$ during $\mathrm{CON}$ and $\mathrm{CBH}$. This reflects the acute resolution of transient hypoxia associated with each breath hold episode. The $\mathrm{P}_{\mathrm{ET}} \mathrm{O}_{2}$ during the last $5 \mathrm{~s}$ (lowest oscillation point shown in the figure) were lower than the peak values during the $25 \mathrm{~s}$ periods over the $30 \mathrm{~s}$ cycles $(p<0.05)$. 


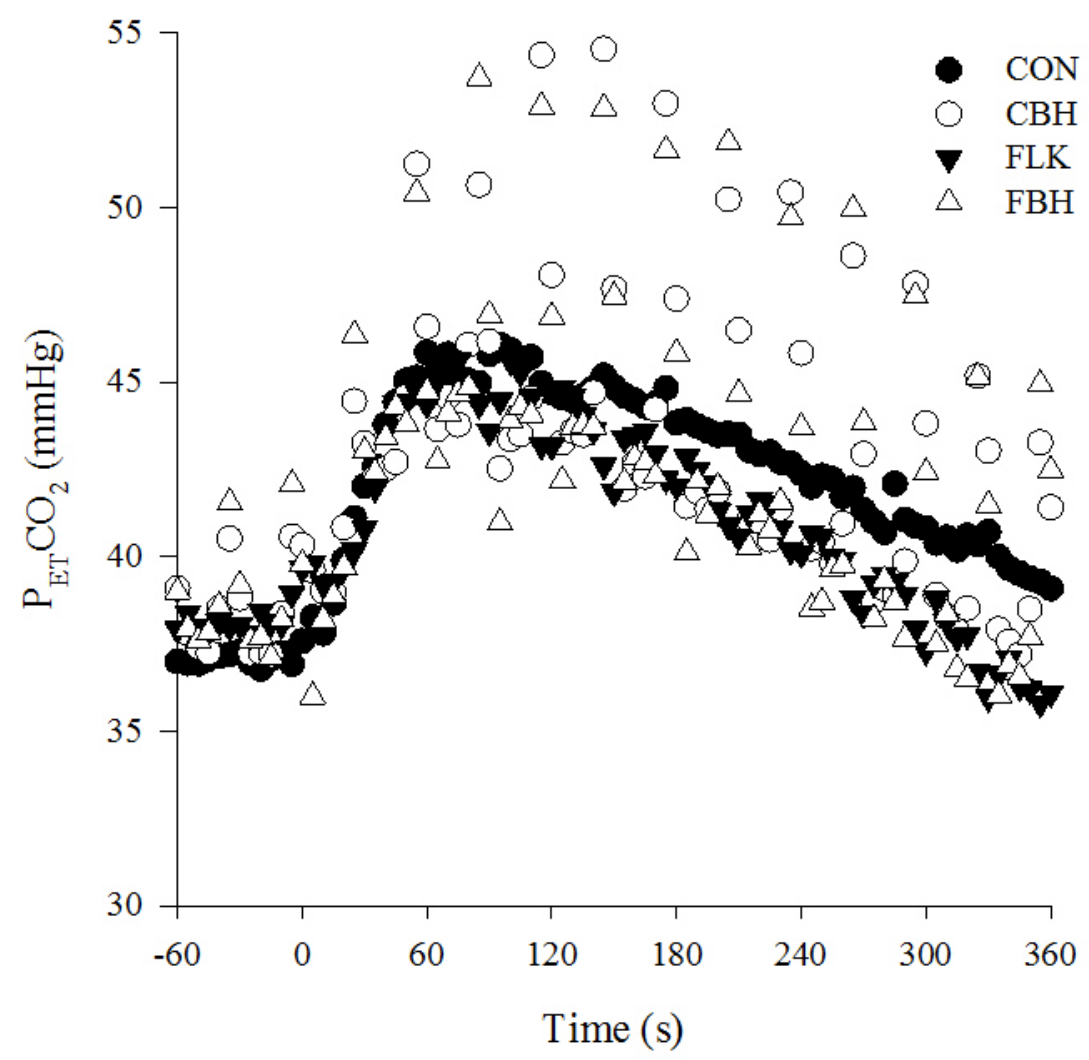

Figure 3a. Mean end-tidal partial pressure of carbon dioxide $\left(\mathrm{P}_{\mathrm{ET}} \mathrm{CO}_{2}\right)$ during $\mathrm{CON}$ (continuous exercise at $\triangle 50: 50$ percent of the difference between the LT and $\dot{\mathrm{V}} \mathrm{O}_{2 \text { peak }}$ ), $\mathrm{CBH}$ (continuous exercise at $\Delta 50$ with repeated $25 \mathrm{~s}$ free breathing and $5 \mathrm{~s}$ breath holds), FLK (repeated $25 \mathrm{~s} \Delta 50$ and $5 \mathrm{~s}$ free breathing sprints - peak work rate attained during ramp incremental test), and FBH (repeated $25 \mathrm{~s}$ free breathing $\Delta 50$ and $5 \mathrm{~s}$ sprints with breath holds). The $\mathrm{P}_{\mathrm{ET}} \mathrm{CO}_{2}$ from $120 \mathrm{~s}$ to the end of exercise was lower in FLK than CON, and greater in FBH than FLK $(p<0.05)$. 


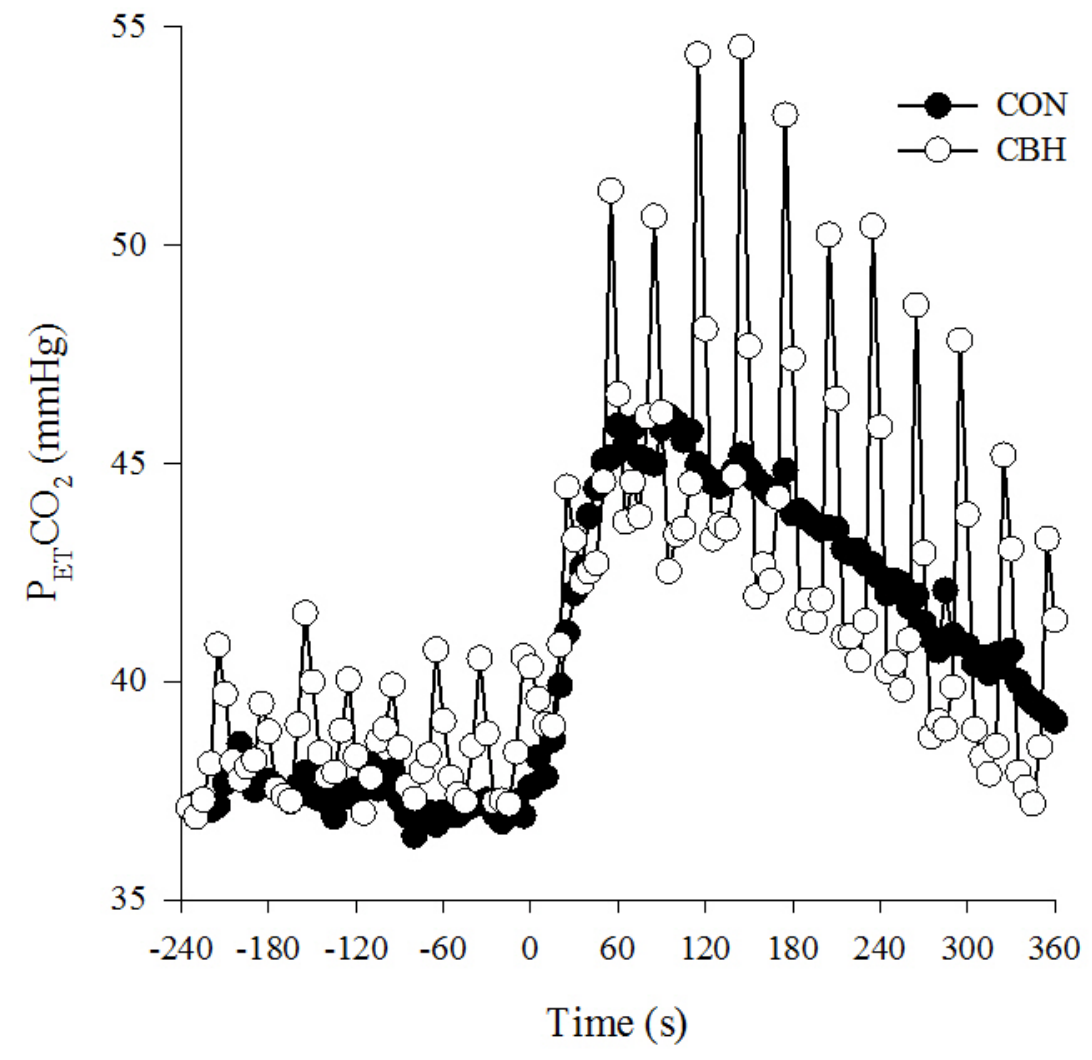

Figure 3b. Fluctuations in mean end-tidal partial pressure of carbon dioxide $\left(\mathrm{P}_{\mathrm{ET}} \mathrm{CO}_{2}\right)$ during $\mathrm{CON}$ and $\mathrm{CBH}$. This reflects the acute resolution of transient hypoxia associated with each breath hold episode. The $\mathrm{P}_{\mathrm{ET}} \mathrm{CO}_{2}$ during the last $5 \mathrm{~s}$ (highest oscillation point shown in the figure) were greater than the nadir values during the $25 \mathrm{~s}$ periods over the 30 s cycles $(p<0.05)$. 


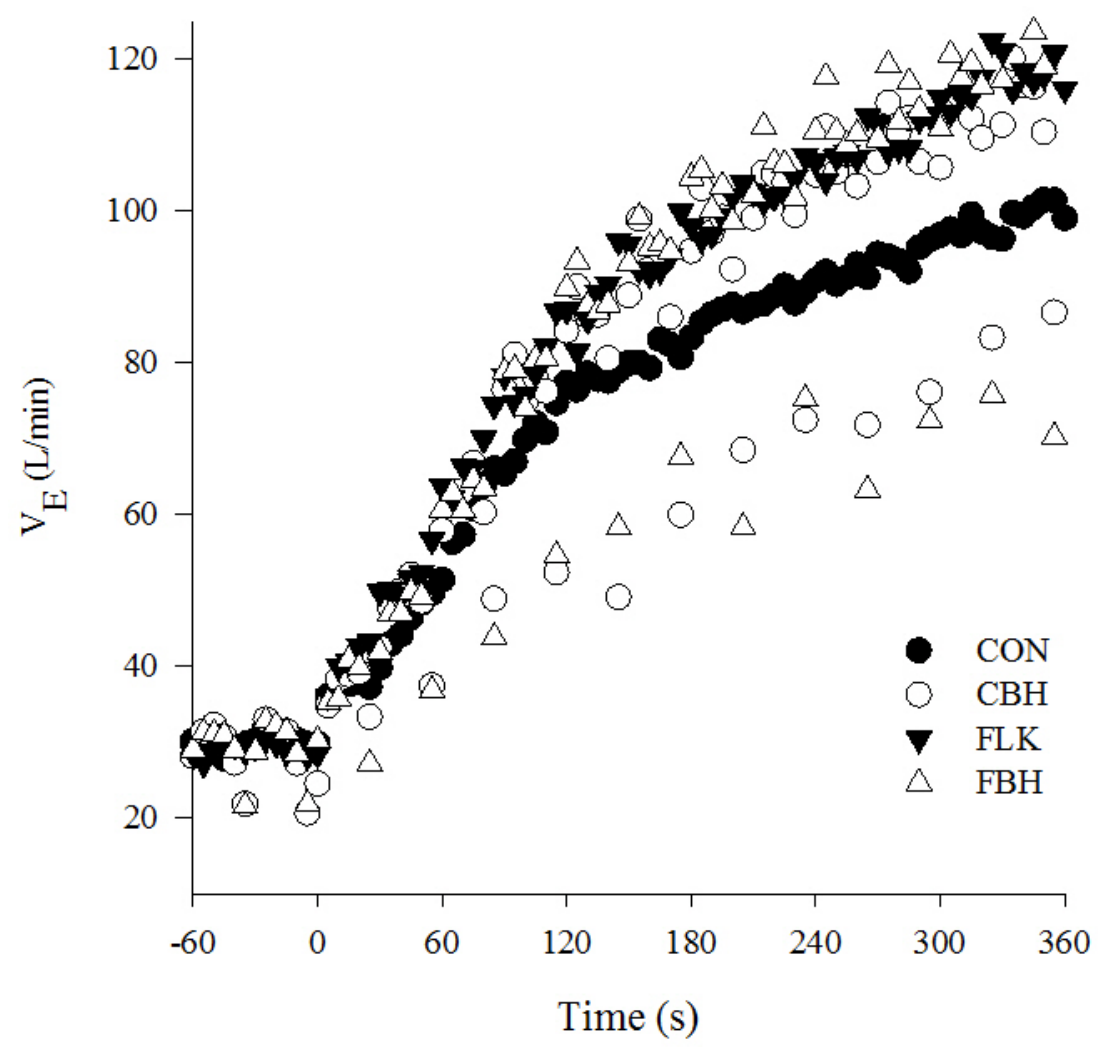

Figure 4. Mean minute ventilation $\left(\dot{\mathrm{V}}_{\mathrm{E}}\right)$ during CON (continuous exercise at $\Delta 50: 50$ percent of the difference between the LT and $\left.\dot{\mathrm{VO}}_{2 \text { peak }}\right), \mathrm{CBH}$ (continuous exercise at $\Delta 50$ with repeated $25 \mathrm{~s}$ free breathing and $5 \mathrm{~s}$ breath holds), FLK (repeated $25 \mathrm{~s}$ $\triangle 50$ and $5 \mathrm{~s}$ free breathing sprints - peak work rate attained during ramp incremental test), and $\mathrm{FBH}$ (repeated $25 \mathrm{~s}$ free breathing $\Delta 50$ and $5 \mathrm{~s}$ sprints with breath holds). The $\dot{V}_{\mathrm{E}}$ from $120 \mathrm{~s}$ to the end of exercise was greater in FLK and $\mathrm{CBH}$ than CON ( $p$ $<0.05)$. 


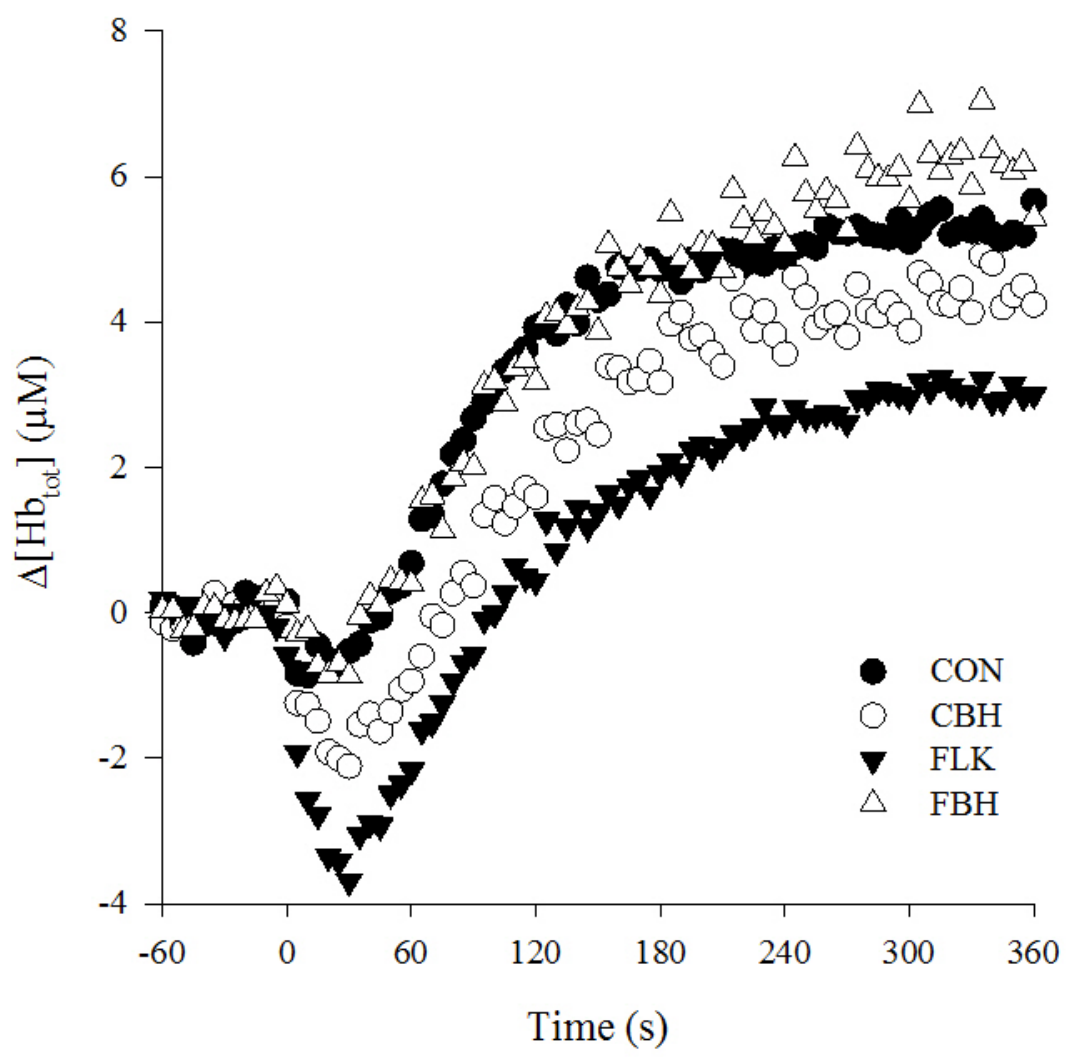

Figure 5a. Mean total hemoglobin concentration changes $\left(\Delta\left[\mathrm{Hb}_{\text {tot }}\right]\right)$ from baseline values during $\mathrm{CON}$ (continuous exercise at $\Delta 50: 50$ percent of the difference between the $\mathrm{LT}$ and $\left.\dot{\mathrm{VO}}_{2 \text { peak }}\right), \mathrm{CBH}$ (continuous exercise at $\Delta 50$ with repeated $25 \mathrm{~s}$ free breathing and $5 \mathrm{~s}$ breath holds), FLK (repeated $25 \mathrm{~s}$ $\Delta 50$ and $5 \mathrm{~s}$ free breathing sprints - peak work rate attained during ramp incremental test), and FBH (repeated $25 \mathrm{~s}$ free breathing $\Delta 50$ and $5 \mathrm{~s}$ sprints with breath holds). The mean $\Delta\left[\mathrm{Hb}_{\text {tot }}\right]$ from $120 \mathrm{~s}$ to the end of exercise during $\mathrm{CBH}$ and FLK were lower than CON and FBH $(p<0.05)$. 


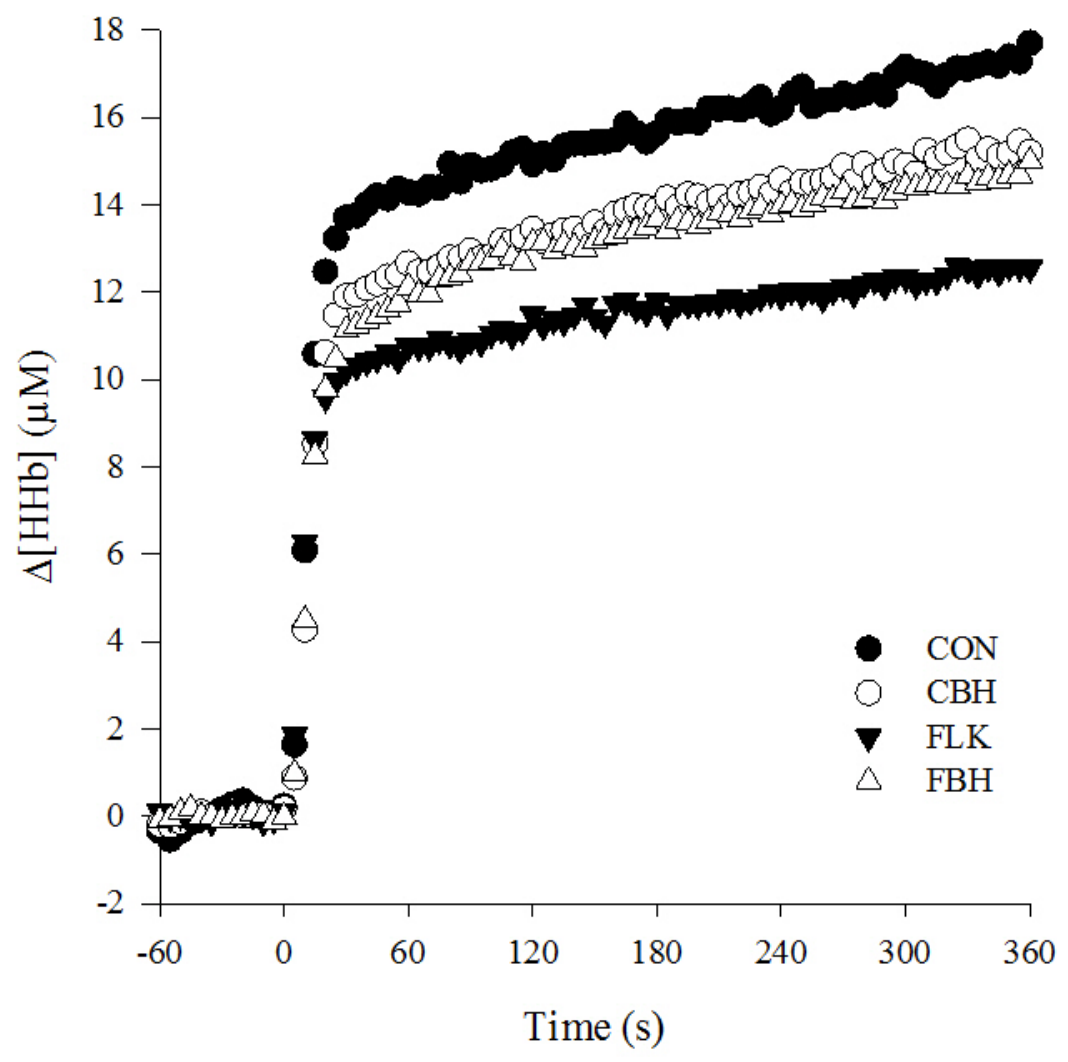

Figure 5b. Mean deoxygenated hemoglobin concentration changes $(\Delta[\mathrm{HHb}])$ from baseline values during $\mathrm{CON}, \mathrm{CBH}, \mathrm{FLK}$, and $\mathrm{FBH}$. The mean $\Delta[\mathrm{HHb}]$ from $120 \mathrm{~s}$ to the end of exercise were different in all conditions $(p<0.05)$. 


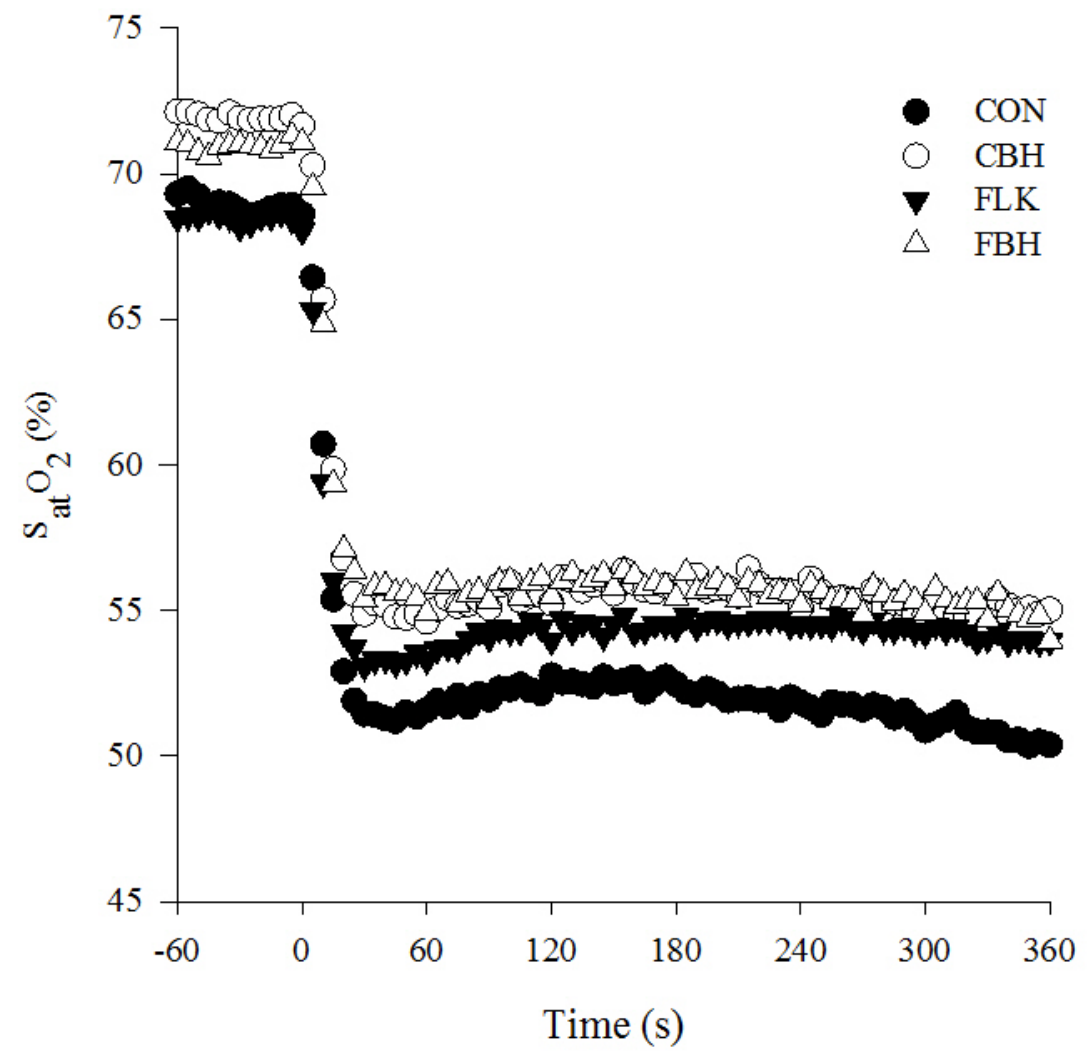

Figure 5c. Mean tissue hemoglobin saturation $\left(\mathrm{S}_{\mathrm{at}} \mathrm{O}_{2}\right)$ during $\mathrm{CON}, \mathrm{CBH}, \mathrm{FLK}$, and $\mathrm{FBH}$. The mean $\mathrm{S}_{\mathrm{at}} \mathrm{O}_{2}$ from $120 \mathrm{~s}$ to the end of exercise during $\mathrm{CBH}$ and FBH were greater than CON $(p<0.05)$. 

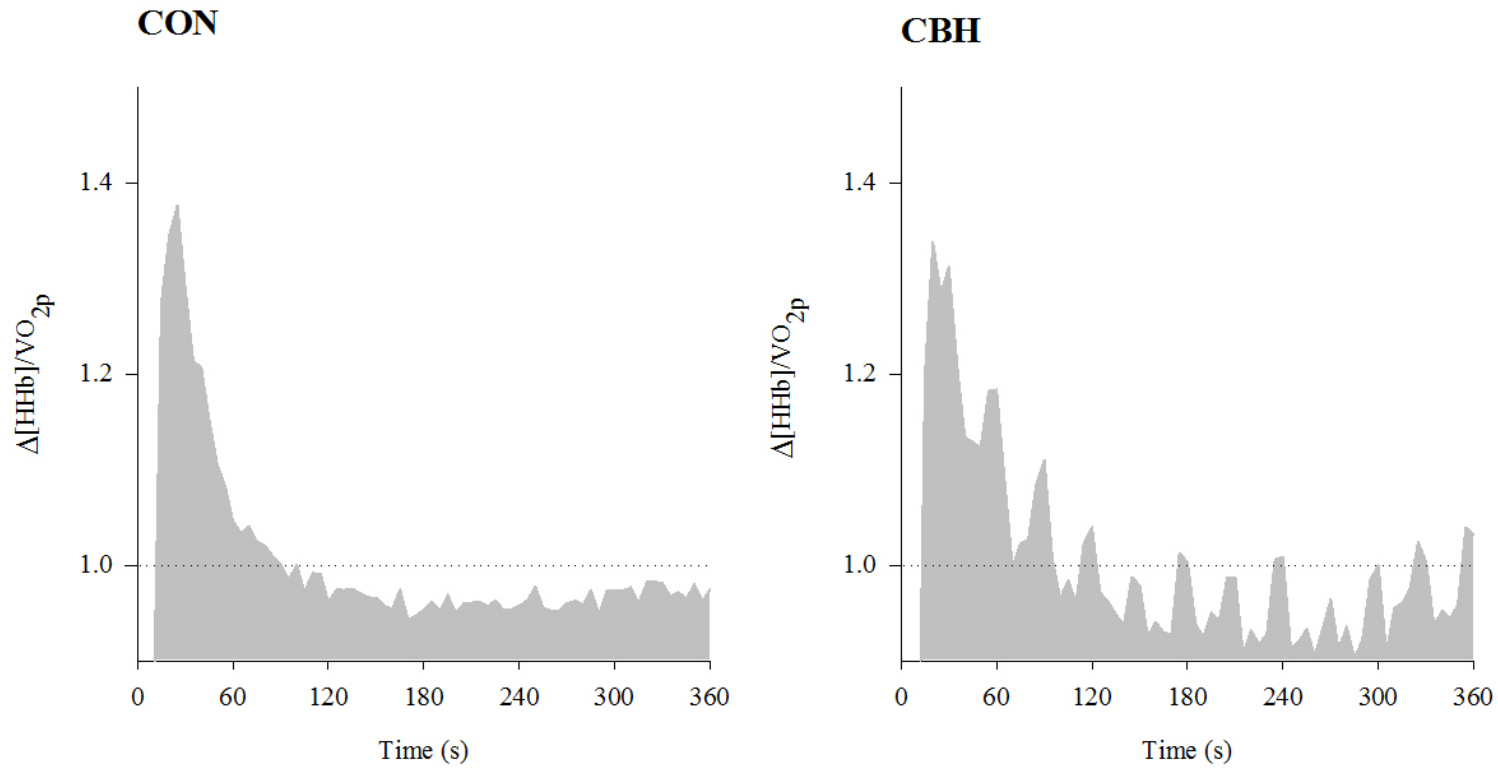

FLK

FBH
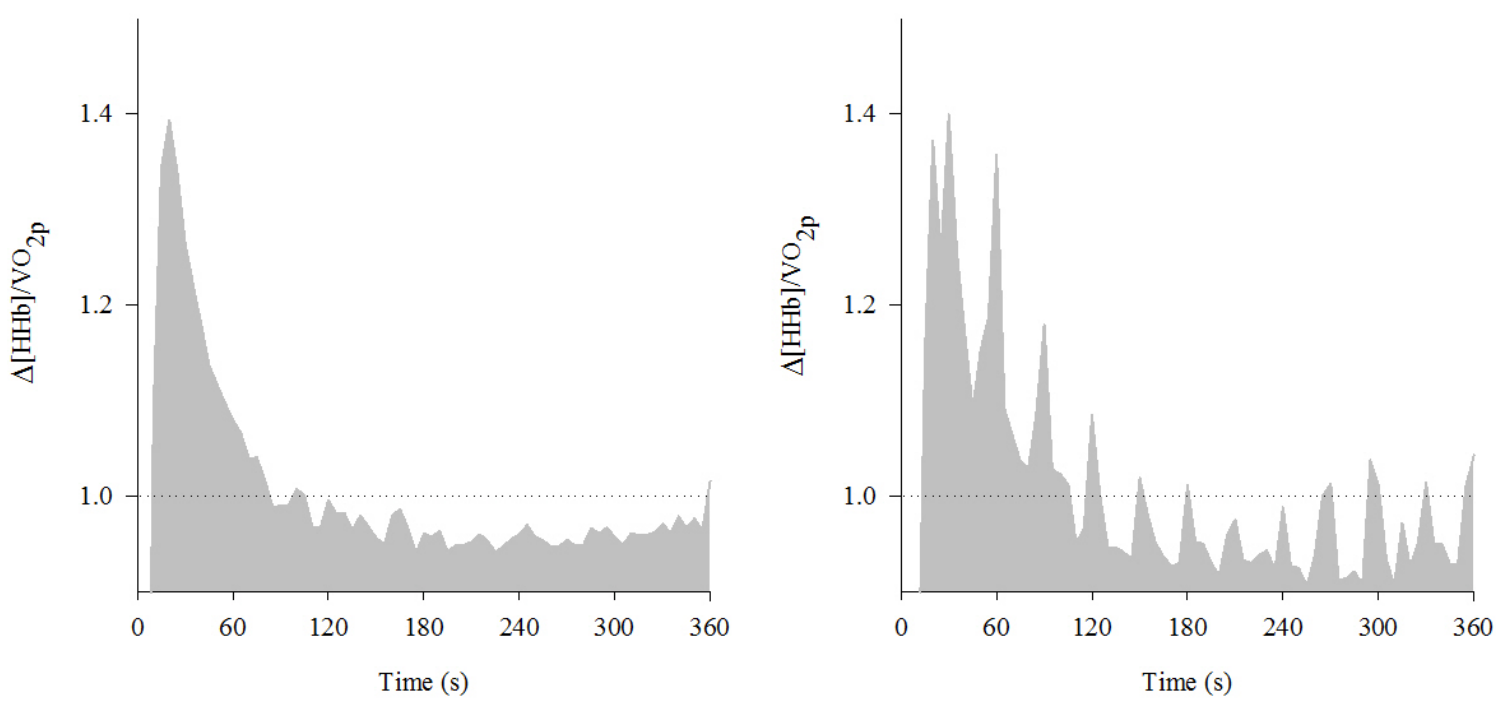

Figure 6. Mean adjustment of normalized [HHb]-to- $\dot{\mathrm{V}} \mathrm{O}_{2 \mathrm{p}}$ ratio $\left(\Delta[\mathrm{HHb}] / \dot{\mathrm{VO}}_{2 \mathrm{p}}\right)$ during CON (continuous exercise at $\triangle 50: 50$ percent of the difference between the $\mathrm{LT}$ and $\dot{\mathrm{V}} \mathrm{O}_{2 \text { peak }}$ ), $\mathrm{CBH}$ (continuous exercise at $\Delta 50$ with repeated $25 \mathrm{~s}$ freebreathing and $5 \mathrm{~s}$ breath holds), FLK (repeated $25 \mathrm{~s} \Delta 50$ and $5 \mathrm{~s}$ free-breathing sprints - peak power output attained during ramp incremental test), and FBH (repeated $25 \mathrm{~s}$ free-breathing $\Delta 50$ and $5 \mathrm{~s}$ sprints with breath holds). $\Delta[\mathrm{HHb}] / \mathrm{VO}_{2 p}$ during the last $5 \mathrm{~s}$ were greater than the nadir values during the $25 \mathrm{~s}$ periods over the $30 \mathrm{~s}$ cycles $(p<0.05)$. 


\subsection{Discussion}

The novel purpose of this study was to compare and contrast mean $\dot{\mathrm{V}} \mathrm{O}_{2 \mathrm{p}}, \dot{\mathrm{V}} \mathrm{O}_{2 \mathrm{p}}$ kinetics, muscle deoxygenation $(\Delta[\mathrm{HHb}])$, heart rate, and arterialized-capillary lactate concentrations ([La`]) during heavy intensity constant-load cycle ergometer exercise $(\mathrm{CON})$, to three different intermittent, heavy intensity exercise protocols. These protocols included $5 \mathrm{~s}$ periods of breath holding $(\mathrm{CBH}), 5 \mathrm{~s}$ periods of higher power output (FLK), or a combination of the two (FBH).

The main findings demonstrated that, compared to $\mathrm{CON}$ : 1) $\mathrm{CBH}$ resulted in similar mean $\dot{\mathrm{VO}}_{2 \mathrm{p}}$ and $\dot{\mathrm{V}}_{2 \mathrm{p}}$ kinetics, increased mean $\dot{\mathrm{V}}_{\mathrm{E}}$, decreased $\Delta\left[\mathrm{HHb}\right.$, similar [La $\left.{ }^{-}\right]$, 2) FLK resulted in increased mean $\dot{\mathrm{VO}}_{2 \mathrm{p}}$, similar $\dot{\mathrm{VO}}_{2 \mathrm{p}}$ kinetics, increased $\dot{\mathrm{V}}_{\mathrm{E}}$, decreased $\Delta[\mathrm{HHb}]$, and similar [ $\left.\mathrm{La}^{-}\right]$, and 3) $\mathrm{FBH}$ resulted in similar mean $\dot{\mathrm{VO}}_{2 \mathrm{p}}$, slower $\dot{\mathrm{VO}}_{2 \mathrm{p}}$ kinetics, increased $\dot{\mathrm{V}}_{\mathrm{E}}$, decreased $\Delta[\mathrm{HHb}]$, and increased $\left[\mathrm{La}^{-}\right]$.

\section{Continuous Breath Hold $(\mathrm{CBH})$.}

Before discussing the outcomes of the addition of breath holds to continuous heavy intensity exercise $(\mathrm{CBH})$, the effects of breath holds in the present study on pulmonary gas pressures, arterial gas pressures, and the subsequent effects on $\mathrm{O}_{2}$ delivery will be discussed. Initially, the breath holds resulted in decreased $\mathrm{P}_{\mathrm{ET}} \mathrm{O}_{2}$ and increased $\mathrm{P}_{\mathrm{ET}} \mathrm{CO}_{2}$ (Table 2; Figure $2 \mathrm{~b}$ and $3 b)$. Under sub-lactate threshold exercise intensities, end-tidal partial pressures have been shown to be in equilibrium with that of arterial partial pressures (78). However, during supralactate threshold intensities, such as were utilized in the present study, $\mathrm{P}_{\mathrm{ET}} \mathrm{O}_{2}$ and $\mathrm{P}_{\mathrm{ET}} \mathrm{CO}_{2}$ are greater and lower than pulmonary capillary pressures, respectively (86). This response is linked to the increased breathing frequencies associated with the ventilatory buffering that occurs at these intensities, and the associated faster breathing frequencies that reduce alveolar-capillary 
diffusion times for both gases, and as such, may not be an accurate reflection of pulmonary capillary gas partial pressures $(86,88)$. However, in the present study, the $\mathrm{P}_{\mathrm{ET}} \mathrm{O}_{2}$ and $\mathrm{P}_{\mathrm{ET}} \mathrm{CO}_{2}$ of $\mathrm{CBH}$ and FBH are determined utilizing the partial pressure of these gases from the last inspiration before the breath hold, and the expiration $5 \mathrm{~s}$ later. Consequently, the confounding effects of the faster breathing frequencies are not an issue, and it is suggested that the fluctuations in $\mathrm{P}_{\mathrm{ET}} \mathrm{O}_{2}$ and $\mathrm{P}_{\mathrm{ET}} \mathrm{CO}_{2}$ consequent to the breath holds (Table 3; Figure 2b and 3b) reflect a distinct hypoxemia and hypercapnia within the pulmonary capillaries (90). It is also suggested that pursuant to hypoxemia and hypercapnia, the hyperventilatory response (Table 2 and 3; Figure 4), presumably via the peripheral and central chemoreceptors (88), was observed. Together, the unchanged mean $\dot{\mathrm{V}}_{2 \mathrm{p}}$ during $\mathrm{CBH}$, compared to $\mathrm{CON}$ (Table 2; Figure 1), suggests that the momentary, breath hold-induced hypoxemia and hypercapnia has been resolved by the hyperventilatory responses to the breath holds (Table 3; Figure 4), reflected by the increased mean $\dot{\mathrm{V}}_{\mathrm{E}}$ throughout the duration of CBH (Table 2; Figure 4).

Previous literature has shown that increases or decreases in NIRS-derived muscle deoxygenation $(\Delta[\mathrm{HHb}])$ and tissue hemoglobin saturation $\left(\mathrm{S}_{\mathrm{at}} \mathrm{O}_{2}\right)$ reflect increases or decreases in the $\mathrm{PO}_{2}$. This is reflects $\mathrm{O}_{2}$ utilization from oxidative phosphorylation, and changes in $\mathrm{O}_{2}$ delivery under constant $\mathrm{V}_{2 p}$ conditions within the microvasculature in the muscle under NIRS interrogation (6). $\mathrm{CBH}$, compared to $\mathrm{CON}$, resulted in decreased heart rate, increased $\mathrm{O}_{2}$-Pulse, and a decrease in total hemoglobin concentration $\left(\Delta\left[\mathrm{Hb}_{\text {tot }}\right]\right)$ (Table 2; Figure 5a). This suggests that any decreases in heart rate was made up by increases in stroke volume as reflected with increased $\mathrm{O}_{2}$-Pulse, and thus $\mathrm{O}_{2}$ delivery was maintained and local muscle blood flow decreased, similar to decreased leg blood flow observed by others under similar hypoxemic conditions (37). However, the decreased $\Delta[\mathrm{HHb}]$ and increased $\mathrm{S}_{\mathrm{at}} \mathrm{O}_{2}$ in $\mathrm{CBH}$, compared to CON (Table 2; 
Figure $5 \mathrm{~b}$ and $5 \mathrm{c}$ ) suggests, despite decreased local blood flow, a dramatic enhancement of microvascular blood flow redistribution has occurred in the muscle under NIRS interrogation $(15,52)$. Effectively, doing more with less. The appropriate temporal response of the microvascular endothelium facilitating this redistribution has been demonstrated in previous animal work (51). These authors observed a $3 \% \cdot \mathrm{s}^{-1}$ increase in vessel radius, after a time delay of $\sim 4 \mathrm{~s}$ from the endothelial vasodilatory stimulus (51). It is suggested that the $\sim 10 \mathrm{~s}$ of hypoxemia and hypercapnia associated with the $5 \mathrm{~s}$ breath holds observed at the lung (Table 3; Figure $2 \mathrm{~b}$ and $3 \mathrm{~b}$ ) would also be present at the muscle for a similar duration, which would have been of sufficient duration for the targeted vasodilatory response to increase microvascular blood flow distribution in the muscle under NIRS interrogation.

Furthermore, increases in $\mathrm{S}_{a t} \mathrm{O}_{2}$ and $\mathrm{O}_{2}$-Pulse under hypoxic and hypercapnic conditions have also been observed at rest (74) and during moderate intensity exercise (33). These investigators suggested that increased breathing frequencies and $\dot{\mathrm{V}}_{\mathrm{E}}$, similar to that observed during $\mathrm{CBH}$, would have elicited a decrease in alveolar gas, and subsequently, blood temperature. This would have shifted the $\mathrm{O}_{2}$ dissociation curve to the left, increasing the $\mathrm{S}_{\mathrm{at}} \mathrm{O}_{2}$ at a given $\mathrm{PO}_{2}$ (47). While it is possible that the increase in $\mathrm{S}_{\mathrm{at}} \mathrm{O}_{2}$ and $\mathrm{O}_{2}$-Pulse observed in $\mathrm{CBH}$ reflects a similar change in blood temperature, our increased $\Delta\left[\mathrm{Hb}_{\mathrm{tot}}\right], \Delta[\mathrm{HHb}]$, and $\mathrm{S}_{\mathrm{at}} \mathrm{O}_{2}$ data suggest the aforementioned enhancement in microvascular blood flow distribution in the muscle under NIRS interrogation.

Conventionally, increases and decreases in the adjustment of the $\Delta[\mathrm{HHb}]-$ to- $\dot{\mathrm{V}}_{2 \mathrm{p}}$ ratio $\left(\Delta[\mathrm{HHb}] / \mathrm{VO}_{2 \mathrm{p}}\right)$ have been utilized to reflect increases and decreases in muscle arterial-venous $\mathrm{O}_{2}$ differences and/or $\mathrm{O}_{2}$ delivery as per the Fick equation $(32,55)$. Within the $30 \mathrm{~s}$ cycles of $\mathrm{CBH}$, $\Delta[\mathrm{HHb}] / \mathrm{VO}_{2 \mathrm{p}}$ oscillations were observed (Table 3; Figure 6), yet no fluctuations in $\Delta[\mathrm{HHb}]$ were 
detected (Table 3). This suggests that the $\Delta[\mathrm{HHb}] / \dot{\mathrm{VO}}_{2 \mathrm{p}}$ oscillations during $\mathrm{CBH}$ (Table 3; Figure 6) were due to fluctuations in $\dot{\mathrm{VO}}_{2 \mathrm{p}}$ (Table 3; Figure 1). It appears that the transient $5 \mathrm{~s}$ breath hold-induced reductions of $\mathrm{P}_{\mathrm{ET}} \mathrm{O}_{2}$ and the subsequent hypoxemia reduced the $\mathrm{O}_{2}$ delivery to the exercising muscle, resulting in a short-lived decrease in oxidative phosphorylation. This elicited both the observed rhythmical decreases of $\dot{\mathrm{VO}}_{2 \mathrm{p}}$ (Table 3; Figure 1) and the synchronous overshoots in $\Delta[\mathrm{HHb}] / \dot{\mathrm{VO}}_{2}$ (Table 3; Figure 6). Notably, similar temporal oscillations in $\dot{\mathrm{V}} \mathrm{O}_{2 \mathrm{p}}$ have been observed in previous intermittent exercise protocols during $5 \mathrm{~s}$ active recovery periods, which reduced $\mathrm{O}_{2}$ demand (7). Taken together, this suggests that, with either a $5 \mathrm{~s}$ period of reduced $\mathrm{O}_{2}$ demand or $\mathrm{O}_{2}$ availability, a concomitant reduction in oxidative phosphorylation results.

$\mathrm{CBH}$, compared to $\mathrm{CON}$, also resulted in bradycardia (Table 2). Similar breath holdinduced bradycardia has been observed in previous breath hold research $(1,38,42)$. Mechanistically, it has been suggested that a breath hold performed after an inspiration increases the intrathoracic pressures and decreases the abdominal pressures $(28,60,75)$, creating a pressure gradient between the infra- and supra-diaphragmatic portions of the inferior vena cava, that draws blood towards the right side of the heart $(28,60,75)$. This facilitates venous return and diastole of the right side of the heart, thus increasing stroke volume concurring with Starling's law (10). It is suggested that this mechanism was responsible for the observed bradycardia during the breath holds in $\mathrm{CBH}$ (Table 2).

The previously observed slowing of $\dot{\mathrm{V}} \mathrm{O}_{2 p}$ kinetics during exercise in hypoxia $(15,17,30$, $76)$ and longer duration breath holds $(28,38,70)$, suggested that breath holds in CBH would result in a similar slowing of $\dot{\mathrm{VO}}_{2 \mathrm{p}}$ kinetics, compared to CON. However, the expectation was that the breath hold-induced hypoxemia and the decrease in oxidative phosphorylation would be 
replaced by increased substrate level phosphorylation $(15,17,24,30,57,76)$. As such, despite increased $\dot{\mathrm{VCO}}_{2 \mathrm{p}}$ and $\dot{\mathrm{V}}_{\mathrm{E}}$, the similar [ $\left.\mathrm{La}^{-}\right]$in $\mathrm{CBH}$, compared to $\mathrm{CON}$ (Table 2) suggests that the expected metabolic stress associated with increased substrate level phosphorylation was resolved. It appears that increased $\dot{\mathrm{V}}_{\mathrm{E}}$ during $\mathrm{CBH}$ (Table 2; Figure 4) reconciled the transient hypoxemia and hypercapnia through increased $\mathrm{CO}_{2}$ elimination during the $25 \mathrm{~s}$ free-breathing periods (Table 3). Moreover, it is suggested that the improvement in microvascular distribution of blood flow in $\mathrm{CBH}$, combined with the increased $\dot{\mathrm{V}}_{\mathrm{E}}$, have also averted any slowing of $\dot{\mathrm{V}}_{2 \mathrm{p}}$ kinetics and increase in [ $\left.\mathrm{La}^{-}\right]$.

Fartlek (FLK).

Our previous work on intermittent exercise patterns have shown that regular insertions of short recovery periods ( $5 \mathrm{~s}$ and $3 \mathrm{~s}$ ) during heavy intensity cycling exercise resulted in decreased mean $\dot{\mathrm{VO}}_{2 \mathrm{p}}$ and $\Delta[\mathrm{HHb}](7,49)$. It was expected in the present study that, if these short recovery periods were replaced with periods of higher power outputs, the increased ATP demand would result in increased mean $\dot{\mathrm{VO}}_{2 \mathrm{p}}, \dot{\mathrm{V}} \mathrm{CO}_{2 \mathrm{p}}, \dot{\mathrm{V}}_{\mathrm{E}}, \Delta[\mathrm{HHb}]$, and [ $\left.\mathrm{La}^{-}\right]$, compared to $\mathrm{CON}$.

Indeed, the insertions of $5 \mathrm{~s}$ periods of higher power outputs (sprints), which increased the mean power output, was resulted in increased mean $\dot{\mathrm{VO}}_{2 \mathrm{p}}, \dot{\mathrm{V}} \mathrm{CO}_{2 \mathrm{p}}$, and $\dot{\mathrm{V}}_{\mathrm{E}}$, and, unexpectedly, similar [La $\left.{ }^{-}\right]$, compared to CON (Table 2; Figure 1 and 4). Utilizing the standard $\mathrm{O}_{2}$ cost of work $\left(\sim 10 \mathrm{ml} \mathrm{O}_{2} \cdot \mathrm{min}^{-1} \cdot \mathrm{W}^{-1}\right)(63)$, our data have shown that the increased ATP demand from the increased mean power output from CON to FLK has been ultimately met by increased mean $\dot{\mathrm{VO}}_{2 \mathrm{p}}$ (Table 2; Figure 1). However, previous work from our lab has demonstrated that during the first $4 \mathrm{~s}$ of work, following brief recovery periods from an elevated baseline during intermittent exercise, has shown that contributions from PCr-derived 
phosphorylation and substrate level phosphorylation were substantial (8). Similarly, in the present study, the repeated transitions from $218 \mathrm{~W}$ during the $25 \mathrm{~s}$ period, to $5 \mathrm{~s}$ sprints at $314 \mathrm{~W}$ (Table 1), would have increased PCr-derived phosphorylation and substrate level phosphorylation and resulted in increased type II fibre recruitment $(24,57)$, intracellular and blood [ $\left.\mathrm{La}^{-}\right](4,43)$. Unexpectedly the post-exercise [ $\left.\mathrm{La}^{-}\right]$in FLK was similar to CON (Table 2). Despite the accumulation of $\mathrm{La}^{-}$and $\mathrm{H}^{+}$that would have developed from the $5 \mathrm{~s}$ sprints, how was [La $\left.{ }^{-}\right]$in FLK, similar to CON? It is suggested that the similar [ $\left.\mathrm{La}^{-}\right]$was mechanistically possible through increased $\dot{V}_{\mathrm{E}}$, reflective of increased ventilatory buffering (Table 2 and 3; Figure 4) of the additional $\mathrm{CO}_{2}$ that had been produced via the carbonic anhydrase reaction $(61,86)$.

FLK, compared to CON, also resulted in increased mean heart rate and similar $\mathrm{O}_{2}$-Pulse (Table 2), reflecting an increase in $\mathrm{O}_{2}$ delivery. This increase in mean heart rate and the expected increase in systolic blood pressure associated with the $5 \mathrm{~s}$ sprints, may have resulted from a central attempt, via increased baroreceptor-mediated sympathetic activation (69). Furthermore, the decreased $\Delta\left[\mathrm{Hb}_{\text {tot }}\right]$ and $\Delta[\mathrm{HHb}]$, and increased $\mathrm{S}_{\mathrm{at}} \mathrm{O}_{2}$, suggests that the increase in $\mathrm{O}_{2}$ delivery was greater than the increased $\mathrm{O}_{2}$ demand associated with FLK (Table 2; Figure 5a, 5b, and 5c). Thus, it appears that the increase in $\mathrm{O}_{2}$ delivery as suggested from increased mean heart rate and $\mathrm{O}_{2}$-Pulse was proportionally greater than what was required, and a maldistribution of microvascular blood flow in the muscle of NIRS interrogation occurred, resulting in the decreased muscle deoxygenation (Table 2; Figure 5b).

Previous intermittent exercise research has also observed a similar maldistribution of microvascular blood flow during muscle contractions performed at greater, compared to lower work rates $(68,81)$. This was linked to increased intramuscular pressures (64) which impeded blood flow in the exercising muscles $(2,21,44)$. As such, it is suggested that the $44 \%$ increase in 
power output, performed during the $5 \mathrm{~s}$ sprints of FLK (Table 2), would have similarly impeded blood flow and elicited the observed decrease in $\Delta\left[\mathrm{Hb}_{\text {tot }}\right]$. Thus, the increase in mean heart rate during FLK may have resulted from a central attempt to improve local muscle blood flow and overcome the aforementioned occlusion-mediated increase in vascular resistance (68).

FLK also resulted in similar $\dot{\mathrm{VO}}_{2 \mathrm{p}}$ kinetics to $\mathrm{CON}$ (Table 2). The previously suggested mechanisms by which $\dot{\mathrm{V}}_{2 \mathrm{p}}$ kinetics may have been slowed $(30,43)$ are suggested to have been offset by increased mean $\dot{\mathrm{VO}}_{2 \mathrm{p}}$ and $\mathrm{O}_{2}$ delivery, compared to $\mathrm{CON}$ (Table 2; Figure 1). It appears that the increased mean $\dot{\mathrm{V}}_{\mathrm{E}}$ and pulmonary-arterial $\mathrm{PO}_{2}$, as suggested by the greater $\mathrm{P}_{\mathrm{ET}} \mathrm{O}_{2}$ in FLK (Table 2; Figure 2a), increased the alveolar-arterial $\mathrm{PO}_{2}$ gradient, and thus, $\mathrm{O}_{2}$ delivery $(61)$.

Fartlek Breath Hold (FBH).

In FBH, it was expected that the combined responses to the insertions of $5 \mathrm{~s}$ breath holds and sprints would overwhelm any hyperventilatory attempts to increase $\dot{\mathrm{V}}_{2 p}$ and attenuate increases in $\left[\mathrm{La}^{-}\right]$, that was observed in the singular interventions in CBH and FLK (83).

Consequent to the insertions of $5 \mathrm{~s}$ sprints, FBH resulted in greater mean power output and ATP demand, as well as increased $\dot{\mathrm{VCO}}_{2 \mathrm{p}}$ and mean $\dot{\mathrm{V}}_{\mathrm{E}}$, compared to CON (Table 2; Figure 4). In comparison to FLK, FBH resulted in lower $\dot{\mathrm{V}}_{2 \mathrm{p}}$ and similar mean $\dot{\mathrm{V}}_{\mathrm{E}}$ (Table 2; Figure 4). This suggests that the increase in mean $\dot{V}_{E}$ during FLK was comparable to that of the breath hold-induced hyperventilatory responses that was observed during the $25 \mathrm{~s}$ free-breathing periods of FBH (Table 3; Figure 4), allowing sufficient ventilation to result in similar and lower mean $\dot{\mathrm{V}}_{2 \mathrm{p}}$, compared to CON and FLK, respectively (89). Nevertheless, the increased [ $\left.\mathrm{La}^{-}\right]$in FBH, compared to all other conditions (Table 2) suggests that the ventilatory responses in FBH 
were overwhelmed by the combination of the breath holds and sprints, and was insufficient to resolve the increased $\mathrm{La}^{-}$production from the sprints.

Moreover, FBH resulted in greater heart rate than CON, and lower heart rate than FLK, but lower $\mathrm{O}_{2}$-Pulse compared to both CON and FLK, suggesting increased $\mathrm{O}_{2}$ delivery (Table 2). As suggested earlier, the increased sympathetic activation (69) may be responsible for the increased heart rate in FBH compared to $\mathrm{CON}$, and the breath hold-induced bradycardia (60, 75), for the decreased heart rate in FBH relative to FLK.

FBH also resulted in increased $\Delta\left[\mathrm{Hb}_{\mathrm{tot}}\right]$, compared to both CON and FLK, decreased and increased $\Delta[\mathrm{HHb}]$, compared to CON and FLK, respectively, and increased $\mathrm{S}_{\mathrm{at}} \mathrm{O}_{2}$, compared to both CON and FLK (Table 2; Figure 5a, 5b, and 5c). These responses suggest that the addition of the breath holds to the sprints increased local muscle blood flow, presumably consequent to the local vasodilatory effects of $\mathrm{La}^{-}(27,40)$. It has been observed previously that increased [ $\left.\mathrm{La}^{-}\right]$and associated acidosis induces local vasodilation through activation of cyclic guanine monophosphate (cGMP) within smooth muscle cells of the muscle microvasculature (12).

Furthermore, in comparison to $\mathrm{CON}$, the increased heart rate, $\Delta\left[\mathrm{Hb}_{\text {tot }}\right]$, and decreased $\mathrm{O}_{2-}$ Pulse during FBH, (Table 2; Figure 5a), suggest an increase in blood velocity that would have decreased $\mathrm{Hb}$ capillary transit and diffusion time within the microvasculature. This would have resulted in a reduction of $\mathrm{O}_{2}$ availability to the working muscle, and thus, resulted in the observed decrease in muscle deoxygenation (Table 2; Figure 5b). In comparison to FLK, in which the blood velocity is relatively slower due to breath hold-induced bradycardia, the smaller decrease in $\mathrm{Hb}$ capillary transit and diffusion time within the microvasculature, has resulted in increased muscle deoxygenation (Table 2; Figure 5b). Similar effects of Hb capillary and diffusion time on muscle deoxygenation have been suggested elsewhere under similar 
hypoxemia during exercise in hypoxia (15). Despite the increased power output and ATP demand of $\mathrm{FBH}$, compared to $\mathrm{CON}$, the unchanged mean $\mathrm{V}_{2 \mathrm{p}}$ during $\mathrm{FBH}$ (Table 2; Figure 1) suggests a similar reduction in $\mathrm{O}_{2}$ availability for oxidative phosphorylation.

FBH also resulted in slower $\dot{\mathrm{VO}}_{2 \mathrm{p}}$ kinetics than both CON and FLK (Table 2), consistent with previous observations of slower $\dot{\mathrm{V}} \mathrm{O}_{2 \mathrm{p}}$ kinetics during exercise in hypoxia $(15,17,30,76)$, and the associated increased type II muscle fibre recruitment $(24,57)$ and blood [ $\left.\mathrm{La}^{-}\right](56)$.

In summary, the metabolic stress resulting from the addition of sprints to the breath holds were unable to be resolved by the ventilatory responses, as was observed in $\mathrm{CBH}$, notably resulting in decreased mean $\dot{\mathrm{V}}_{2 \mathrm{p}}$, slower $\dot{\mathrm{V}}_{2 \mathrm{p}}$ kinetics, and increased [La'] (Table 2; Figure 1).

\section{Practical Applications}

In swimming, athletes utilize different strategies of achieving the $\sim 5 \mathrm{~s}$ underwater kicking phase. In backstroke swimming, swimmers tend to be faster kicking underwater and therefore may perform these underwater breath hold phases at greater intensity to maximize their velocity over these $5 \mathrm{~s}$. The present study provides preliminary insight into the singular and combined physiological resolutions associated with $30 \mathrm{~s}$ cycles, comprised of $5 \mathrm{~s}$ breath holds and/or sprints, followed by $25 \mathrm{~s}$ of free-breathing performed at an identical power output. Our data suggest that choosing to perform such breath hold phases at greater intensity places a greater demand on substrate level phosphorylation and will precipitate an earlier onset of fatigue.

\section{Conclusion}

To our knowledge, this is the first study to examine the physiological responses to the insertions of intermittent $5 \mathrm{~s}$ breath holds and/or sprints during heavy intensity cycling exercise. 
It has been established that the breath hold-induced hyperventilatory responses and improved microvascular distribution of blood flow during $\mathrm{CBH}$, were sufficient to maintain similar $\dot{\mathrm{V}}_{2 \mathrm{p}}$ to CON. However, when breath holds were combined with the sprints, the hyperventilatory responses were overwhelmed and precipitated greater metabolic stress.

\subsection{Future Directions and Limitations}

\section{Future Directions}

The present study on the physiological responses to the breath holds during heavy intensity exercise were observed among but limited to recreationally active, healthy young male participants. Investigation of similar protocols in women and/or older populations would enable comparisons between sex and with aging, enabling to further characterize the physiological responses to breath holds and sprints during heavy intensity exercise.

\section{Limitations}

The NIRS signals are affected by subcutaneous adipose tissue thickness (5). The penetration depth is roughly half of the optode distance (19). Since our measures were not corrected for the adipose tissue thickness, subject variabilities in adipose tissue thickness may have influenced the NIRS signals. 


\subsection{References}

1. Andersson JP, Linér MH, Fredsted A, Schagatay EK. Cardiovascular and respiratory responses to apneas with and without face immersion in exercising humans. $J$ Appl Physiol 96: 1005-1010, 2004.

2. Barcroft BYH, Dornhorst AC. The blood flow through the human calf during rhythmic exercise. J Physiol 109: 402-411, 1949.

3. Barstow TJ, Mole PA. Linear and nonlinear characteristics of oxygen uptake kinetics during heavy exercise. J Appl Physiol 71: 2099-2106, 1991.

4. van Beekvelt MC, Borghuis MS, van Engelen BG, Wevers RA, Colier WN. Adipose tissue thickness affects in vivo quantitative near-IR spectroscopy in human skeletal muscle. Clin Sci (Lond) 101: 21-28, 2001.

5. Behnke BJ, Kindig CA, Musch TI, Koga S, Poole DC. Dynamics of microvascular oxygen pressure across the rest-exercise transition in rat skeletal muscle. Respir Physiol 126: 53-63, 2001.

6. Belfry GR, Paterson DH, Murias JM, Thomas SG. The Effects of Short Recovery duration on VO2 and muscle deoxygenation during intermittent exercise. Eur J Appl Physiol 112: 1907-1915, 2012.

\section{Belfry GR, Raymer GH, Marsh GD, Paterson DH, Thompson RT, Thomas SG.}

Muscle metabolic status and acid-base balance during 10-s work : 5-s recovery intermittent and continuous exercise. J Appl Physiol 113: 410-417, 2012. 
8. Da Boit M, Bailey SJ, Callow S, Dimenna FJ, Jones AM. Effects of interval and continuous training on $\mathrm{O} 2$ uptake kinetics during severe-intensity exercise initiated from an elevated metabolic baseline. J Appl Physiol 116: 1068-77, 2014.

9. Braunwald E, Frahm CJ. Studies on Starling's Law of the Heart: IV. Observations on the Hemodynamic Functions of the Left Atrium in Man. Circulation 24: 633-642, 1961.

10. Chen Y, Messina J, Wolin S. Evidence arteriolar for cGMP mediation dilation to lactate of skeletal muscle. J Appl Physiol 81: 349-354, 1996.

11. DeLorey DS, Shaw CN, Shoemaker JK, Kowalchuk JM, Paterson DH. The effect of hypoxia on pulmonary $\mathrm{O} 2$ uptake, leg blood flow and muscle deoxygenation during single-leg knee-extension exercise. ExpPhysiol 89: 293-302, 2004.

12. Dicker SG, Lofthus GK, Thornton NW, Brooks G. Respiratory and heart rate responses to tethered controlled frequency breathing swimming. Med Sci Sports Exerc 12: 20-23, 1980.

13. Engelen M, Porszasz J, Riley M, Wasserman K, Maehara K, Barstow TJ. Effects of hypoxic hypoxia on $\mathrm{O} 2$ uptake and heart rate kinetics during heavy exercise. $J$ Appl Physiol 81: 2500-2508, 1996.

14. Ferrari M, Mottola L, Quaresima V. Principles, techniques, and limitations of near infrared spectroscopy. Can J Appl Physiol 29: 463-87, 2004.

15. Folkow B, Gaskell P, Waaler BA. Blood Flow through Limb Muscles during Heavy Rhythmic Exercise. Acta Physiol Scand 80: 61-72, 1970. 
16. Gollnick PD, Sjödin B, Karlsson J, Jansson E, Saltin B. Human soleus muscle: A comparison of fiber composition and enzyme activities with other leg muscles. Pflügers Arch Eur J Physiol 348: 247-255, 1974.

17. Hill A V., Long CNH, Lupton H. Muscular Exercise, Lactic Acid, and the Supply and Utilisation of Oxygen. Ergebnisse der Physiol 24: 43-51, 1925.

18. Hoffmann U, Smerecnik M, Leyk D, Essfeld O. Cardiovascular responses to apnea during dynamic exercise. Int J Sports Med 26: 426-431, 2005.

19. Hughson RL, Kowalchuk JM. Kinetics of oxygen uptake for submaximal exercise in hyperoxia, normoxia, and hypoxia. Can J Appl Physiol 20: 198-210, 1995.

20. Karpman VL. The theoretical analysis of Fick's equation. On the centennial of the use of Fick's principle in physiology. Z Kardiol 64: 801-808, 1975. http://www.ncbi.nlm.nih.gov/pubmed/769376.

21. Katayama K, Sato Y, Ishida K, Mori S, Miyamura M. The effects of intermittent exposure to hypoxia during endurance exercise training on the ventilatory responses to hypoxia and hypercapnia in humans. Eur J Appl Physiol Occup Physiol 78: 189-94, 1998.

22. Keir DA, Murias JM, Paterson DH, Kowalchuk JM. Breath-by-breath pulmonary O2 uptake kinetics: effect of data processing on confidence in estimating model parameters. Exp Physiol 99: 1511-22, 2014.

23. Koskolou MD, Calbet JAL, Rådegran G, Roach RC. Hypoxia and the cardiovascular response to dynamic knee-extensor exercise. Am J Physiol 272: H2655-H2663, 1997. 
24. Kume D, Akahoshi S, Song J, Yamagata T, Wakimoto T, Nagao M, Matsueda S, Nagao N. Intermittent breath holding during moderate bicycle exercise provokes consistent changes in muscle oxygenation and greater blood lactate response. $J$ Sports Med Phys Fitness 53: 327-335, 2013.

25. Lamarra N, Whipp BJ, Ward SA, Wasserman K. Effect of interbreath fluctuations on characterizing exercise gas exchange kinetics. J Appl Physiol 62: 2003-12, 1987. http://www.ncbi.nlm.nih.gov/pubmed/3110126.

26. Laughlin MH, Armstrong RB. Muscle blood flow during locomotory exercise. Exerc Sport Sci Rev 13: 95-136, 2003.

27. Lindholm P, Linnarsson D. Pulmonary gas exchange during apnoea in exercising men. Eur J Appl Physiol 86: 487-491, 2002.

28. Lindholm P, Sundblad P, Linnarsson D. Oxygen-conserving effects of apnea in exercising men. J Appl Physiol 87: 2122-2127, 1999.

29. Linnarsson D, Karlsson J, Fagraeus L, Saltin B. Muscle metabolites with exercise and oxygen deficit and hyperoxia. J Appl Physiol 36: 399-402, 1974.

30. Lutjemeier BJBJ, Miura AA, Scheuermann BWBW, Koga SS, Townsend DKDK, Barstow TJTJ. Muscle contraction-blood flow interactions during upright knee extension exercise in humans. J Appl Physiol 98: 1575-1583, 2005.

31. Manning JM. Physiology of Sport and Exercise. J Athl Train 34: 298-299, 1999.

32. Matheson GO, McKenzie DC. Breath holding during intense exercise: arterial blood 
gases, pH, and lactate. J Appl Physiol 64: 1947-52, 1988.

33. McCrudden M, Keir DA, Belfry G. The effects of short work versus longer work periods within intermittent exercise on VO2p kinetics, muscle deoxygenation and energy system contribution. J Appl Physiol 122: 1435-1444, 2017.

34. Murias JM, Dey A, Campos OA, Estaki M, Hall KE, Melling CWJ, Noble EG. HighIntensity Endurance Training Results in Faster Vessel-Specific Rate of Vasorelaxation in Type 1 Diabetic Rats. PLoS One 8: e59678, 2013.

35. Murias JM, Keir DA, Spencer MD, Paterson DH. Sex-related differences in muscle deoxygenation during ramp incremental exercise. Respir Physiol Neurobiol 189: 530-536, 2013.

36. Murias JM, Kowalchuk JM, Paterson DH. Speeding of VO2 kinetics in response to endurance-training in older and young women. Eur J Appl Physiol 111: 235-243, 2011.

37. Murias JM, Spencer MD, Paterson DH. The Critical Role of O2 Provision in the Dynamic Adjustment of Oxidative Phosphorylation. Exerc Sport Sci Rev 42: 4-11, 2014.

38. Murphy PC, Cuervo LA, Hughson RL. A study of cardiorespiratory dynamics with step and ramp exercise tests in normoxia and hypoxia. Cardiovasc Res 23: 825-832, 1989.

39. Nuutinen EM, Nishiki K, Erecinska M, Wilson DF. Role of mitochondrial oxidative phosphorylation in regulation of coronary blood flow. Am J Physiol - Hear Circ Physiol 243: H159-H169, 1982.

40. Ozyener F, Rossiter HB, Ward S a, Whipp BJ. Influence of exercise intensity on the 
on- and off-transient kinetics of pulmonary oxygen uptake in humans. J Physiol 533: 891902, 2001.

41. Paterson DJ, Wood GA, Morton AR, Henstridge JD. The entrainment of ventilation frequency to exercise rhythm. Eur J Appl Physiol Occup Physiol 55: 530-537, 1986.

42. Paulev P -E. Cardiac Rhythm during Breath-Holding and Water Immersion in Man. Acta Physiol Scand 73: 139-150, 1968.

43. Peronnet F, Aguilaniu B. Lactic acid buffering, nonmetabolic $\mathrm{CO} 2$ and exercise hyperventilation: A critical reappraisal. Respir Physiol Neurobiol 150: 4-18, 2006.

44. Poole DC, Gaesser GA, Hogan MC, Knight DR, Wagner PD. Pulmonary and leg VO2 during submaximal exercise: implications for muscular efficiency. $J$ Appl Physiol 72: 805-810, 1992. http://www.ncbi.nlm.nih.gov/entrez/query.fcgi?cmd=Retrieve\&db=PubMed\&dopt=Citati on\&list_uids=1559962.

45. Rådegran G, Saltin B. Muscle blood flow at onset of dynamic exercise in humans. Am J Physiol - Hear Circ Physiol 274: H314-H322, 1998. http://ajpheart.physiology.org/content/274/1/H314.abstract.

46. Rossiter HB, Ward SA, Doyle VL, Howe FA, Griffiths JR, Whipp BJ. Inferences from pulmonary $\mathrm{O} 2$ uptake with respect to intramuscular [phosphocreatine] kinetics during moderate exercise in humans. $J$ Physiol 518: 921-932, 1999.

47. Saltin B, Rådegran G, Koskolou MD, Roach RC. Skeletal muscle blood flow in 
humans and its regulation during exercise. Acta Physiol Scand 162: 421-436, 1998.

48. Saul JP, Rea RF, Eckberg DL, Berger RD, Cohen RJ. Heart rate and muscle sympathetic nerve variability during reflex changes of autonomic activity. Am J Physiol 258: H713-21, 1990.

49. Schagatay E, Andersson JPA, Nielsen B. Hematological response and diving response during apnea and apnea with face immersion. Eur J Appl Physiol 101: 125-132, 2007.

50. Siegmund GP, Edwards MR, Moore KS, Tiessen DA, Sanderson DJ, McKenzie DC. Ventilation and locomotion coupling in varsity male rowers. J Appl Physiol 87: 233-242, 1999. http://jap.physiology.org/content/87/1/233.short.

51. Skorski S, Faude O, Caviezel S, Meyer T. Reproducibility of Competition Pacing Profiles in Elite Swimmers. Int J Sports Physiol Perform 9: 217-225, 2013.

52. Somers VK, Mark a L, Zavala DC, Abboud FM. Contrasting effects of hypoxia and hypercapnia on ventilation and sympathetic activity in humans. $J$ Appl Physiol 67: 21012106, 1989.

53. Song SH, Lee WK, Chung YA, Hong SK. Mechanism of apneic bradycardia in man. $J$ Appl Physiol 27: 323-327, 1969.

54. Springer C, Barstow T, Wasserman K, Cooper D. Oxygen uptake and heart rate responses during hypoxic exercise in children and adults. Med. Sci. Sports Exerc. 23: 7179, 1991. http://europepmc.org/abstract/MED/1997815.

55. Suskind M, Bruce RA, McDowell ME, Yu PNG, Lovejoy FWJ. Normal variations in 
end-tidal air and arterial blood carbon dioxide and oxygen tensions during moderate exercise. J Appl Physiol 3: 282-290, 1950.

56. Veiga S, Cala A, Mallo J, Navarro E, Arellano R, Terres-Nicoli JM, Redondo JM, Veiga S, Roig A. Underwater and surface strategies of $200 \mathrm{~m}$ world level swimmers. $J$ Sports Sci 34: 1-6, 2015.

57. Walløe $\mathbf{L}$, Wesche $\mathbf{J}$. Time course and magnitude of blood flow changes in the human quadriceps muscles during and following rhythmic exercise. J Physiol 405: 257-73, 1988.

58. Ward DS, Nguyen TT. Ventilatory response to sustained hypoxia during exercise. Med Sci Sports Exerc 23: 719-726, 1991.

59. Wasserman K, Van Kessel AL, Burton GG. Interaction of physiological mechanisms during exercise. J Appl Physiol 22: 71-85, 1967.

60. Wasserman K, Whipp BJ, Castagna J. Cardiodynamic hyperpnea: hyperpnea secondary to cardiac output increase. J Appl Physiol 36: 457-464, 1974.

61. Wein J, Andersson JP, Erdéus J. Cardiac and ventilatory responses to apneic exercise. Eur J Appl Physiol 100: 637-644, 2007.

62. Whipp BJ. The hyperpnea of dynamic muscular exercise. Exerc Sport Sci Rev 5: 295311, 1977.

63. Whipp BJ, Davis JA. Peripheral chemoreceptors and exercise hyperpnea. Med Sci Sports Exerc 11: 204-212, 1979.

64. Whipp BJ, Ward SA, Lamarra N, Davis JA, Wasserman K. Parameters of ventilatory 
and gas exchange dynamics during exercise. J Appl Physiol 52: 1506-13, 1982.

http://www.ncbi.nlm.nih.gov/pubmed/6809716.

65. Whipp BJ, Wasserman K. Alveolar-arterial during graded gas tension differences exercise. J Appl Physiol 27: 361-365, 1969.

66. Woorons X, Bourdillon N, Lamberto C, Vandewalle H, Richalet J-P, Mollard P, Pichon A. Cardiovascular Responses During Hypoventilatior at Exercise. Int J Sports Med 32: 438-445, 2011. 


\title{
Appendix
}

\section{Ethics Approval Notice}

Research Ethics

Western

ResearChestern University Health Science Research Ethics Board HSREB Full Board Initial Approval Notice

\author{
Principal Investigator: Glen Belfry \\ Department \& Institution: Health Sciences|Kinesiology, Western University \\ Review Type: Full Board \\ HSREB File Number: 107170 \\ Study Title: The Effects of Periodic Breath-Holding During Intermittent Exercise on Energy System Contribution, \\ Lactate Threshold, and Regional Blood Flow Distribution. \\ Sponsor: Natural Sciences and Engineering Research Council \\ HSREB Initial Approval Date: January 08, 2016 \\ HSREB Expiry Date: January 08, 2017 \\ Documents Approved and/or Received for Information:

\begin{tabular}{|c|c|c|}
\hline Document Name & Comments & Version Date \\
\hline Advertisement & Received November 24, 2015 & \\
\hline Other & PAR-Q form - Received December 18, 2015 & \\
\hline Letter of Information \& Consent & & $2015 / 11 / 24$ \\
\hline Western University Protocol & & $2015 / 12 / 18$ \\
\hline
\end{tabular}

The Western University Health Science Research Ethics Board (HSREB) has reviewed and approved the above named study, as of the HSREB Initial Approval Date noted above.

HSREB approval for this study remains valid until the HSREB Expiry Date noted above, conditional to timely submission and acceptance of HSREB Continuing Ethics Review.

The Western University HSREB operates in compliance with the Tri-Council Policy Statement Ethical Conduct for Research Involving Humans (TCPS2), the International Conference on Harmonization of Technical Requirements for Registration of Pharmaceuticals for Human Use Guideline for Good Clinical Practice Practices (ICH E6 R1), the Ontario Personal Health Information Protection Act (PHIPA, 2004), Part 4 of the Natural Health Product Regulations, Health Canada Medical Device Regulations and Part C, Division 5, of the Food and Drug Regulations of Health Canada.

Members of the HSREB who are named as Investigators in research studies do not participate in discussions related to, nor vote on such studies when they are presented to the REB.

The HSREB is registered with the U.S. Department of Health \& Human Services under the IRB 


\section{Curriculum Vitae}

Name: David John Lim

Post-secondary

The University of Western Ontario

Education and

Degrees:

London, Ontario, Canada

2017-2021 DDS

The University of Western Ontario

London, Ontario, Canada

2016-2017 M.Sc.

The University of Western Ontario

London, Ontario, Canada

2014-2016 B.A.

The University of Western Ontario

London, Ontario, Canada

2009-2014 B.Sc.

Honours and Awards:

Related Work Experience:
Western Graduate Research Scholarship

2016-2017

UWO In-Course Scholarships Year II 2015

Western's $125^{\text {th }}$ Anniversary Alumni Awards 2015

Laurene Paterson Estate Scholarship

2012

Teaching Assistant

The University of Western Ontario

2016-2017

\section{Publications:}

